\title{
Desenvolvimento de Uma Ferramenta de Apoio à Avaliação de Qualidade de Processo de Software para Pequena Empresa
}

\author{
Dinamérico Alonso Gaspar
}

Orientadora: Profa. Dra. Rosely Sanches

Dissertação apresentada ao Instituto de Ciências Matemáticas e de Computação - ICMC-USP, como parte dos requisitos para obtenção do título de Mestre em Ciências - Área: Ciências de Computação e Matemática Computacional. 
Aos meus pais Gaspar e Páscoa por serem sempre o melhor exemplo a ser seguido e por me proporcionarem a possibilidade de executar este trabalho.

Às minhas irmãs Dinamar e Denise pelo apoio constante. 


\section{Agradecimentos}

Em primeiro lugar a Deus, pelos dons que me concedeu, por estar sempre me proporcionando os melhores momentos em minha vida, por ser sempre o ponto de partida que anima e o ponto de chegada que conforta, por ter me ungido com a graça de estar sempre acercado de pessoas amigas e companheiras.

À Prof ${ }^{a}$ Rosely Sanches, minha orientadora, por toda ajuda, compreensão e constante otimismo para que este trabalho fosse realizado.

Ao Prof. Caetano Traina Jr., por todo o apoio e confiança que em mim depositou.

À Kátia, por estar sempre dizendo palavras de apoio, de carinho, de entusiasmo e pela sua imensa compreensão.

Ao Enzo Seraphim, um exemplo de pessoa fiel a Deus, pela amizade verdadeira, companheirismo e ajuda que me proporcionou.

Ao Prof. Djalma Domingues da Silva, grande professor de Análise e Projeto de Sistemas, por toda ajuda.

Aos amigos Walter, Cláudia, Will, Gedson, Renato, Igor, Vangrei, José, Léo, Cláudio e Luis Paulo pelo companherismo e ajuda.

A todos do grupo de jovens Sementes do Futuro e da banda Ecclesis.

Aos demais amigos do ICMC-USP, que de uma maneira ou outra contribuíram com o estímulo para o prosseguimento deste trabalho. 


\section{Sumário}

Lista de Figuras iv

Lista de Tabelas $v i$

Resumo $v i i$

Abstract viii

Capitulo 1 9

1. Introdução 9

1.1 Situação do Problema e Motivação 9

1.2 Objetivos 11

1.3 Organização do Trabalho 12

Capítulo 2 14

2. Modelo de Melhoria de Processo de Software

2.1 Considerações Iniciais ___ 14

2.2 Qualidade _ـ_ 14

2.3 Qualidade de Software ________________________ 15

2.4 Qualidade de Produto de Software ___ 17

2.5 Qualidade de Processo de Software _____________ 19

2.6 Melhoria de Processo de Software ___ 19

2.7 O modelo CMM - Capability Maturity Model

2.8 Estratégia para Iniciar Melhoria de Processo de Software em Empresa de Pequeno Porte __ 25

2.8.1 Nivel 2 do SW-CMM - Repetível ___ 26

2.8.1.1 Gerenciamento de Requisitos ___ 27

2.8.1.2 Planejamento de Projeto de Software ___ 28

2.8.1.3 Visão Geral e Acompanhamento do Projeto _____ 28

2.8.1.4 Gerenciamento de Subcontratos de Software ___ 29

2.8.1.5 Garantia de Qualidade de Software___ 29

2.8.1.6 Gerenciamento de Configuração de Software___ 30

2.8.2 O Plano de Avaliação de Processo de Software____ 30

2.9 Consideraçōes Finais ___ 33

Capítulo 3

3. Adição de Atividades à Estratégia para Iniciar Melhoria de Processo de Software ___ 34

3.1 Considerações Iniciais _....____ 34

3.2 Seleção e Inclusão de KPAs adicionais ___ 34

3.3 A Pesquisa de Brodman \& Johnson ___ 35 
3.4 O Nível 3 do SW-CMM ___ 39

3.4.1 Processo de Software Definido ___ 40

3.4.2 KPA Foco no Processo da Organizaçāo______________ 43

3.4.3 KPA Definição do Processo da Organização___ 43

3.4.4 KPA Programa de Treinamento___ 44

3.4.5 KPA Gerenciamento de Software Integrado __ 44

3.4.6 KPA Engenharia de Produto de Software

3.4.7 KPA Coordenação Intergrupos _______ 45

3.4.8 KPA Revisões ___ 45

3.5 Instrumento de Coleta de Dados Modificado__ 45

3.6 Considerações Finais _ 56

Capitulo $4+57$

4. A Ferramenta SProQ_____ 57

4.1 Considerações Iniciais ___ 57

4.2 Objetivos Gerais da Ferramenta ___ 57

4.3 Desenvolvimento da Ferramenta ___ 58

4.4 A Fase de Análise___ 58

4.4.1 Modelo de Objetos______________ 58

4.4.2 Modelo de Interfaces ___ 60

4.4.2.1 Modelo de Ciclo de Vida _ 61

4.4.2.2 Modelo de Operaçōes _________ 62

4.5 A Fase de Projeto ___ 63

4.5.1 Grafos de Interação de Objetos ______ 63

4.5.2 Grafos de Visibilidade ___ _ 64

4.5.3 Descrições de Classes _____________________ 64

4.5.4 Mapeamento do Modelo de Objetos para um Modelo Físico de Dados _____ 65

4.6 A Fase de Implementação ___ 66

4.7 Considerações Finais ___ 69

Capítulo $5+71$

5. Conclusões e Trabalhos Futuros___ 71

5.1 Conclusões Finais ___ _ 71

5.2 Contribuições _ 71

5.3 Sugestões de Trabalhos Futuros _________ 73

Capítulo $6 \ldots$

6. Referências Bibliográficas _____ 75

Apêndices ___ 79 
Apêndice A - Documentos da Fase de Análise da Ferramenta SProQ 79

Apêndice B - Documentos da Fase de Projeto da Ferramenta SProQ 93 Apêndice C - O Plano de Avaliação da Estratégia para Iniciar Melhoria de Processo de Software 109

Apêndice D - O Questionário de Avaliação da Estratégia para Iniciar Melhoria de Processo de Software 115 


\section{Lista de Figuras}

Figura 1 - Estratégia para Iniciar Melhoria de Processo de Software. 10

Figura 2 - Estratégia criada para a fase de Diagnóstico do IDEAL [Endo, 1998]. II

Figura 3 - O Modelo IDEAL [Gremba, 1998]. 21

Figura 4 - Modelo de Objetos para os Questionários da ferramenta SProQ. 59

Figura 5 - Modelo de Objetos para os Relatórios e Graficos da ferramenta SProQ. 60

Figura 6 - Modelo de Interfaces: Cenário de Cadastramento de Questões do SW-CMM. __ 61

Figura 7 - Esquema da operação cadastro_nível. _____ 63

Figura 8 - Grafo de Interação do objeto Nível. ___ 64

Figura 9 - Grafo de Visibilidade para os Questionários. _____ 64

Figura 10 - O mapeamento do modelo de objetos da ferramenta SProQ para o Modelo Relacional. __ 66

Figura II - Tela para Cadastramento das Questões do SW-CMM. _______ 68

Figura 12 - Tela para Cadastramento das Respostas de uma Avaliação de Processo de Software. __ 69

Figura 13 - Características a serem acrescentadas à Estratégia para Iniciar Melhoria de Processo de Software._73

Figura 14 - Modelo de Interfaces: Cenário de Avaliações. ______________ 83

Figura 15 - Modelo de Interfaces: Cenário de Alteração de Questionário. ___ 84

Figura 16 - Modelo de Interfaces: Cenário de Emissão de Relatório SW-CMM. _ 85

Figura 17 - Modelo de Interfaces: Cenário de Emissão de Relatório dos Questionários. _____ 86

Figura 18 - Modelo de Interfaces: Cenário de Geração de Gráfico de Medições. ___ 87

Figura 19-Operação: Cadastramento de KPAs.________ 88

Figura 20-Operação: Cadastramento de Grupos. _____ 88

Figura 21-Operaçāo: Cadastramento de Metas. ______ 88

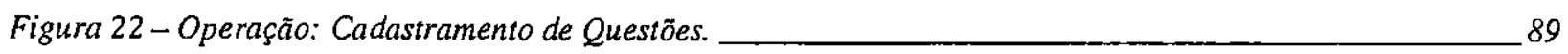

Figura 23 - Operação: Cadastramento de Relacionamentos Metas x Questōes. __ 89

Figura 24 - Operação: Cadastramento de Composição de Questões. __ 90

Figura 25 - Operação: Criação de Questionários. ___ 90

Figura 26 - Operaçāo: Responder Questionário. __________ 91

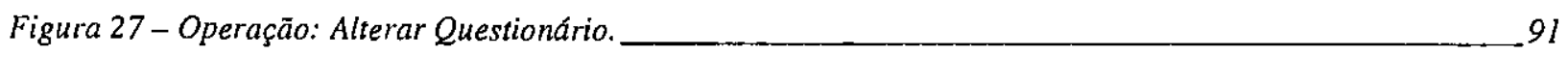

Figura 28 - Operação: Imprimir Relatório SW-CMM. ___ $9 J$

Figura 29 - Operação: Imprimir Rẹlatório de Questöes. ______._. 92

Figura 30 - Operação: Gerar Gráfico de Medição. ___ 92

Figura 31 - Grafo de Visibilidade para as Questões do SW-CMM.____ 100

Figura 32 - Grafo de Visibilidade para as Respostas.

Figura 33 - Grafo de Visibilidade para o Relatório SW-CMM._IOI

Figura 34 - Grafo de Visibilidade para o Relatório de Questionários.

Figura 35 - Grafo de Visibilidade para os Gráficos.

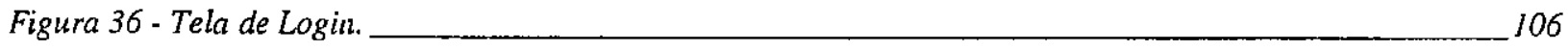


Figura 37 - Tela de Visualização de Grupos de Processo. 106

Figura 38 - Tela de Cadastramento de um novo Questionário. 107

Figura 39 - Tela de Visualização/Alteraçāo das Respostas dos Questionários. 107 


\section{Lista de Tabelas}

Tabela 1 - Caracteristicas e subcaracteristicas de qualidade da norma ISO/IEC 9126 (1994). 18

Tabela 2 - O Modelo SW-CMM.

Tabela 3 - Áreas chave de processo do SW-CMM. 25

Tabela 4 - Estrutura do Plano de Avaliaçāo da Estratégia para Iniciar Melhoria de Processo de Software. 32

Tabela 5 - Aspectos do SW-CMM considerados inatingiveis pelas pequenas empresas [Brodman \& Johnson, 1994]. 36

Tabela 6 - Expressóes do ciclo de vida da ferramenta SProQ. 62

Tabela 7 - Dicionário de Dados do Modelo de Objetos da Ferramenta SProQ. 81

Tabela 8 - Dicionário de Dados: A Interface do Sistema da Ferramenta SProQ. 83 


\section{Resumo}

A busca pela qualidade de processo de software é uma constante cada vez mais crescente entre as empresas produtoras de software. Para auxiliar na obtenção dessa qualidade, modelos de melhoria de processo de software vêm sendo desenvolvidos em todo o mundo. A Estratégia para Iniciar Melhoria de Processo de Software [Endo, 1998] define, relaciona e organiza as principais atividades que devem ser realizadas para avaliar um Processo de Software com relação ao nível 2 do SW-CMM'1.

Este trabalho de mestrado seleciona e adiciona à Estratégia as atividades das áreas-chave do nível 3 do SW-CMM, propiciando às empresas a avaliação de seu processo de software para que atinjam esse nível.

Também a ferramenta SProQ ${ }^{2}$ foi desenvolvida por este trabalho de mestrado para auxiliar na coleta de dados e reporte de resultados existente na Estratégia, configurando-se um importante sistema de informação destinado entre outras coisas a auxiliar nas tomadas de decisão quanto à melhoria do processo de software das empresas.

${ }^{1}$ SW-CMM: Software Capability Maturity Model

2 SProQ: Software Process Quality 


\section{Abstract}

The search for the software process quality is more and more a constant growing among the companies producing of software. To aid in the obtaining of that quality, models of improvement of software process come being developed all over the world. The Estratégia para Iniciar Melhoria de Processo de Software [Endo, 1998] it defines, it relates and it organizes the main activities that should be accomplished to evaluate a Software Process with relationship at the level 2 of SW-CMM.

This work selects and adds to the Estratégia the activities of the key process area of the level 3 of SW-CMM, propitiating to the companies the evaluation of its software process so that they reach that level.

Also the tool SProQ was developed by this work to aid in the collection of data and existent reporte of results in the Estratégia. Thus, the SProQ is an important information system destined among other things to aid in the takings of decision with relationship to the improvement of the software process of the companies. 


\section{Capitulo 1}

\section{Introdução}

\subsection{Situação do Problema e Motivação}

Nos dias atuais, cada vez mais se fala em qualidade - qualidade de produtos e qualidade de serviços. E essa demanda por qualidade tem forçado a ambos, indústrias e prestadores de serviços, a fazerem uma avaliação a respeito da qualidade de seus serviços e produtos. Melhorar a qualidade do produto final significa obter vantagem competitiva, ter menor custo de retrabalho, maior aceitação do produto pelo mercado consumidor e, consequentemente, maiores lucros [Melo, 1997].

Para se garantir que o produto final tenha qualidade, é preciso avaliar também a capacitação do processo de produção da organização. Quanto melhor o processo, melhores serão os produtos [Tsukumoto, 1995].

O setor de software no Brasil é caracterizado por uma grande participação de micro e pequenas empresas [Melo, 1997]. Segundo o Ministério da Ciência e Tecnologia, $77 \%$ das empresas de software brasileiras são micro e pequenas empresas com menos de 50 empregados. Apesar de várias dessas empresas já reconhecerem a importância da qualidade de software no Brasil, grande parte delas ainda não conhece ou não utiliza normas para o processo e para avaliação do produto [QUALIDADE, 1997].

Existem diversos estudos de âmbito internacional que se propõem a fornecer modelos para a melhoria da qualidade de processo de software das organizações. Dentre os mais conhecidos estão o SW-CMM [Paulk, 1992], o SPICE [SPICE1], o Bootstrap [Haase, 1994] entre outros.

Esses modelos porém, são projetados especialmente para grandes organizações produtoras de software. Eles não se ajustam à realidade das pequenas empresas brasileiras. Essa empresas enfrentam problemas, principalmente de recursos (recursos humanos, recursc financeiros), que tornam praticamente inviável a aplicação de quaisquer desses métodos. Fa se então necessária a criação de modelos que se adeqüem a essa realidade.

Assim, dentro do contexto de melhoria do processo de software, e visando atender necessidades das pequenas empresas brasileiras, foi elaborado no ICMC-USP de São CaI 
em 1998, uma Estratégia para Iniciar Melhoria de Processo de Software. Trata-se de uma estratégia simples de executar, auxiliando as pequenas empresas a avaliarem seu processo de software com relação ao nível 2 do SW-CMM. Essa estratégia culminou com a elaboração de um plano de avaliação e de um instrumento para coleta de dados, na forma de um questionário, o qual auxilia na execução da estratégia proposta [Endo, 1998].

A Estratégia para Iniciar Melhoria de Processo de Software abrange as fases de Inicialização e Diagnóstico do ciclo de melhoria de processo proposto pelo modelo IDEAL [Gremba, 1998]. Nesse modelo (Figura 1), a fase de inicialização contém as atividades de estímulo para a melhoria de processo de software, definição do contexto do patrocinador e estabelecimento da infra-estrutura inicial para o suporte da melhoria. A partir dessa fase, o processo de melhoria entra em um ciclo que permite a melhoria contínua do processo de software. A fase de diagnóstico visa caracterizar o estado atual e o estado futuro desejado da organização, além do desenvolvimento de recomendações de como se deve proceder nas etapas seguintes [Gremba, 1998].

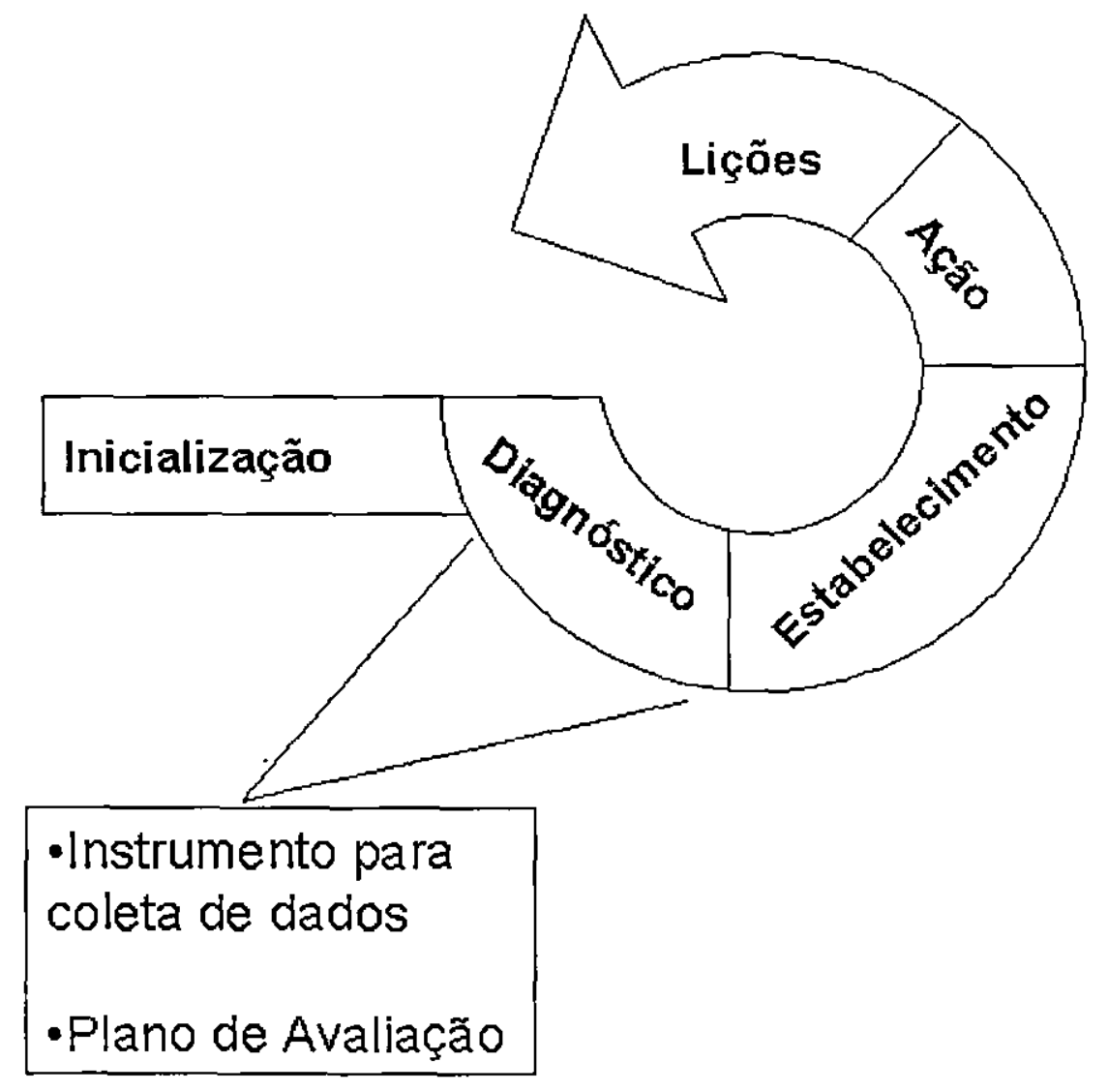

Figura 1 - Estratégia para Iniciar Melhoria de Processo de Software. 
A Estratégia para Iniciar Melhoria de Processo de Software (Figura 2) torna possivel a realização de uma avaliação rápida e segura, quando aplicada a pequenos grupos de desenvolvedores de software. Por ser baseada em abordagens já existentes e bastante utilizadas por inúmeras empresas de consultoria do mercado, a Estratégia para Iniciar Melhoria de Processo de Software proporciona um meio fácil e eficiente de se realizar um diagnóstico nessas pequenas organizações [Endo, 1999].

A Estratégia para Iniciar Melhoria de Processo de Software avalia o processo de software somente com relação às atividades do nivel 2 do SW-CMM, não contemplando assim os níveis 3,4 e 5 desse modelo. Nesses níveis existem diversas atividades que poderiam ter grande relevância para essa estratégia, pois tratam de atividades de vital importância para a implantação e manutenção da qualidade do processo de software das empresas.

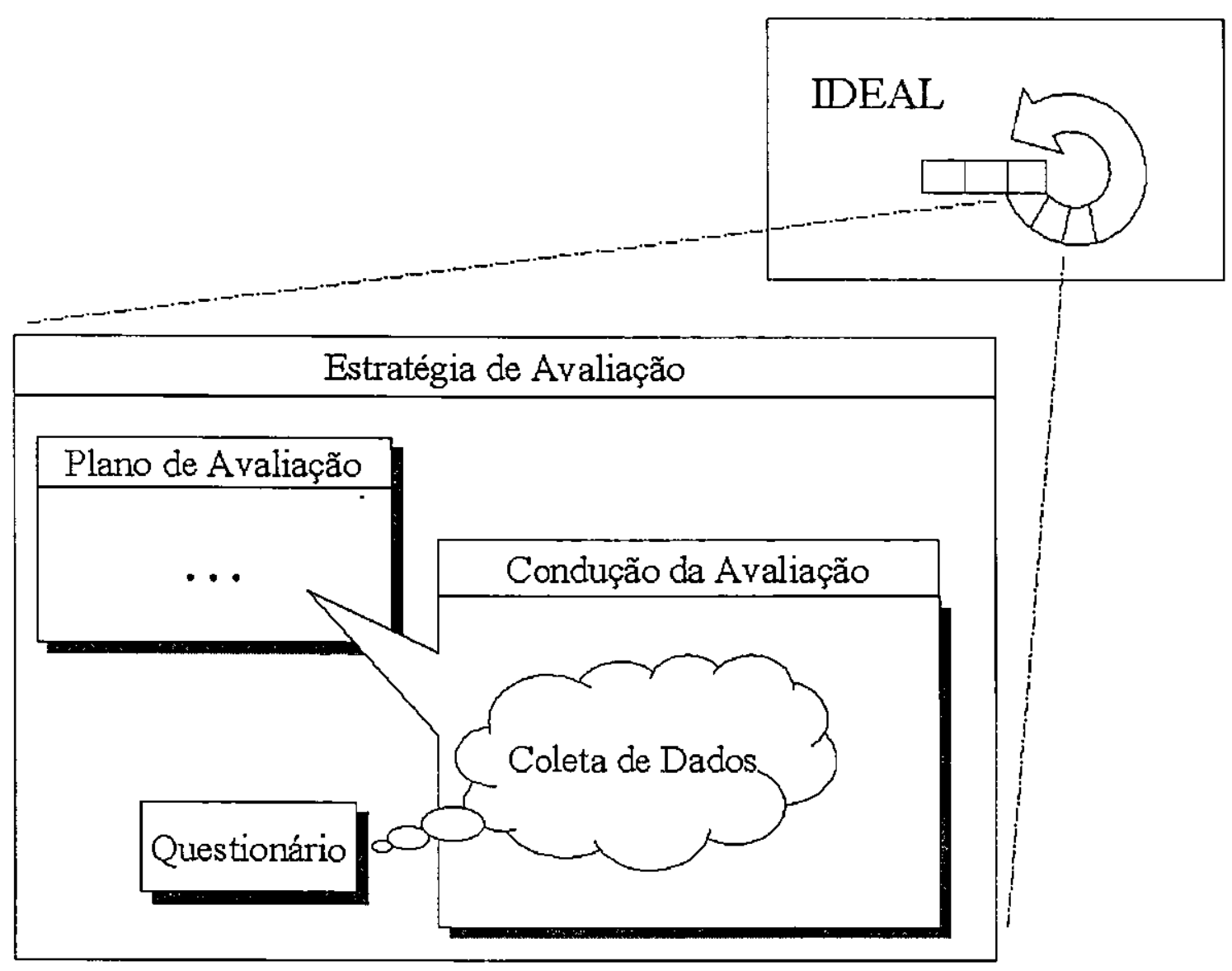

Figura 2 - Estratégia criada para a fase de Diagnóstico do IDEAL [Endo, 1998].

\subsection{Objetivos}


Considerando-se a situação acima apresentada, este trabalho de mestrado atuou em dois segmentos diferentes:

a) Foi realizado um estudo para a seleção e inclusão de algumas atividades dos outros níveis do SW-CMM, também importantes para uma empresa de pequeno porte, mas que, no entanto não foram abrangidos pela Estratégia para Iniciar Melhoria de Processo de Software, de ENDO. Tais adiçōes visam aumentar a abrangência de atividades, contribuindo assim para a melhoria do processo de software das pequenas empresas brasileiras.

b) Foi elaborada uma ferramenta automatizada para auxiliar as pequenas empresas nas etapas de coleta de dados e reporte de resultados da Estratégia para Iniciar Melhoria de Processo de Software. Tal ferramenta é importante para a Estratégia, pois se utiliza de uma base de dados para armazenamento dos dados coletados, e fornece diferentes visões desses dados com o intuito de se aprimorar a utilização da estratégia. Trata-se ainda de um sistema de informação para auxílio na tomada de decisões dentro da avaliação do processo de software das organizações.

\subsection{Organização do Trabalho}

Este trabalho está estruturado em seis capítulos e quatro apêndices. Este primeiro capítulo apresenta uma abordagem introdutória sobre o problema da qualidade de processo de software nas pequenas empresas brasileiras e expõe os objetivos atingidos por este trabalho de mestrado.

No capítulo 2 é apresentada a revisão bibliográfica que embasa este trabalho. É apresentada uma visão geral sobre Qualidade, com uma subdivisão desta em duas partes: Qualidade de Produto e Qualidade de Processo, seguido de uma apresentação de três dos modelos de melhoria de processo de software bastante conhecidos: o SW-CMM, O SPICE e a norma ISO9000. Na seqüência, é descrito o contexto de melhoria de processo de software, juntamente com a abordagem de melhoria de processo de software IDEAL, fazendo-se uma apresentação da etapa de avaliação de processo de software e da Estratégia para Iniciar Melhoria de Processo de Software.

No capítulo 3 mostra em detalhes o nível 3 do SW-CMM e apresenta o procedimento para a seleção e inclusão de KPAs adicionais à Estratégia para Iniciar Melhoria de Processo de Software. 
No capítulo 4 é descrito o desenvolvimento de uma ferramenta automatizada desenvolvida para auxiliar as pequenas empresas nas etapas de coleta de dados e reporte de resultados da Estratégia para Iniciar Melhoria de Processo de Software, bem como toda a documentação dessa ferramenta.

No capítulo 5 encontram-se as conclusões finais e propostas de trabalhos futuros, sugeridos a partir dos estudos realizados durante a elaboração desta dissertação.

No último capítulo encontram-se as Referências Bibliográficas.

No apêndice $\mathrm{A}$ encontram-se o dicionário de dados e documentos da fase de análise, obtidos durante a elaboração da ferramenta automatizada desenvolvida durante este trabalho de mestrado.

No apêndice B encontram-se os documentos da fase de projeto, obtidos durante a elaboração da ferramenta automatizada desenvolvida durante este trabalho de mestrado.

No apêndice $C$ encontra-se o Plano de Avaliação de Processo de Software da Estratégia para Iniciar Melhoria de Processo de Software.

No apêndice D encontra-se o Questionário de Avaliação da Estratégia para Iniciar Melhoria de Processo de Software. 



\section{Capítulo 2}

\section{Modelo de Melhoria de Processo de Software}

\subsection{Considerações Iniciais}

Este capítulo fornece uma contextualização quanto ao fator qualidade de uma maneira geral, bem como qualidade de software, de produto de software e de processo de software. Faz também uma abordagem quanto à melhoria de processo de software e apresenta uma visão detalhada de uma Estratégia para Iniciar Melhoria de Processo de Software, a qual define, relaciona e organiza as principais atividades que devem ser realizadas para avaliar um Processo de Software.

\subsection{Qualidade}

Atualmente, a grande preocupação no relacionamento cliente-fornecedor, em todo o mundo, é com relação à qualidade dos produtos e dos serviços prestados. $O$ fator qualidade tornou-se uma necessidade básica na busca pela competitividade de uma empresa no mercado. Existem diversas definições de qualidade. Essas definiçōes dependem do ponto de vista de quem as analisa. Na visão mais popular a qualidade é vista como um artigo de luxo; produtos mais caros, sofisticados e complexos tendem a ter mais qualidade do que seus similares mais simples. Na visão mais profissional, qualidade significa conformidade com os requisitos designados para o produto; e essa qualidade pode ser medida, avaliada, monitorada e melhorada. Alguns autores têm sua própria definição do que seja qualidade:

- Qualidade é a satisfação do cliente, obtida através de dois componentes: características do produto, referente à qualidade do projeto; e ausência de defeitos, referente à qualidade de conformidade, ou grau de atendimento aos requisitos do produto [Juran, 1993];

- A boa qualidade significa um grau previsível de uniformidade e confiabilidade do produto a baixo custo, estando a qualidade adequada ao mercado. O sucesso japonês na conquista de mercados com produtos inovadores, baratos $e$ de boa qualidade deve-se, fundamentalmente, aos seus ensinamentos [Deming, 1986];

- Qualidade pode ser interpretada de duas formas. De forma mais restrita, qualidade significa qualidade do produto. De forma mais ampla, qualidade significa: qualidade de trabalho; 
qualidade de serviço; qualidade de informação; qualidade de processo; qualidade de pessoal (incluindo operários, engenheiros, gerentes e executivos); qualidade de sistema; qualidade de empresa; e qualidade de objetivos [Ishikawa, 1993].

Segundo a norma NBR ISO 8402, que é a atual norma brasileira sobre o assunto, qualidade é "A totalidado das características de uma entidade que the confere a capacidade de satisfazer às necessidades explícitas e implícitas".

Essa definição formal exige alguns complementos como, por exemplo, definir o que são as entidades e o que são as necessidades explícitas e implícitas. A entidade é o próprio produto do qual está-se tratando, o qual pode ser um bem (por exemplo, um eletrodoméstico, um software, etc.) ou um serviço. As necessidades explícitas são as próprias condições e objetivos propostos pelo produtor. As necessidades implícitas incluem as diferenças entre os usuários, a evolução no tempo, as implicações éticas, as questões de segurança e outras visões subjetivas.

\subsection{Qualidade de Software}

Um software também é um produto, e sua comercialização é o meio de sobrevivência de inúmeras empresas. Nesse aspecto, uma empresa produtora de software também deve estar preocupada com a qualidade de seu produto final [Valente, 1999]. Porém, por vezes encontrase nesse ponto um grande problema: muitas pessoas acham que criar programas é uma arte que não pode seguir regras, normas ou padrões [Belloquim, 1998]. Segundo Pressman [Pressman, 1995], isso acontece principalmente porque:

- Produtos de software são complexos, até mais do que o hardware onde são executados;

- Software não tem produção em série. Seu custo está no projeto e desenvolvimento;

* Software não se desgasta e nem se modifica com o uso;

- O software é abstrato, ou seja, é um componente lógico. Sua representação em grafos e diagramas não é precisa;

- Não há um acordo entre os profissionais da área sobre o que é Qualidade de Software.

Apesar de tudo isso, é preciso entender que o problema não está no software em si, mas na forma como as pessoas tem desenvolvido software até os dias atuais. 
Na literatura apresentam-se várias definições do que seja qualidade relacionada a um software:

- "Um produto de software apresenta qualidade dependendo do grau de satisfação das necessidades dos clientes sob todos os aspectos do produto" [Sanders, 1994].

- "Qualidade de software é o grau em que o software possui uma combinação desejada de atributos" [IEEE Std 729, 1983].

- "Qualidade de software é o grau em que os atributos do software são capazes de desempenhar sua finalidade especificada" [DoD - Std 2168].

- "A percepçāo da qualidade de software é vista principalmente em termos de tempo em que um sistema de software opera corretamente" [Smith, 1989].

Desde a coleta dos requisitos até a entrega de um software para utilização pelos usuários, um complexo processo de desenvolvimento é percorrido, no qual vários fatores podem influenciar a boa ou a má qualidade do software. Esse processo de desenvolvimento é composto de várias fases, as quais possuem, além dos requisitos estipulados pelos usuários, um conjunto específico de requisitos inerentes àquela fase. $O$ não cumprimento de todos os requisitos de uma fase compromete as fases seguintes, além de comprometer o processo como um todo.

Estabelecer, compreender e controlar esse processo pode ajudar a alcançar a obtenção de qualidade do produto, desde que sejam definidos claramente os requisitos de qualidade desse produto. Assim, pode-se definir a qualidade de software pela ótica do usuário como sendo a conformidade aos requisitos estabelecidos [Andrade, 1996]. Sob a ótica do desenvolvedor, um software com qualidade é aquele de fácil manutenção e fácil de testar. Do ponto de vista gerencial, o software que possa ser desenvolvido com baixo custo pode ser um software de alta qualidade. Isso demonstra que, mesmo dentro da qualidade de software, podem existir várias visões diferentes, como tem sido para a definiçāo da qualidade como um termo geral [Gillies, 1993].

Para se realizar estudos sobre a qualidade de software, tem-se dividido a qualidade de software em duas grandes áreas: qualidade de produto de software e qualidade de processo de software. 


\subsection{Qualidade de Produto de Software}

A Qualidade de Produtos de Software é caracterizada pela concentraçāo de esforços para obter-se um controle de qualidade do produto final, para que um produto defeituoso não chegue às mãos do cliente.

Tendo-se como base os trabalhos apresentados por McCall (1977), foi criada a norma ISO/IEC 9126 (1994), a qual procura definir um conjunto de fatores ou características que evidenciam a qualidade do produto final [Cavano, 1978]. Tais características sāo definidas para representar as necessidades e os desejos daqueles que estāo envolvidos direta ou indiretamente com o software [Tsukumoto, 1995]. As necessidades dos envolvidos, direta ou indiretamente, com o software devem ser mapeadas como características que o produto de software deve possuir.

A norma ISO/IEC 9126 (1994) é uma das mais antigas da área de qualidade de software e possui sua tradução para o Brasil, publicada em agosto de 1996 como NBR 13596. Essas normas listam o conjunto de características que devem ser verificadas em um software para que ele seja considerado um "software de qualidade". Săo seis grandes grupos de características, cada um dividido em subcaracterísticas, representados na Tabela 1.

\begin{tabular}{|c|c|c|}
\hline Característica & Subcaracterísticas & Palavra chave para a característica \\
\hline Funcionalidade & Adequação & $\begin{array}{l}\text { Propōe-se a fazer o que é } \\
\text { aproprlado? }\end{array}$ \\
\hline \multirow[t]{4}{*}{$\begin{array}{l}\text { (Satisfação às } \\
\text { necessidades) }\end{array}$} & Acurácia & $\begin{array}{l}\text { Faz o que foi proposto de forma } \\
\text { correta? }\end{array}$ \\
\hline & Interoperabilidade & $\begin{array}{l}\text { Interage com os sistemas } \\
\text { especificados? }\end{array}$ \\
\hline & Conformidade & $\begin{array}{l}\text { Está de acordo com as normas, leis, } \\
\text { etc.? }\end{array}$ \\
\hline & Segurança de acesso & $\begin{array}{l}\text { Evita acesso não autorizado aos } \\
\text { dados? }\end{array}$ \\
\hline Confiabilidade & Maturidade & $\begin{array}{l}\text { Com que freqüência apresenta } \\
\text { falha? }\end{array}$ \\
\hline \multirow[t]{2}{*}{ (Imunidade às falhas) } & Tolerância a falhas & Ocorrendo falhas, como ele reage? \\
\hline & Recuperabilidade & É capaz de recuperar dados em caso \\
\hline
\end{tabular}




\begin{tabular}{|c|c|c|}
\hline & \multirow{2}{*}{\multicolumn{2}{|c|}{\begin{tabular}{l|l}
$\cdot$ & de falha?
\end{tabular}}} \\
\hline & & \\
\hline \multirow{3}{*}{$\begin{array}{l}\text { Usabilidade } \\
\text { (Facilidade de uso) }\end{array}$} & Inteligibilidade & $\begin{array}{l}\text { E fácil entender o conceito e a } \\
\text { aplicação? }\end{array}$ \\
\hline & Apreensibilidade & É fácil aprender a usar? \\
\hline & Operacionalidade & É fácil de operar e controlar? \\
\hline \multirow{2}{*}{$\begin{array}{l}\text { Eficiência } \\
\text { (é rápido e "enxuto"?) }\end{array}$} & Tempo & $\begin{array}{l}\text { Qual é o tempo de resposta, a } \\
\text { velocidade de execução? }\end{array}$ \\
\hline & Recursos & $\begin{array}{l}\text { Quanto recurso usa? Durante quanto } \\
\text { tempo? }\end{array}$ \\
\hline \multirow{4}{*}{$\begin{array}{l}\text { Manutenibilidade } \\
\text { (é de fácil } \\
\text { manutenção?) }\end{array}$} & Analisabilidade & $\begin{array}{l}\dot{E} \text { fácil de encontrar uma falha, } \\
\text { quando ocorre? }\end{array}$ \\
\hline & $\begin{array}{l}\text { Modificabilidade } \\
\text {. }\end{array}$ & É fácil modificar e adaptar? \\
\hline & Estabilidade & $\begin{array}{l}\text { Há grande risco quando se faz } \\
\text { alterações? }\end{array}$ \\
\hline & Testabilidade & $\begin{array}{l}\text { E fácil testar quando se faz } \\
\text { alterações? }\end{array}$ \\
\hline \multirow{4}{*}{$\begin{array}{l}\text { Portabilidade } \\
\text { (Facilidade quanto ao } \\
\text { uso em outros } \\
\text { ambientes) }\end{array}$} & Adaptabilidade & É fácil adaptar a outros ambientes? \\
\hline & $\begin{array}{l}\text { Capacidade para ser } \\
\text { instalado }\end{array}$ & É fácil instalar em outros ambientes? \\
\hline & Conformidade & $\begin{array}{l}\text { Está de acordo com padrões de } \\
\text { portabilidade? }\end{array}$ \\
\hline & $\begin{array}{l}\text { Capacidade } \\
\text { substituir }\end{array}$ & É fácil usar para substituir outro? \\
\hline
\end{tabular}

Tabela 1 - Características e subcaracterísticas de qualidade da norma ISO/IEC 9126 (1994). 


\subsection{Qualidade de Processo de Software}

$\mathrm{Na}$ área de qualidade de software, os estudos mais recentes, na sua maioria, estão voltados para se obter um aprimoramento sobre o processo de desenvolvimento de software. Em outras palavras, existe uma grande busca por se estabelecer métodos e padrões que determinem práticas sobre como desenvolver melhores softwares. Apesar da importância da existência da qualidade do produto de software, ao se garantir a qualidade de processo de um software, está-se dando um grande passo para se garantir a qualidade do produto de software.

O Processo de Software é constituído por uma série de atividades, políticas, práticas, eventos, ferramentas e métodos que garantem, técnica e administrativamente, que o software seja desenvolvido de maneira organizada, disciplinada e previsível. O Processo de Software é representado por um conjunto seqüencial de atividades, objetivos, transformaçōes e eventos que encapsulam estratégias para cumprimento da evolução do software [Paulk et. al., 1993].

Para que o processo de software seja efetivo no cumprimento de seus objetivos, é necessário que haja um planejamento muito bem detalhado, o qual leve em consideração o ambiente em que o software está sendo desenvolvido. Aspectos específicos de projeto tais como equipe de desenvolvimento, metas e políticas, cronogramas, disponibilidade de recursos humanos, técnicos, o fluxo de informações através das fases do processo, os papéis desempenhados pelas pessoas no processo, a interface entre os processos e as ferramentas, e outros, todos devem ser considerados [Marciniat, 1994].

Por tudo isso, os mais recentes estudos no tocante à qualidade propõem um controle total sobre o processo do software. Isso implica que, para o desenvolvimento de um software; deve haver um processo que garanta que o mesmo seja produzido de acordo com os padrões impostos pelas cláusulas do contrato [Garmus, 1996]. Assim, espera-se que um processo de software controlado propicie segurança frente às variações que o produto possa sofrer em relação às suas especificações iniciais [Smith, 1989].

Para atender a essas características, um ambiente deve fornecer métodos e ferramentas para planejar, executar e mudar os processos, considerando as necessidades em questão e suas restrições. Assim, haverá um controle explícito de qualidade, orçamento e cronograma referentes ao sistema em desenvolvimento.

\subsection{Melhoria de Processo de Software}

O aumento crescente do reconhecimento, por parte das empresas produtoras de software, da importância de se melhorar a qualidade do seu produto de software tem feito com que cada 
vez mais as organizações se preocupem com a melhoria do controle sobre todos os elementos envolvidos com esse processo de desenvolvimento. Cada vez mais as empresas desenvolvedoras de software estão reconhecendo o fato de que, melhorando-se a qualidade do seu processo de software, consequentemente seu produto de software estará ganhando qualidade.

Melhoria do processo de software significa definir as atividades que uma organização deve seguir para melhorar o seu processo de software ao longo de todo o tempo. É preciso considerar que todas as atividades relacionadas ao desenvolvimento de software possam ser controladas, medidas e melhoradas. Isso aumenta a visibilidade sobre todo o processo, o que torna as atividades durante o desenvolvimento e manutenção do software mais gerenciáveis. Consequentemente, reduz-se custos e os cronogramas tornam-se mais confiáveis, além de facilitar a adoção e implantação de novas tecnologias [Maidantchik, 1997].

Por se tratar de uma decisão que depende de toda a organização e de seus resultados serem, na maioria das vezes, perceptíveis somente a longo prazo, as pessoas tendem a adiar a implantação de melhoria de processo. Melhoria de processo não é uma atividade trivial, sendo que vários dos elementos a serem considerados para sua implantação envolvem a própria organização, tais como comprometimentos, responsabilidades, recursos, habilidades profissionais e gerenciais [Glass, 1998].

Para se obter qualidade em um processo de software, é importante que as tarefas, responsabilidades, atividades, funções, recursos e pessoas que farão parte do processo de software a ser adotado sejam estudados, preparados e planejados com antecedência [Endo, 1998]. Assim, é necessário que se estabeleça uma estratégia para melhoria de processo de software, a qual permita que todos os elementos envolvidos no processo de software sejam definidos e executados. É através da utilização de uma estratégia de melhoria de processo que a organização poderá avaliar seu estado atual, ou seja, em qual nível de maturidade se encontra o seu processo de software.

Existem atualmente várias Estratégias de Melhoria de Processo de Software. Dentre eles, pode-se citar o PDCA [Werkema, 1995], o IDEAL [Gremba, 1998], o SPICE (parte 7) [SPICE7, 1997], etc. O importante a ser ressaltado é que, independentemente da estratégia que seja adotada por uma organização, a melhoria do processo de software deve ser muito bem planejada e controlada, consciente, e o grau a ser atingido deve ser bem definido [Curtis, 1998].

\section{Melhoria Contínua através da Abordagem IDEAL}


O Modelo IDEAL (Figura 3), desenvolvido pela SEI (Software Engineering Institute), descreve uma abordagem sistemática de gerência que ajuda as organizações a melhorarem o seu processo de software, através do estabelecimento de um programa de melhoria contínua de processo de software. Essa melhoria é obtida através da introdução de novas políticas, tecnologias, métodos e ferramentas para a construção de um ambiente de desenvolvimento mais eficaz.

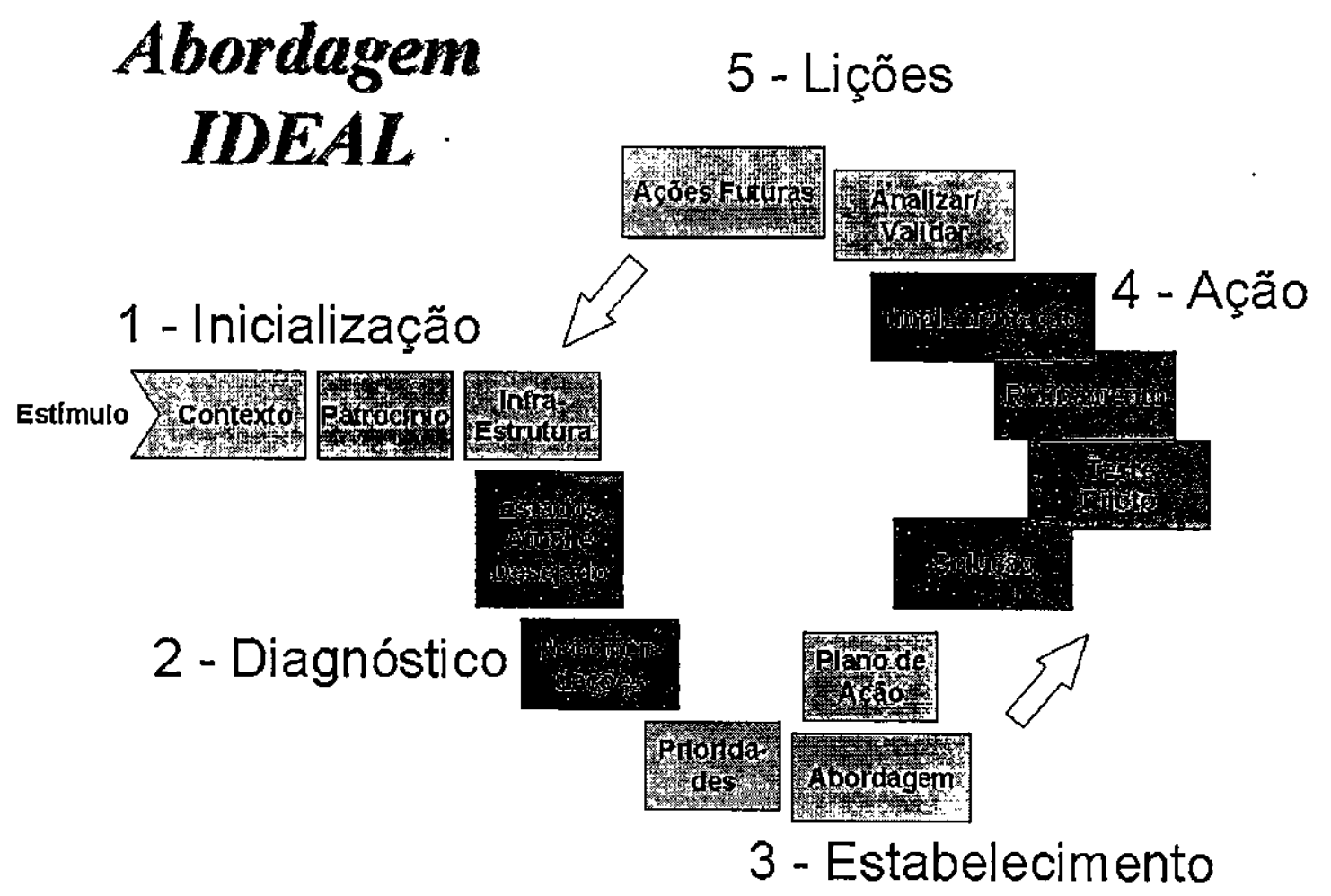

Figura 3 - O Modelo IDEAL [Gremba, 1998].

IDEAL é o acrônimo que engloba as cinco fases do ciclo de melhoria de processo de software: Inicialização (Initiating), Diagnóstico (Diagnosing), Estabelecimento (Establishing), Ação (Acting) e Lições (Learning). Ele contém as atividades de diagnóstico do processo atual, a elaboração de um plano para melhoria, a implementação desse plano de melhoria e a confirmação das atividades implantadas através do diagnóstico do processo, iniciando novamente o ciclo [Gremba, 1998].

- Fase de Inicialização: essa fase é composta pelo estímulo à melhoria do processo de software; definição do contexto e do patrocinador; estabelecimento de uma infra-estrutura inicial para o suporte à melhoria; 
- Fase de Diagnóstico: essa fase visa caracterizar o estado atual e o estado futuro desejado da organização, os quais são utilizados para desenvolver recomendações de como proceder nas fases subseqüentes;

- Fase de Estabelecimento de Diretrizes: essa fase se propõe a definir as prioridades para as alterações; desenvolver uma estratégia para a realização do trabalho e identificar recursos disponiveis; desenvolver um plano de implementaçāo detalhado;

- Fase de Ação: essa fase visa criar a melhor solução que atenda as necessidades organizacionais identificadas; validar a solução criada através de um teste piloto; modificar a solução para refletir o conhecimento, experiência e lições obtidas do teste; implementar a solução em toda a organização;

- Fase de Lições: nessa fase as lições são coletadas, analisadas e documentadas e as necessidades identificadas na fase de inicialização são reexaminadas para verificar se foram atendidas; as propostas de alterações para melhoria futura são fornecidas.

\subsection{O modelo CMM - Capability Maturity Model}

Os Modelos de Melhoria de Processo de Software fornecem uma estrutura dentro da qual as atividades de software podem ser implementadas, além de prover o encapsulamento da melhor, ou pelo menos, da mais apropriada prática, através de um conhecimento adquirido depois de um longo período de tentativas e erros. Dessa forma, modelos disponibilizam métodos e práticas para que uma tarefa possa ser repetida e obter sucesso cada vez que for executada [Horch, 1996].

Existem vários esforços no sentido de se elaborar normas e modelos de processos que visem a melhor qualidade nos processos de construção de um software. Nos dias atuais, um dos modelos mais utilizados é o SW-CMM [Paulk et. al., 1993].

O SW-CMM (Software Capability Maturity Model) desenvolvido pelo SEl (Software Engineering Institute), é um modelo que apoia a melhoria do processo de software de uma organizaçāo através da aplicação criteriosa de conceitos de gerenciamento de processo e de melhoria de qualidade do desenvolvimento e manutenção de software [Marciniat, 1994], seguindo a estratégia de melhoria do modelo IDEAL.

O SW-CMM oferece um framework baseado na idéia de pequenos passos evolucionários, ao invés de passos revolucionários [Fox, 1997].

O SW-CMM diferencia as organizações em dois grupos bem distintos: 
- As organizações imaturas, as quais são caracterizadas por possuírem um processo de software ad hoc, indisciplinado e extremamente dependente dos profissionais desenvolvedores, além de baixa produtividade, altos custos de manutenção e baixa visibilidade do progresso e da qualidade, e

- As organizações maduras, as quais possuem ampla habilidade de gerenciamento e manutenção do processo de software. Seu processo de software é definido, documentado e melhorado constantemente; como conseqüência, as expectativas de custos, cronograma, funcionalidade e qualidade de produto são alcançadas (projetos efetivamente concluídos) e a melhoria do processo pode ser obtida [Humphrey, 1992].

O SW-CMM classifica as organizações em cinco nf́veis diferentes. O nível de classificação indica os conjuntos de atividades, denominadas áreas-chave de processo, que uma organizaçāo cumpre em cada nível [Grady, 1997]. Em cada um dos níveis de maturidade (Tabela 2) são focalizados aspectos específicos do processo de software. No primeiro nível, o foco está na coragem e competência das pessoas. No segundo nível, o foco está no processo de gerenciamento de projetos. No terceiro nivel, o foco está no processo de engenharia $\theta$ suporte organizacional. No quarto nível, o foco está na qualidade de produto e de processo. $E$ finalmente, no quinto nível, o foco é o processo de melhoria contínua [Endo, 1998]. Alcançar cada nível de maturidade significa estabelecer um componente diferente no processo de software, resultando num incremento na capacidade do processo da organização. Sem esses componentes, programas de melhoramentos podem ser ineficientes, devido ao fundamento necessário para apoiar melhoramentos sucessivos não ter sido estabelecido. Segundo o modelo definido pelo SW-CMM, mesmo depois de ter obtido o nível 5, a organização ainda permanece em um programa de melhoria contínua de processo [Lowe, 1996].

\begin{tabular}{|l|l|}
\hline \multicolumn{1}{|c|}{ Nível } & \multicolumn{1}{c|}{ Foco } \\
\hline 5: Otimizaçāo & Processo de Melhoria Contínua \\
\hline 4: Gerenciado & Qualidade de Produto e de Processo \\
\hline 3: Definido & Processo de Engenharia e Suporte Organizacional \\
\hline 2: Repetível & Processos de Gerenciamento de Projeto \\
\hline 1: Inicial & Pessoas Competentes e Heróicas \\
\hline
\end{tabular}

Tabela 2 - O Modelo SW-CMM. 
Exceto no nível 1, todos os níveis sāo subdivididos em áreas-chave de processo, conhecidas como KPA's - Key Process Areas (Tabela 3). Essas áreas são atividades relacionadas entre si, as quais a organização deve focar para melhorar o seu processo de software. Para que uma empresa atinja um determinado nivel de maturidade SW.CMM, ela deve realizar completamente todos os processos relacionados às áreas-chave daquele nível.

\begin{tabular}{|c|c|}
\hline Nível SW-CMM & KPA's \\
\hline 5: Otimizado & $\begin{array}{l}\text { - Prevenção de defeitos } \\
\text { - Gerenciamento de mudanças tecnológicas } \\
\text { - Gerenciamento de mudanças no processo }\end{array}$ \\
\hline 4: Gerenciado & $\begin{array}{l}\text { - Gerenciamento quantitativo dos processos } \\
\text { - Gerenciamento da qualidade de software }\end{array}$ \\
\hline 3: Definido & $\begin{array}{l}\text { - } \text { Foco do processo organizacional } \\
\text { - } \text { Definição do processo organizacional } \\
\text { - } \text { - Gerenciamento de software integrado } \\
\text { - Engenharia de produto de software } \\
\text { - Coordenação intergrupos } \\
\text { - Revisão conjunta }\end{array}$ \\
\hline 2: Repetível & $\begin{array}{l}\text { - Gerenciamento de requisitos } \\
\text { - Planejamento do projeto } \\
\text { - Gisão geral e acompanhamento do projeto } \\
\text { - Gerenciamento de subcontratados } \\
\text { - Garantia da qualidade do software }\end{array}$ \\
\hline
\end{tabular}




\begin{tabular}{|l|l|}
\hline & $\begin{array}{c}\cdot \text { Gerenciamento de configuração } \\
.\end{array}$ \\
\hline 1: Inicial & Não possui KPA - ad hoc \\
\hline
\end{tabular}

Tabela 3 - Áreas chave de processo do SW-CMM.

O modelo SW-CMM define um conjunto objetivos para cada área-chave. Esses objetivos definem aquilo que deve ser alcançado no caso dos processos dessa área-chave serem completamente realizados.

\subsection{Estratégia para Iniciar Melhoria de Processo de Software em Empresa de Pequeno Porte}

Em 1998 foi apresentado no ICMC/USP-São Carlos um trabalho de mestrado cujo objetivo foi, tomando como base o modelo IDEAL, desenvolver uma Estratégia, para atender a fase de inicialização e de diagnóstico dentro de um programa de melhoria de processo de software para empresas de pequeno porte [Endo, 1998].

$\mathrm{Na}$ fase de inicialização da estratégia de melhoria de processo de software deve-se articular, claramente, a aplicação dos esforços para satisfazer as necessidades de negócio, deve-se assegurar o suporte ao gerenciamento e deve-se, finalmente, colocar em prática uma infraestrutura para gerenciar os detalhes de implementação do processo de melhoria. Ela é firmada em três pontos:

- Estímulo para mudança: são definidas as necessidades de negócio que alavancam as mudanças nas práticas da organização. Os estímulos para mudanças podem ser: um evento inesperado ou uma circunstância, uma ordem de alguém superior ou informações obtidas por uma atividade de "benchmarking". Em geral, quando as necessidades de mudanças são evidenciadas por razões de negócio é mais fácil convencer a organização, como um todo, e existem maiores chances de sucesso.

- Estabelecer Contexto: após estarem definidas, claramente, as razões para a melhoria, a gerência da organlzação pode estabelecer o contexto para o trabalho que vai ser realizado. Isso significa definir, claramente, aonde os esforços vão se enquadrar na estratégia de negócio da organização, que metas e objetivos de negócio serăo afetados pelas mudanças, como isso vai incidir sobre outras iniciativas e trabalhos futuros, e que benefícios são 
esperados. O contexto e as implicações se tornarão mais evidentes à medida que o processo de melhoria seja encaminhado, mas é importante que essas questões estejam definidas, de maneira mais clara possível, antes de iniciar os esforços.

- Definir Patrocinador. um patrocinador efetivo é um dos fatores mais importantes para os esforços de melhoria de processo. O patrocinador deve ajudar a manter o compromisso nos momentos de dificuldades e principalmente na situação de caos que a organização pode se encontrar no princípio do processo de melhoria. Outra função do patrocinador é garantir os recursos essenciais utilizados durante a melhoria.

A fase de diagnóstico da estratégia de melhoria de processo de software caracteriza-se por dois estados da organização: um que representa o estado atual e outro que representa 0 estado futuro desejado. Para se verificar o estado atual do processo, é necessário que seja realizada uma avaliação do mesmo. A avaliação de processo significa capturar informaçōes que descrevam a capacidade real do processo de uma organização e é motivada pelo desejo de determinar ou melhorar a capacidade desse processo. Uma avaliação de processo de software visa, principalmente, descobrir os pontos fracos e fortes de uma organização. Os pontos fracos são utilizados para priorizar as atividades que devem ser melhoradas, e os pontos fortes podem ser mantidos ou adaptados.

A estratégia proposta Endo define, relaciona e organiza as principais atividades que devem ser realizadas para avaliar um processo de software [Endo, 1999], tomando como base o nível 2 do SW-CMM.

\subsubsection{Nível 2 do SW-CMM - Repetível}

Nesse nível do SW-CMM são estabelecidas políticas para implantar e gerenciar um projeto de software. O planejamento e gerenciamento de novos projetos é baseado no sucesso de projetos semelhantes anteriores. Um dos objetivos alcançados nesse nível é a institucionalização de um processo de gerenciamento efetivo para projetos de software, o que permite às organizações repetirem o sucesso de práticas desenvolvidas em projetos anteriores, embora processos específicos possam diferir entre si. Um processo efetivo pode ser caracterizado como um processo praticado, documentado, obrigatório, treinado, medido e capaz de ser melhorado.

O nível repetível apresenta as organizações com controles de gerenciamento de software básicos. Compromissos realísticos de projetos são feitos baseados em resultados obtidos em projetos anteriores, considerando-se as exigências do projeto atual. São realizadas baselines para controlar a integridade dos trabalhos desenvolvidos com relação aos requisitos de 
software exigidos. São definidos padrões de projeto de software, e a organização assegura que esses sejam fielmente seguidos.

Esse nível possui seis áreas-chave de processo:

\subsubsection{Gerenciamento de Requisitos}

A finalidade dessa área-chave é estabelecer um entendimento comum entre cliente e a equipe do projeto, sobre os requisitos do software que serão abordados. Isso envolve documentar e controlar os requisitos do cliente e manter os planos, produtos $\theta$ atividades consistentes com esses requisitos. Um "cliente" pode ser interpretado como um grupo de engenharia de sistemas, um grupo de marketing, uma outra organização externa ou mesmo um cliente externo. Esse entendimento deve envolver tanto os requisitos técnicos como não-técnicos (por exemplo, a data de entrega). Ele forma a base para o estímulo, planejamento, execução e avaliação das atividades através do ciclo de vida do software.

A alocação dos requisitos de sistema para software, hardware e outros componentes do sistema (por exemplo, recursos humanos) podem ser executados por um grupo externo ao grupo de engenharia de software, e o grupo de engenharia de software não pode ter controle sobre o primeiro. Dentro das diretrizes do projeto, o grupo de engenharia de software decide os passos a serem seguidos para assegurar que os requisitos de sistema alocados ao software são documentados e controlados.

Para conseguir isso, o grupo de engenharia de software faz revisões dos requisitos de sistema alocados ao software para identificar e resolver problemas antes que eles sejam incorporados ao projeto de software. Sempre que os requisitos de sistema alocados ao software são alterados, os planos, produtos de trabalho e atividades de software afetados são ajustados para permanecerem consistentes com as alterações realizadas.

Assim, as duas metas dessa área-chave são:

- Controlar os requisitos do software através de uma linha de referência (baseline) para o uso na engenharia de software e no gerenciamento.

- Manter os planos de software, produtos e atividades consistentes com os requisitos do software. 


\subsubsection{Planejamento de Projeto de Software}

A finalidade dessa área-chave é estabelecer planos razoáveis para desenvolver e gerenciar o processo de software. Isso envolve desenvolver estimativas, determinar os compromissos e definir um plano para realizar o trabalho.

Esse plano se inicia com a definição do trabalho a ser executado e de outras diretrizes e objetivos que definem e delineiam o projeto de software (objetivos esses estabelecidos pela área-chave anterior). O plano inclui estimativa do tamanho dos produtos de software e também dos recursos necessários, elaboração de um cronograma, identificação e avaliação dos riscos, e estabelecimento de compromissos. A iteração através desses passos pode ser necessária para estabelecer o plano para o projeto de software.

Este plano apresenta as bases para execução e gerenciamento das atividades do projeto de software, e atribui os compromissos para com os clientes de acordo com os recursos, diretrizes e capacidades do projeto.

Assim, as três metas dessa área-chave são:

- Documentar as estimativas de software para serem utilizadas no planejamento e acompanhamento do projeto de software.

- Planejar e documentar as atividades de projeto de software e compromissos.

- Os grupos e os indivíduos envolvidos obedecerem aos seus compromissos relacionados ao projeto de software.

\subsubsection{Visão Geral e Acompanhamento do Projeto}

A finalidade dessa área-chave é oferecer visibilidade adequada do progresso real do projeto, para que a gerência possa tomar medidas efetivas quando o desempenho do projeto se desvia significativamente do plano. Isso envolve acompanhar e revisar os resultados e as realizaçōes do software confrontando com as estimativas documentadas, compromissos e planos. Envolve, também, ajustar os planos com base nos resultados e realizações efetivamente alcançados. Os mecanismos utilizados são revisões internas e revisões formais com clientes. Quando ocorre um desvio entre os planos e os resultados efetivos, deve-se alterar a forma como o trabalho está sendo feita e/ou ajustar os planos.

Assim, as três metas dessa área-chave são:

- Acompanhamento dos resultados reais e desempenho do projeto em relação ao plano de software. 
- Realizar e gerenciar as ações corretivas quando os resultados reais e o desempenho desviarem significativamente do plano de software.

- As mudanças nos compromissos de software serem obedecidas pelos indivíduos e grupos envolvidos.

\subsubsection{Gerenciamento de Subcontratos de Software}

A finalidade dessa área-chave é selecionar fornecedores (que se responsabilizam por parte do trabalho) qualificados e gerenciá-los eficazmente. Isso envolve selecionar o fornecedor, estabelecer compromissos, acompanhar e revisar o desempenho e os resultados obtidos. Essas práticas cobrem desde o gerenciamento (somente) do subcontrato de software até o gerenciamento de componentes do subcontrato, o que inclui software, hardware, $\theta$ possivelmente outros componentes do sistema.

$\mathrm{Na}$ seleção e gerenciamento do fornecedor são necessários documentos como: cláusula de contrato, requisitos do projeto, produtos a serem entregues, padrões e procedimentos a serem seguidos. As atividades de planejamento, acompanhamento e supervisão dos subcontratados são executadas pelo subcontratante. O contratante garante que essas atividades são executadas corretamente $\theta$ que os produtos de software gerados satisfazem seu critério de aceitação.

Assim, as quatro metas dessa área-chave são:

- O contratante selecionar os subcontratado de software qualificado.

- O contratante e o subcontratado de software concordarem com os compromissos de ambas as partes.

- Manutenção da comunicação entre o contratante e o subcontratado de software.

- Acompanhamento, pelo contratante, do resultado real e desempenho do subcontratado de software em relação aos seus compromissos.

\subsubsection{Garantia de Qualidade de Software}

A finalidade dessa área-chave é oferecer gerenciamento, com vlsibilidade apropriada, do processo que está sendo utilizado e dos produtos que estão sendo desenvolvidos. Isso envolve revisões e auditorias nos produtos de software e nas atividades para assegurar que estão em conformidade com os padrões e procedimentos aplicados. Envolve também fornecer esses resultados para os gerentes envolvidos. 
Assim, as quatro metas dessà área-chave são:

- Planejamento das atividades de garantia de qualidade de software

- Verificação objetiva da conformidade dos produtos de software e atividades ao padrão aplicado, aos procedimentos e aos requisitos.

- Os grupos e indivíduos envolvidos serem informados sobre as atividades de garantia de qualidade e de seus resultados.

- Encaminhamento, ao gerente sênior, dos problemas de questões que não podem ser resolvidos no projeto de software.

\subsubsection{Gerenciamento de Configuração de Software}

A finalidade dessa área-chave é estabelecer e manter a integridade dos produtos do projeto de software ao longo do cicio de vida do software. Isso envolve identificar os itens de configuração, controlar sistematicamente as alterações e manter a integridade da configuração ao longo do ciclo de vida do software. O gerenciamento da configuração utiliza linhas de referência (baselines) que servem como um marco no ciclo de vida do software. Os itens que passam por uma linha de referência podem ser alterados somente através de procedimentos formais de controle de mudanças. Esta área-chave abrange as práticas para executar a função de gerenciamento de configuração de software.

Assim, as quatro metas dessa área-chave são:

- Planejamento das atividades de gerenciamento de configuração de software.

- Os produtos de trabalhos de software selecionados serem identificados, controlados e disponibilizados.

- Controle das mudanças em produtos de trabalhos de software identificados.

- Os grupos e indivíduos envolvidos serem informados sobre a situação e conteúdos das linhas de referências (bașeline).

\subsubsection{O Plano de Avaliação de Processo de Software}

Existem diversas variáveis que podem influenciar o sucesso de uma avaliação, principalmente quando o processo de software que se avalia é um processo complexo. Além disso, para a avaliação ter sucesso é preciso que exista: comprometimento, motivação, confidencialidade, relevância e credibilidade. 
Desse modo, para que uma avaliação seja realizada de maneira organizada e controlada, é muito importante que essa avaliação seja planejada, com antecedência, levando-se em consideração todos os elementos que fazem parte do processo de avaliação de software. É necessário que se utilize um plano de avaliação de software que contenha os objetivos, as atividades, o cronograma, as pessoas envolvidas, o comprometimento, enfim, tudo que possa dizer respeito ao processo de avaliação.

O plano de avaliação da Estratégia de Endo foi baseado no modelo CAF [Masters \& Bothwell, 1995], que auxilia a criação de um plano de avaliação baseado no modelo SW-CMM.

O questionário de avaliação, utilizado como instrumento de coleta de dados na avaliação, encontra-se no anexo A, e a estrutura do plano de avaliação é representada na Tabela 4.

Plano de Avaliação do Proçesşo de Software
1. Introdução
1.1. Objetivo
1.2. Escopo
1.3. Papéis e Responsabilidades
- Patrocinador
- Gerente Sênior
- Participantes da Avaliação
1.4. Termos-Chave
1.5. Referências
Atividades de Avaliação
2.1. Condução da Avaliação
2.2. Consolidação e Validação dos Dados
2.3. Realização do Julgamento das Medidas
3.1. Reporte dos Resultados da Avaliação
3.2. Proteção de Informações Confidenciais
2.


3.3. Preservação das Gravações

4. Estimativas de Cronograma e Recursos

4.1. Cronograma

4.2. Recursos

Tabela 4 - Estrutura do Plano de Avaliação da Estratégia para Iniciar Melhoria de Processo de Software.

A seção 1 do Plano de Avaliação - Introdução - é dividida em cinco subseções:

* Objetivos: o objetivo da avaliação é ajudar a realizar melhoria interna;

- Escopo: o escopo escolhido é o nível 2 do SW-CMM, e o escopo da empresa escolhido é um projeto que tenha seu próprio cronograma e orçamento;

- Responsabilidades: as responsabilidades são atribuídas ao patrocinador, gerente sênior, avaliador e participantes para que sejam definidos os comprometimentos por cada parte. A qualificação mínima exigida de um avaliador é que conheça a estrutura do SW-CMM, como ele é utilizado, os seus níveis de maturidade, principalmente o nível 2, e que possua um bom conhecimento de engenharia de software, sendo necessários apenas dois avaliadores para uma equipe. Os participantes são todos aqueles envolvidos com o projeto escolhido, sendo sua preparação feita através de apresentaçōes sobre o SW-CMM e sobre o contexto de melhoria de processo;

- Termos-Chave: foram incluídos os termos-chave usados no plano;

- Referências: foi incluída uma bibliografia para ser consultada caso sejam necessários maiores esclarecimentos sobre os temas abordados pelo plano.

A seção 2 do Plano de Avaliação - Atividades de Avaliação - é dividida em três subseções:

- Condução da Avaliação: os dados devem ser coletados através de um questionário;

- Consolidação e Validaçãó dos Dados: depois de coletados, os dados devem ser agrupados por área-chave, onde cada conjunto de respostas deve ser analisado para verificar o cumprimento ou não da área-chave do nível 2.

- Realização do Julgamento das Medidas: partindo-se das informações da atividade anterior é possível julgar cada área-chave segundo os valores: satisfeito, não satisfeito, não 
aplicável e não medido. No questionário proposto, todas as perguntas de cada área-chave devem ser respondidas sim para que a área-chave seja considerada satisfeita.

A seção 3 do Plano de Avaliação - Reporte de Resultados - é dividida em três subseções:

- Reporte dos Resultados da Avaliação: descreve a maneira como os resultados devem ser reportados e suas análises;

- Proteção de Informações Confidenciais: é importante que sejam definidos o que pode e como podem ser divulgadas essas informações através de publicações e outros meios;

- Preservação das Gravações. é importante realizar um histórico das anotações, observações, qualquer informação que possa ser útil: para os avaliadores para aperfeiçoar o processo de avaliação, e para os avaliados e patrocinadores para poder realizar pesquisas posteriores.

A seção 4 do Plano de Avaliação - Estimativa de Cronogramas e Recursos - apresenta, com base na situação real do processo de avaliação, as estimativas de recursos necessários e o cronograma das atividades.

\subsection{Considerações Finais}

Este capítulo apresentou os aspectos de qualidade referentes ao produto e ao processo de software em organizações produtoras de software, bem como os aspectos relacionados à melhoria desse processo de software. Fez também uma explanação vertical sobre a Estratégia para Iniciar Melhoria de Processo de Software, a qual auxilia pequenas empresas a avaliar seu próprio processo de software em relação ao nível 2 do SW-CMM.

O próximo capítulo apresenta as pesquisas realizadas para selecionar e incluir as atividades das áreas-chave do nível 3 do SW-CMM à Estratégia. 


\section{Capítulo 3}

\section{Adição de Atividades à Estratégia para Iniciar Melhoria de \\ Processo de Software}

\subsection{Considerações Iniciais}

Neste capítulo é apresentada uma pesquisa realizada junto a pequenas empresas de software que utilizaram ou quiseram utilizar o SW-CMM para avaliar e controlar seu processo de software. Tal pesquisa serve de base para se obter uma visão real das dificuldades encontradas por pequenas empresas quando se propõem a utilizar tal modelo. É também apresentada uma visão mais ampla e específica do Nível Definido (nível 3) do SW-CMM. São detalhadas ainda as KPAs adicionadas por este trabalho à Estratégia para Iniciar Melhoria de Processo de Software, bem como as questões adicionadas ao instrumento de avaliação dessa estratégia.

\subsection{Seleção e Inclusão de KPAs adicionais}

Um dos objetivos propostos neste trabalho é a seleção e inclusão, na Estratégia para Iniciar Melhoria de Processo de Software [ENDO, 1998], de algumas atividades dos outros níveis do SW-CMM não abrangidos pela mesma. Essas outras atividades seriam aquelas consideradas importantes para uma empresa de pequeno porte e que, no entanto não fazem parte da Estratégia.

Uma extensa pesquisa bibliográfica foi realizada e não se encontrou publicações que relatassem estudos com sugestōes especificas de atividades (KPAs) que pudessem ser "dispensadas" na melhoria de processo de software de empresas de pequeno porte. Todas as atividades previstas pelo modelo SW-CMM são necessárias para a melhoria de processo de software.

Diante disso considerou-se como indicativo subjetivo para a escolha de outras KPAs a serem incluídas na estratégia de melhoria de processo de ENDO [Endo, 1998], os resultados de um trabalho de Brodman \& Johnson, publicado em 1994 [Brodman \& Johnson, 1994], o qual relata as dificuldades experimentadas por pequenas empresas de software com relação à aplicação 
do modelo SW-CMM e onde é constatado que a grande maioria dessas empresas deseja atingir, no máximo, o nível 3 do SW-CMM.

Levando-se isso em consideração, este trabalho de mestrado indica, subjetivamente, as sete KPAs do nível 3 do SW-CMM, para serem adicionadas à Estratégia: Foco no Processo da Organização, Definição do Processo da Organização, Programa de Treinamento, Gerenciamento de Software Integrado e Engenharia de Produto de Software, Revisōes (peer review) e Coordenação Intergrupos.

\subsection{A Pesquisa de Brodman \& Johnson}

No trabalho de Brodman \& Johnson foi verificado que as pequenas empresas possuem muita dificuldade na implantação de um modelo do porte do SW-CMM, pois lhes faltam recursos (tempo, dinheiro e pessoal) necessários para resolver problemas referentes à aplicação das áreas-chave do SW-CMM.

O estudo foi dividido em duas fases:

- Fase de Pesquisa: nessa fase foi gerado e aplicado um questionário, cujo objetivo era fornecer um feedback sobre o estado dos programas de melhoria de processo nas pequenas empresas. Esse questionário foi enviado a 327 empresas de pequeno porte, a maioria delas em torno de até 40 funcionários. A análise dos resultados mostrou que $70 \%$ dessas pequenas empresas possuíam problemas com a implantação de programas de melhoria, sendo que desses programas, 39\% eram baseados no SW-CMM. O suporte a um programa de melhoria modelado pelas práticas do SW-CMM mostrou-se ser o ponto de maior dificuldade entre as empresas, pois a disponibilidade de recursos financeiros, pessoas e grupos, para a aplicação de tal programa, é extremamente limitado.

- Fase de Entrevista: após a aplicação do questionário, foi realizada uma entrevista com as pessoas responsáveis pela implantação de melhoria de processos nas empresas envolvidas no estudo. Foi verificado que $63 \%$ dessas empresas objetivavam apenas o nível 3 do SW-CMM (ou até mesmo, em alguns casos, somente o nível 2). Nessa entrevista foi solicitado aos participantes que apresentassem os pontos específicos nos quais as empresas possuíam maior dificuldade na implantação do SW-CMM. As atividades de treinamento, documentação, revisão, ferramentas, bem como a limitação na disponibilidade de pessoas e dinheiro para alocação na melhoria de processo foram os pontos que mais sofreram críticas por parte dos entrevistados. 
A Tabela 5 apresenta os aspectos do SW-CMM considerados como inatingíveis pelas empresas participantes do estudo.

\begin{tabular}{|l|c|}
\hline \multicolumn{1}{|c|}{ Aspectos do SW-CMM } & Número de citações \\
\hline Gerenciamento de Configuração & 2 \\
\hline Documentação & 4 \\
\hline Independência de grupos (dedicados, organizações separadas) & 5 \\
\hline Estrutura organizacional, papéis administrativos & 12 \\
\hline $\begin{array}{l}\text { Burocracia dos processos, sobrecarga do Grupo de Processo } \\
\text { de Engenharia de Software (SEPG) }\end{array}$ & 7 \\
\hline Garantia de Qualidade de Software (SQA) & 4 \\
\hline Testes & \\
\hline Treinamentos & 3 \\
\hline Métricas & 1 \\
\hline \begin{tabular}{l} 
Ferramentas, tecnologias novas \\
\hline
\end{tabular}
\end{tabular}

Tabela 5 - Aspectos do SW-CMM considerados inatingíveis pelas pequenas empresas [Brodman \& Johnson, 1994].

O gerenciamento de configuração de software (SCM) é uma atividade abrangente que é aplicada em todo o processo de engenharia de software. Sua funçāo é identificar, controlar, realizar auditoria e relatar as modificações que invariavelmente ocorrem desde o início do desenvolvimento de um software até o momento em que ele deixa de ser usado [Pressman, 1995]. Sua finalidade é estabelecer e manter a integridade dos produtos do projeto de software ao longo do ciclo de vida do software [Paulk et. al., 1993]. O estudo constatou que as pequenas empresas não dispõem de pessoas para se dedicarem em tempo integral às atividades de gerenciamento de configuração de software.

O SW-CMM estabelece vários grupos dentro de uma organização (coleção de departamentos, gerentes, e indivíduos), os quais trabalham independentemente uns dos outros, inclusive em locais físicos distintos (e até mesmo distantes). Desse modo, necessitam manter uma 
documentação dos processos muito bem organizada e gerenciada, para que a comunicação entre eles seja eficiente. Nessa documentação estão incluídas todas as políticas, práticas, procedimentos, relatórios, planos, especificações e padrões dos processos dentro da organização [Ginsberg \& Quinn, 1995]. O estudo constatou que nas pequenas empresas, por possuírem um número pequeno de pessoas envolvidas com os projetos, a comunicação é feita verbalmente entre essas pessoas. E ainda, pelo fato de possuírem poucas pessoas envolvidas nos projetos torna-se difícil manter grupos totalmente independentes entre si.

O SW-CMM exige uma Estrutura Organizacional e um conjunto de papéis administrativos bem definidos e funcionais para desenvolvimento e manutenção de software. Como exemplos desses papéis estão o Grupo de Processo de Engenharia de Software (SEPG), Grupo de Gerenciamento de Configuraçāo, o Grupo de Garantia de Qualidade de Software e o Grupo de Treinamento [Ginsberg \& Quinn, 1995]. Um grupo deve ser entendido como uma coleção de departamentos, gerentes, e indivíduos que possuem responsabilidade sobre um conjunto de tarefas ou atividades [Paulk et. al., 1993]. A criação desses grupos implica na disponibilidade de pessoas nas empresas para exercerem tais tarefas. O estudo constatou que as pequenas empresas nāo dispõem de pessoal em quantidade suficiente para criar tais grupos.

O Grupo de Processo de Engenharia de Software (SEPG) trata-se de um grupo de especialistas dedicados à definição, manutenção e melhoria do processo de software usado pela organização. Nas práticas-chave do SW-CMM, esse grupo é geralmente referenciado como "o grupo responsável pelas atividades de processo de software". Entre outras coisas, o SW-CMM indica o SEPG como o grupo responsável pelo planejamento das estratégias de melhoria de uma organização, determinação de quais processos devem ser melhorados, análise e decisão sobre a introdução de novas tecnologias e a avaliação dessas novas tecnologias, bem como o gerenciamento de mudanças nas tecnologias existentes [Paulk et. al., 1993]. Todo esse controle é muito burocrático, visto que o SW-CMM exige muita documentação sobre todos os processos existentes [Ginsberg \& Quinn, 1995]. Nota-se que o SEPG trata-se de um grupo com uma sobrecarga muito grande de funções e responsabilidades. O estudo mostrou que, nas pequenas empresas, não existe número de pessoas suficiente para se destinar um grupo delas a se dedicarem única e exclusivamente a esse trabalho realizado por um SEPG. 
A Garantia de Qualidade de Software (SQA) é um padrão sistemático e planejado de ações que são exigidas para garantir a qualidade de software [Pressman, 1995]. A garantia de qualidade de software compreende uma variedade de tarefas associadas a sete grandes atividades: aplicação de métodos técnicos; realização de revisões técnicas formais; atividades de testes de software; aplicação de padrões; controle de mudanças; medição; e manutenção de registros e reportagem. Isso significa que muitos participantes diferentes de uma organização são responsáveis pela garantia de qualidade de software - engenheiros, gerentes de projeto, clientes, equipes de vendas e as pessoas que integram o grupo de SQA. O estudo constatou que as pequenas empresas não dispõem de pessoas para se dedicarem em tempo integral às atividades de garantia de qualidade de software.

As pessoas envolvidas na Melhoria de Processo de Software, através do SW-CMM, devem entender exatamente o que significa Processo de Software bem como a Melhoria desses Processos dentro de uma organização; devem saber exatamente o que acontece em cada uma das áreas-chave dispostas nesse modelo e devem conhecer toda a terminologia e práticas da Engenharia de Software. Torna-se necessário então que essas pessoas sejam treinadas para isso [Paulk et. al., 1993]. O estudo constatou que, para as pequenas empresas, o custo de implementação dos requisitos de treinamentos encontrados nas áreas-chave do SW-CMM são vistos como excessivos para elas, as quais possuem uma certa tendência em contratar uma pessoa de nível sênior, altamente educada e treinada para ocupar tal cargo. Os custos de treinamento com os quais as pequenas empresas devem arcar não podem ser amortizados sobre um grande número de projetos, como pode acontecer nas grandes organizações.

No modelo SW-CMM, mais especificamente no nível 3, as organizações necessitam criar um Processo de Software Padrão, o qual servirá de base para todos os outros projetos desenvolvidos por essa organização. A organização deve possuir também um sistema de banco de dados para armazenar, controlar e analisar parâmetros de qualidade definidos no processo. Através da utilização desses dados, pode-se prevenir problemas futuros no processo, melhorar a eficiência e realizar uma análise minuciosa da atual situação da organização diante de um desafio [Endo, 1998]. O estudo constatou que, para as pequenas empresas, os custos de se utilizar métricas para gerar esses históricos é muito alto, principalmente pela necessidade de automação de tais tarefas, tornando-se assim mais um empecilho para a aplicação do modelo. Nesse ponto, o estudo mostrou também que a necessidade de aquisição, estudo e implantação de novas tecnologias são fatores 
dispendiosos para as pequenas empresas pois, como dito anteriormente, elas não conseguem amortizar, em seus projetos, os seus (elevados) custos.

De modo geral, o estudo apresentou as seguintes constatações, com relação à melhoria de processo nas pequenas empresas entrevistadas:

* A grande maioria delas deseja atingir no máximo o nível 3 do SW-CMM;

- Não possuem recursos suficientes em termos de pessoal para dar suporte separado e independente aos grupos exigidos pelo SW-CMM (por exemplo, grupo de engenharia de processo de software (SEPG), grupo de Gerenciamento de Configuração (CM), grupo de Gerenciamento de Qualidade de Software (SQA), etc.);

- A necessidade de programas de treinamento e de uma estrutura organizacional hierárquica incorre em custos que essas pequenas empresas não podem pagar;

- Para pequenos projetos, as práticas ao nível de projeto do SW-CMM (por exemplo, pessoas dedicadas exclusivamente ao Gerenciamento de Configuração e Garantia de Qualidade de Software, e também muitas das práticas relacionadas à documentação) não são aplicáveis devido ao tamanho reduzido desses projetos.

Como visto, a aplicação de um modelo de melhoria de processo de software nas pequenas empresas não é tão simples de se conseguir. O SW-CMM é um modelo muito rico em termos de requisitos, e exige que todas as suas áreas-chave sejam cumpridas para que as organizações saiam de um de seus níveis para outro superior.

\subsection{O Nível 3 do SW-CMM}

No nivel 3 do SW-CMM, a capacitação do processo de software das organizações pode ser resumida como padronizada e consistente, porque ambos engenharia de software e atividades de gerenciamento são estáveis e repetíveis. As linhas de produto, custos, prazos e funcionalidades estabelecidas estão todas sob controle, e a qualidade do software é garantida. Essa capacitação dos processos é baseada em um comum e total entendimento das atividades, regras e responsabilidades da organização num processo de software definido. 


\subsubsection{Processo de Software Definido}

O Nível Definido (nível 3) do SW-CMM apresenta como principal característica a existência de um Processo de Software Definido da Organização, o qual é bem documentado e abrange ambos Engenharia de Software e Gerenciamento dos Processos. Esse processo é usado (e alterado, quando necessário) para ajudar os gerentes de software e o pessoal dos setores técnicos a trabalharem mais eficientemente. Um Processo de Software Definido é desenvolvido, mantido e implementado utilizando-se o que o SW-CMM denomina bens de processo. Os bens de processo ficam então disponíveis para serem utilizados pelos projetos no desenvolvimento, manutenção e implementação de seu processo de software definido. Esses bens de processo são:

- Processo de software padrão da organização: estabelece os elementos de processo de software fundamentais (por exemplo, elementos de estimativa de software, elementos de design de software, elementos de codificação e elementos de revisão) que se deseja que cada projeto de software incorpore em seu processo de software definido. Estabelece também a arquitetura de processo de software, ou seja, como esses elementos de processo de software vão se relacionar. Essa arquitetura de processo de software trata-se de uma descrição alto-nível (isto é, sumarizada) das interfaces, interdependências e outros relacionamentos entre os elementos de processo de software do processo de software padrão da organização, bem como deles para com outros processos externos, como por exemplo, engenharia de sistemas, engenharia de hardware e gerenciamento de contratos. Observa-se então a importância do processo de software padrão da organização, pois ele forma a base para os processos de software definidos dos projetos, fornecendo continuidade às atividades de processo da organização, e servindo também de referência para medidas e melhorias a longo prazo do processo de software usado pela organização.

- Descrição dos ciclos de vida aprovados para utilização dentro da organização: um ciclo de vida é o período de tempo que dura desde a concepção do produto de software até quando este é tirado de utilização. Geralmente inclui as etapas de concepção, levantamento de requisitos, design, implementação, teste, instalação, operação e manutenção do produto de software. Pelo fato de uma organização estar produzindo software para uma grande variedade de diferentes clientes e usuários, com domínios totalmente diferentes entre si, a utilização de um único ciclo de vida pode não ser praticável. Assim, a organização pode identificar mais do que um ciclo de vida para usar em seus projetos. Tais ciclos de vida são geralmente obtidos em literatura de engenharia de software, e podem ser modificados pela organização. Desse modo, esses ciclos de vida definidos pela organização ficam 
disponiveis para serem utilizados, junto com o processo de software padrão da organização, no desenvolvimento do processo de software definido dos projetos.

- Guias e critérios para adaptação ao processo de software padrão da organização: o processo de software padrão da organização é descrito de maneira genérica, o que pode não ser diretamente utilizável pelos projetos. Guias são então definidos para conduzir os projetos de software na (1) seleção de um ciclo de vida dentre aqueles aprovados para utilização e (2) adaptação do processo de software padrão da organização e do ciclo de vida selecionado, para que estes se ajustem às características específicas desses projetos. Esses guias e critérios de adaptação ajudam a garantir a existência de uma base comum entre todos os projetos de software para planejamento, implementação, medição, análise e melhoria do processo de software definido dos projetos. Em outras palavras, descrevem como adaptar o processo de software padrão da organização a um projeto em específico.

- Um banco de dados de processos da organização: serve para coletar e tornar disponíveis dados sobre os processos de software e os resultados dos produtos de trabalho de software (estimativas de tamanho, esforço e custo de software, dados atuais sobre o tamanho, esforço e custo de software, produtividade, eficiência e cobertura de revisões, número e grau de severidade de defeitos encontrados no código do software, etc.), particularmente os relacionados no processo de software padrão da organização. Essa base de dados contém ou referencia tanto os dados de medidas atuais quanto de informações anteriormente relatadas, necessárias ao entendimento dessas medições e avaliações. Serve então como um repositório de importantes informações a serem utilizadas na elaboração, adaptação e desenvolvimento de novos projetos.

- Uma biblioteca de documentação de processos de software relatados: utilizada para (1) armazenar documentos de processos que são essencialmente úteis para outros projetos, tanto atuais quanto futuros, particularmente aqueles relacionados ao processo de software padrão da organização, e (2) torná-los disponíveis para compartilhamento dentro da organização. Essa biblioteca contém documentos e fragmentos de documentos para serem utilizados por projetos futuros quando eles forem adaptados ao processo de software padrão da organização. Trata-se de um importante recurso que pode ajudar a reduzir a quantidade de esforços requeridos para se iniciar um novo projeto, fornecendo, como ponto de partida, exemplos de projetos bem sucedidos. 
De organização para organização, esses bens de processo podem ser organizados de maneiras diferentes, dependendo de como cada uma deseja estabelecer seu processo de software padrão.

A descrição do processo de software definido do projeto é a definição operacional do processo de software utilizado pelo projeto. Trata-se de um processo de software bem caracterizado e entendido, descrito em termos de padrões, procedimentos, métodos e ferramentas de software. É desenvolvido selecionando-se um ciclo de vida de software dentre os aprovados pela organização e adaptando-o, juntamente com o processo de software padrão da organização, para que se encaixem às características específicas do projeto. Nada impede que um projeto possua mais do que um processo de software definido (por exemplo, um para software operacional e outro para software de suporte a testes), ou então que um mesmo processo de software definido seja usado para projetos similares.

Geralmente a descrição do processo de software definido do projeto não é específico o suficiente para ser executado diretamente. Embora essa descrição tipicamente identifique coisas tais como papéis (isto é, quem executa uma determinada tarefa) e tipos de produtos trabalho de software (entenda-se por produtos de trabalho de software o conjunto completo, ou parte desse conjunto, de programas de computador, procedimentos, documentação e dados designados à entrega do software ao cliente ou usuário final) necessários para se executar uma tarefa, ela não especifica os indivíduos que assumirão tais papéis, quais produtos de trabalho de software especificamente serão criados, nem um calendário para a execução das tarefas e atividades. Torna-se então necessário o estabelecimento de um Plano de Desenvolvimento de projeto de software. Pode ser um simples documento ou até mesmo uma coleção de planos que coletivamente referem-se a um plano de desenvolvimento de software, fornecendo uma ponte entre o processo de software definido do projeto (o quê será feito, e como será feito) e as especificações de como o projeto será executado (quais indivíduos produzirão quais produtos de trabalho de software de acordo com qual calendário). A combinação entre o projeto de software definido do projeto e seu plano de desenvolvimento de software tornam possível a execução do processo.

No nível 3, a ênfase é dada à organização. Isso significa que o nível 3 é caracterizado pela presença de um grupo, dentro da organização, responsável pelas atividades do processo de software. Esse grupo garante que os procedimentos de gerência e de desenvolvimento sejam 
bem definidos, documentados, compreendidos e integrados, e também garante que as saídas de uma atividade fluam naturalmente para as entradas da próxima atividade.

Outra característica desse estágio é que a organização oferece programas de treinamento para garantir a integridade dos objetivos entre a gerência e o grupo de desenvolvimento, e para amenizar qualquer crise gerada pela mudança no processo. Isso é muito importante, uma vez que processos definidos pela própria organização são caracterizados por constantes modificações nos fundamentos do processo estabelecido.

Todas essas características podem auxiliar a organização no sentido de valer-se de um processo previamente definido ou adaptado e com uma certa preparação da equipe, como um todo, diante de um novo desafio que a organização possa vir a enfrentar.

O nível 3 do SW-CMM possui sete áreas-chave de processo:

\subsubsection{KPA Foco no Processo da Organização}

Essa área-chave visa determinar a responsabilidade organizacional para as atividades de software que melhoram a capacidade do processo de software como um todo na organização. Nisso estão envolvidos o desenvolvimento e manutenção da compreensão dos processos de software da organização e a coordenação das atividades de avaliação, desenvolvimento, manutenção e melhoria desses processos. Uma forma típica de se dirigir o foco é manter um grupo de processo dentro da organização que será responsável por estabelecer um padrão de processo, manter uma base de dados, oferecer educação e consultoria, e realizar avaliações periódicas para gerar relatórios sobre a situação real do processo.

\subsubsection{KPA Definição do Processo da Organização}

Essa área-chave objetiva desenvolver e manter um conjunto de bens de processo de software que melhore o desempenho do processo e ofereça uma base para benefícios cumulativos e de longo prazo. As atividades dessa área-chave podem ser mantidas por uma organização para uso dos projetos de desenvolvimento, adaptação, manutenção e implementação das práticas de software. Como visto, os bens de processo são: o processo de software padrão da organização, um conjunto de descrições de ciclos de vida em uso, as diretrizes e os critérios 
adotados para o processo de software em uso, uma base de dados e uma biblioteca de documentação de assuntos relacionados ao processo de software.

\subsubsection{KPA Programa de Treinamento}

O propósito dessa área-chave de processo é desenvolver as habilidades e o conhecimento dos indivíduos dentro da organização, de modo que eles possam executar suas tarefas mais efetiva e eficientemente. Isso significa, em primeira instância, identificar quais são os treinamentos necessários, e então desenvolver (ou mesmo obter externamente) treinamento que atendam a essas necessidades.

\subsubsection{KPA Gerenciamento de Software Integrado}

Essa área-chave visa integrar a engenharia de software do projeto às atividades de gerenciamento em um processo de software definido e coerente. Nisso está envolvido o desenvolvimento de um processo de software definido adaptando o processo de software padrão da organização e gerenciando o projeto de software de acordo com esse processo de software definido, pois no nível 3, cada projeto adapta o processo de software padrão da organização às suas necessidades particulares. Pelo fato de os processos de software dos projetos serem todos adaptados de um processo de software padrão da organização, esses projetos de software podem compartilhar dados e as liçōes aprendidas.

\subsubsection{KPA Engenharia de Produto de Software}

Essa área-chave objetiva estabelecer, de maneira consistente, um processo de engenharia bem definido que integre todas as atividades de engenharia de software para produzir, de forma eficiente, produtos de software consistentes e adequados. Isso envolve desempenhar as tarefas de engenharia, tais como definir o ciclo de vida para construir e manter software utilizando ferramentas e métodos adequados. Um ciclo de vida de software corresponde à execução de várias atividades de desenvolvimento como análise dos requisitos, projeto de software, codificação, teste e manutenção. Todas essas atividades devem ser devidamente documentadas. 


\subsubsection{KPA Coordenação Intergrupos}

Essa área-chave visa estabelecer meios para que o grupo de engenharia de software interaja ativamente com outros grupos, a fim de que o projeto possa satisfazer eficientemente as necessidades dos clientes. Nisso estão envolvidas uma interação disciplinada e uma coordenação dos grupos de engenharia de projeto para que sejam abordados requisitos em nível de sistema, objetivos e planos. Exemplos de grupos que precisam se inter-relacionar numa organização são: marketing, treinamento, gerenciamento de subfornecedores e outros.

\subsubsection{KPA Revisões}

O propósito dessa área-chave de processo é remover, com antecedência e eficientemente, os defeitos dos produtos obtidos durante o desenvolvimento de software (produtos intermediários). Também é desenvolvido um melhor entendimento desses produtos e dos defeitos que poderiam ser prevenidos. Isso envolve um exame metódico desse produto para identificar defeitos e áreas onde mudanças são necessárias.

\subsection{Instrumento de Coleta de Dados Modificado}

No modelo SW-CMM, uma KPA identifica um grupo de atividades relacionadas que, quando realizadas coletivamente, atịngem um conjunto de metas consideradas importantes para 0 aumento da capacitação do processo. Para se cumprir uma determinada KPA, todas as suas metas devem ser atingidas; e para se atingir uma meta, todas as atividades relacionadas à referida meta devem ser cumpridas [Masters \& Bothwell, 1995]. É importante observar que, dentro de uma mesma KPA, uma mesma questão pode estar relacionada a mais de uma meta dessa KPA.

O instrumento de avaliação de ENDO [Endo, 1998] agrupa as atividades relativas à cada KPA de acordo com as metas a serem atingidas quando essas atividades são realizadas. Para completar o Instrumento de avaliação desenvolvido, o qual abrangia as seis áreas-chave de processo do nível 2 do SW-CMM, foram incluídas 52 questōes relativas às áreas-chave do nível 3 do SW-CMM, mantendo-se a organização das mesmas pelas metas a serem atingidas [Masters \& Bothwell, 1995].

O instrumento de coleta de dados da Estratégia para Iniciar Melhoria de Processo de Software fol então acrescido das seguintes questões: 


\section{Meta1}

Desenvolvimento dos processos de software e atividades de avaliação serem coordenados como um todo na organização.

\section{Sim Năo Não se aplica Não sei}

3: As atividades de projeto e organizacionais para desenvolvimento e melhoria de seus processos de

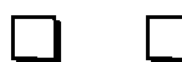
software são coordenados a nível de organização?

4: O uso da base de dados de processo de software da organização é coordenado a nível organizacional?

5: Novos processos, métodos e ferramentas de uso limitados na organização são monitorados, avaliados e, se apropriado, transferidos para outras partes da organização?

6: Treinamentos no processo de software de projetos e organizacionais são coordenados por toda organização?

7: Os grupos envolvidos na implementação dos processos de software são informados sobre as atividades de projetos e organizacionais para desenvolvimento e melhoraria de processo de software?

\section{Meta2}

Os pontos fortes e fracos do processo de software utilizados serem identificados em relação ao processo padrão.

Sim Não Não se aplica Não sei 
1: O processo de software é avaliado periodicamente e planos de ação são desenvolvidos para orientar as descobertas avaliadas?

\section{Meta3}

O processo de desenvolvimento e atividades de melhoria a nível organizacional serem planejados.

Sim Não Não se aplica Não sei

2: A organização desenvolve e mantém um plano para seu desenvolvimento de processo de software e para as atividades de melhoria?

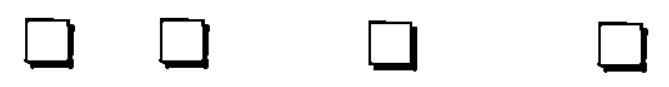

Anotações:

Definição do Processo da Organização

\section{Meta1}

Um processo de software padrão para a organização ser desenvolvido e mantido.

Sim Não Não se aplica Não sei

1: O processo de software padrão da organização é desenvolvido e mantido de acordo com um

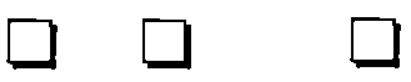
procedimento documentado?

2: O processo de software padrão da organização é documentado de acordo com os padrōes organizacionais estabelecidos?

3: Descrições dos ciclos de vida de software que
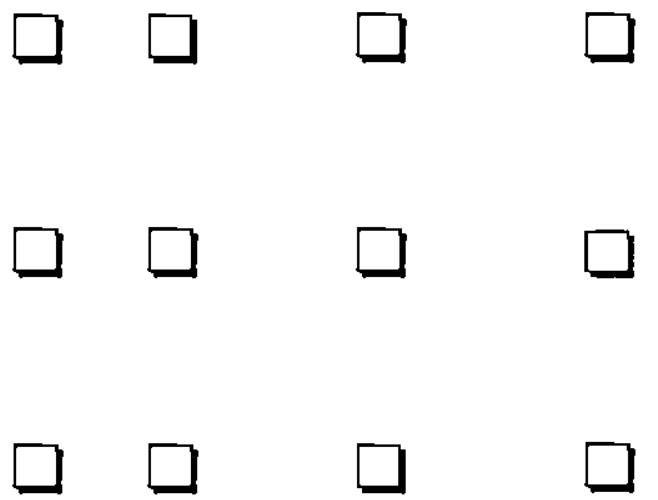
foram aprovados para uso pelos projetos são documentados e mantidos?

4: Diretrizes e critérios para adaptação dos projetos ao processo de software padrão da organização são desenvolvidos e mantidos?

\section{Meta2}

As informações referentes ao uso do processo de software padrão da organização pelos projetos de software serem coletadas, revisadas e disponibilizadas.

\section{Sim Não Não se aplica Não sei}

5: A base de dados do processo de software da organização é estabelecida e mantida?

6: Uma biblioteca de documentos relacionados ao processo de software é estabelecida e mantida?
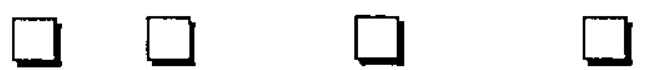

Anotaçōes:

\section{Programa de Treinamento}

\section{Meta1}

As atividades de treinamento serem planejadas.

Sim Não Não se aplica Não sei

1: Cada projeto de software desenvolve e mantém um plano de treinamento que especifica suas necessidades de treinamento?

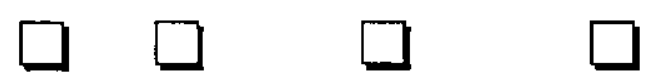


2: O plano de treinamento da organização é desenvolvido e revisto de acordo com o procedimento documentado?

3: O treinamento para a organização é executado de acordo com o plano de treinamento da organização?
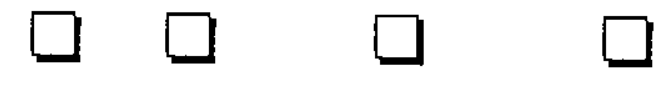

\section{Meta2}

Treinamentos para desenvolver as habilidades e conhecimentos necessários para executar gerenciamento de software e tarefas técnicas são executados.

\section{Sim Não Não se aplica Não sei}

3: O treinamento para a organização é executado de acordo com o plano de treinamento da organização?

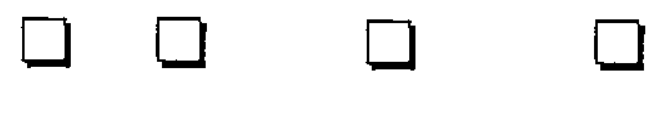

4: Cursos de treinamento preparados a nível de organização são desenvolvidos e mantidos de acordo com os padrões da organização?

\section{Meta3}

Indivíduos no Grupo de Engenharia de Software e dos demais grupos relacionados com software recebem treinamento necessário para executar suas tarefas.

\section{Sim Não Não se aplica Não sei}

5: Um procedimento de corte para os treinamentos requeridos é estabelecido e usado para determinar

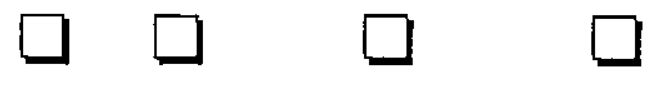
se os indivíduos já possuem o conhecimento e a habilidade requeridos para executar as tarefas a que foram designados?

6: Os registros dos treinamentos são mantidos?

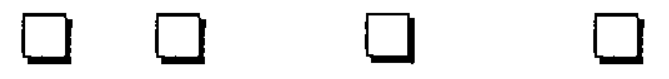

Anotações: 


\section{Meta1}

O processo de software definido do projeto ser uma adaptação ao processo de software padrão da organização.

\section{Sim Não Não se aplica Não sei}

1: O processo de software definido do projeto é desenvolvido para se adaptar ao processo de software padrão da organização de acordo com um procedimento documentado?

2: Cada processo de software definido do projeto é revisto de acordo com um procedimento documentado?

3: O plano de desenvolvimento de software do projeto, o Qual descreve o uso do processo de software definido do projeto, é desenvolvido e revisto de acordo com um procedimento documentado?
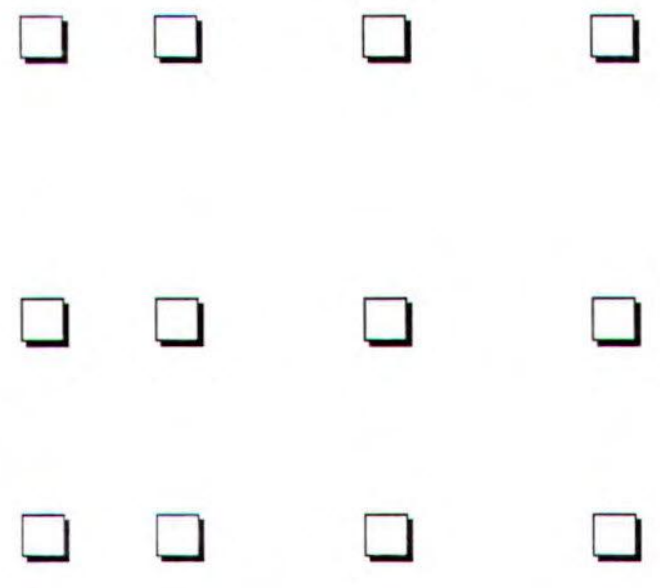

\section{Meta2}

O projeto ser planejado e gerenciado de acordo com o processo de software padrão definido do projeto.

\section{Sim Não Não se aplica Não sei}

3: O plano de desenvolvimento de software do projeto, o Qual descreve o uso do processo de software definido do projeto, é desenvolvido e revisado de acordo com um procedimento documentado? 
4: O projeto de software é gerenciado de acordo com o processo de software definido do projeto?

5: A base de dados de processo de software da organização é usado para planejamento e estimativa do software?

6: O tamanho dos produtos de trabalho do software (ou tamanho das mudanças nos produtos de trabalho do software) é gerenciado de acordo com um procedimento documentado?

7: Os esforços e custos do projeto de software são gerenciados de acordo com um procedimento documentado?

8: Os recursos computacionais críticos do projeto são gerenciados de acordo com um procedimento documentado?

9: As dependências e caminhos críticos dos cronogramas do projeto são gerenciados de acordo com um procedimento documentado?

10: Os riscos de projeto são identificados, avaliados, documentados e gerenciados de acordo com um<smiles>C1CCC1</smiles><smiles>C1CCC1</smiles><smiles>C1CCC1</smiles>
procedimento documentado?

11: Revisões do projeto de software são realizadas periodicamente para determinar as ações necessárias para trazer os resultados $e$ desempenho do projeto de software alinhados com as necessidades atuais e projetadas de negócio, clientes e usuários finais, conforme apropriado?

Anotações: 


\section{Meta1}

As tarefas de engenharia de software serem definidas, integradas e executadas de forma consistente para a produção de software.

\section{Sim Não Não se aplica Não sei}

1: Métodos de engenharia de software e ferramentas apropriados são integrados ao processo de software definido do projeto?

2: Os requisitos de software são desenvolvidos, mantidos, documentados e verificados por análise sistemática dos requisitos alocados de acordo com o processo de software definido do projeto?

3: O projeto de software é desenvolvido, mantido, documentado e verificado de acordo com o processo de software definido do projeto, para acomodar os requisitos de software e formar o framework para codificação?

4: O código de software é desenvolvido, mantido, documentado e verificado de acordo com o processo

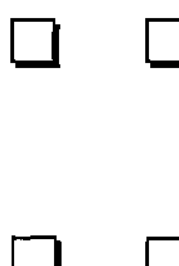

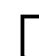<smiles>C1CCCC1</smiles><smiles>C1CCCC1</smiles><smiles>C1CCC1</smiles><smiles>C1CCC1</smiles><smiles>C1CCC1</smiles>
de software definido do projeto, para implementar os requisitos de software e projeto de software?

5: Teste de software é executado de acordo com o processo de software definido do projeto?

7: Teste de sistema e teste de aceitação do software são planejados e executados para demonstrar que 0 software satisfaz seus requisitos?

8: A documentação que será utilizada para operar e manter o software é desenvolvida e mantida de

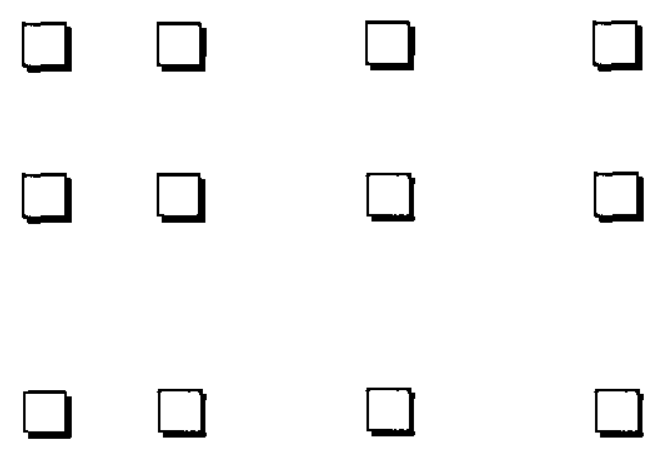


acordo com o processo de software definido do projeto?

9: Dados sobre os defeitos identificados nas revisões e testes são coletados e analisados de acordo com o processo de software definido do projeto?

\section{Meta2}

Produtos de software serem consistentes uns com os outros.

Sim Não Não se aplica Não sei

10: A consistência é mantida ao longo dos produtos de trabalho de software, incluindo os planos de software, descrição dos processos, requisitos alocados, requisitos de software, projeto de software, código, planos de teste e procedimentos de teste?

Anotaçōes:

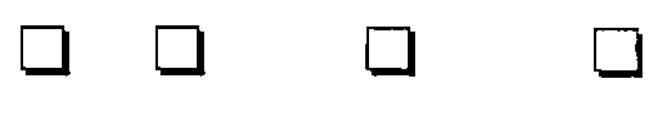

\section{Coordenação Intergrupos}

\section{Meta1}

Os requisitos dos clientes são consenso entre todos os grupos envolvidos.

Sim Não Não se aplica Não sei

1: O grupo de engenharia de software e os outros grupos de engenharia participam, juntamente com

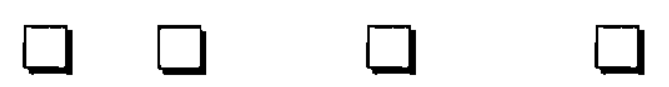
os clientes e os usuários finais, de maneira 
apropriada, para estabelecer os requisitos do

sistema?

\section{Meta2}

Os comprometimentos entre os grupos de engenharia são consenso entre todos os grupos envolvidos.

\section{Sim Não Não se aplica Não sei}

3: Um plano documentado é usado para comunicação de compromețimentos intergrupos e para coordenar e acompanhar $\circ$ trabalho executado?

4: Dependências críticas entre grupos de engenharia são identificadas, negociadas, e acompanhadas de acordo com um procedimento documentado?

5: Produtos de trabalho produzidos como entrada para outros grupos de engenharia são revistos por representantes dos grupos que os recebem para assegurar-se de que os produtos de trabalho satisfazem suas necessidades?

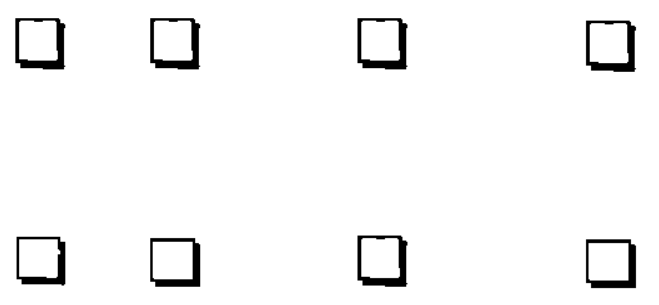

\section{Meta3}

Os grupos de engenharia identificam, localizam e resolvem as questões intergrupos.

\section{Sim Não Não se aplica Não sei}

2: Representantes do grupo de engenharia de software do projeto trabalham com representantes de outros grupos de engenharia para monitorar e coordenar atividades técnicas e resolver problemas técnicos?

6: Problemas intergrupos não resolvidos pelos representantes dos grupos de engenharia de projeto

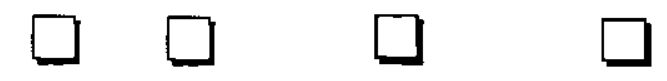
são tratados de acordo com um procedimento 
documentado?

7: Representantes dos grupos de engenharia de projeto conduzem revisões técnicas e trocas de informações periodicamente?

Anotações:

\section{Revisões}

\section{Meta1}

As atividades de revisão são planejadas.

Sim Não Não se aplica Não sei

1: Revisões são planejadas e os planos são $\square \square$

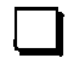
documentados?

\section{Meta2}

Os defeitos dos produtos intermediários são identificados e removidos.

Sim Não Não se aplica Não sei

2: Revisões são executadas de acordo com um
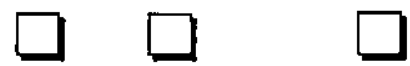
procedimento documentado?

3: Dados sobre a condução e os resultados das revisões são armazenados?
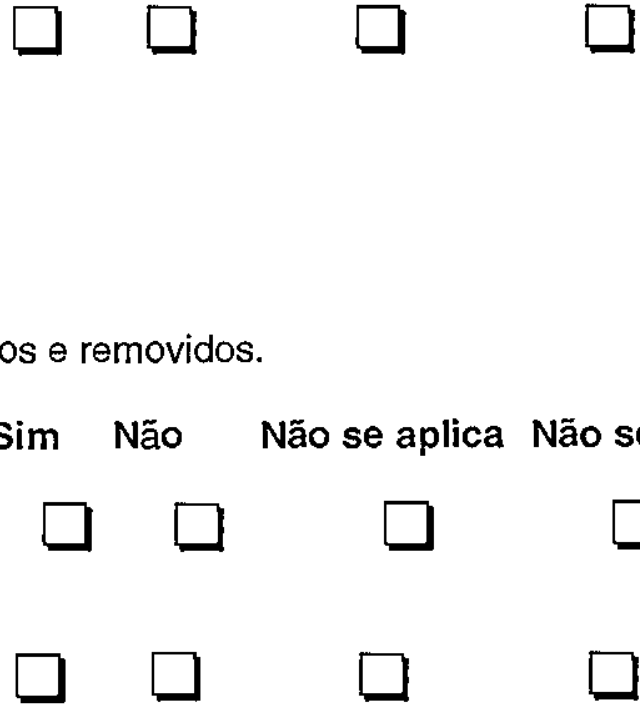

Anotações: 


\subsection{Considerações Finais}

Neste capítulo foram apresentadas, baseando-se numa pesquisa realizada por Brodman \& Johnson [Brodman \& Johnson, 1994], as dificuldades encontradas por pequenas empresas quando se propõem a utilizar o SW-CMM para avaliar e controlar seu processo de software. Após uma apresentação bem mais vertical do Nível Definido (nível 3) do SW-CMM, foram apresentadas também as KPAs adicionadas por este trabalho à Estratégia para Iniciar Melhoria de Processo de Software, bem como as questões adicionadas ao instrumento de avaliação dessa estratégia. No capítulo seguinte é apresentada a ferramenta desenvolvida para dar suporte ao instrumento de avaliação da Estratégia para Iniciar Melhoria de Processo de Software, além de ser mostrado todo o processo de desenvolvimento dessa ferramenta. 


\section{Capítulo 4}

\section{A Ferramenta SProQ}

\subsection{Considerações Iniciais}

Neste capítulo são apresentados o processo de desenvolvimento e o funcionamento da ferramenta Software Process Quality - SProQ. Todas os seus requisitos, entradas, saídas, layouts, restrições, critérios de validação, procedimentos bem como a modelagem de sua base de dados são apresentados de forma detalhada, a fim de se fornecer a documentação pertinente à ferramenta SProQ.

\subsection{Objetivos Gerais da Ferramenta}

O objetivo da ferramenta SProQ é fornecer apoio automatizado à Avaliação do Processo de Software em Pequenas Empresas, tendo como base o questionário proposto por [Endo, 1998] em sua Estratégia para Iniciar Melhoria de Processo de Software. A fim de manter as informações disponiveis para pesquisas a qualquer momento, bem como mantê-las para servirem de base para melhorias futuras, tais informações são armazenadas em uma base de dados. Pelo fato das informações serem, em sua grande maioria, confidenciais, esse ponto também é considerado pela ferramenta, não possibilitando assim que pessoas não autorizadas acessem informações indevidas. Visando fornecer uma melhor visibilidade sobre os resultados obtidos pelas avaliações, a ferramenta SProQ disponibiliza alguns relatórios e gráficos. Esses relatórios e gráficos servem para auxiliar os avaliadores no diagnóstico, por exemplo, dos pontos a serem melhorados dentro do processo de software avaliado. Isso faz com que a ferramenta SProQ torne-se um Sistema de Informação também destinado ao auxílio à tomada de decisões dentro da empresa. E finalmente, a ferramenta SProQ é aberta no sentido de que pode manter e analisar não somente os dados existentes no questionário da Estratégia para Iniciar Melhoria de Processo de Software, como também comporta todas as questões inseridas por este trabalho de mestrado (capítulo 3) bem como a adição de quaisquer outras questões existentes no modelo Software-CMM (SW-CMM). 


\subsection{Desenvolvimento da Ferramenta}

A Engenharia de Software abrange um conjunto de três elementos fundamentais: métodos, ferramentas e procedimentos. Tais elementos possibilitam o controle do processo de desenvolvimento do software, oferecendo uma base para a construção de um software com qualidade. Os métodos proporcionam detalhes de "como fazer" para construir o software. As ferramentas proporcionam apoio automatizado ou semi-automatizado aos métodos. $E$ finalmente os procedimentos constituem o elo de ligação que mantém juntos os métodos e as ferramentas [Pressman, 1995]. O método Fusion [Coleman et. al., 1996] fornece um modelo de processo de desenvolvimento de software, dividindo esse processo em três fases: Análise, Projeto e Implementação. A descrição da ferramenta SProQ será feita seguindo-se esse modelo.

\subsection{A Fase de Análise}

Nessa fase do processo há o estabelecimento dos requisitos para todos os elementos do sistema. Ela envolve a coleta dos requisitos em nível de sistema, com uma pequena quantidade de projeto e análise de alto nível. A fase de Análise é composta pelo Modelo de Objetos e pelo Modelo de Interface.

\subsubsection{Modelo de Objetos}

Os modelos de objetos fornecem os conceitos existentes no domínio do problema e os relacionamentos existentes entre eles. Para a ferramenta SProQ dividiu-se a modelagem de objetos em duas partes, para maior compreensão e legibilidade. A primeira (Figura 4) mostra o modelo de objetos referente aos questionários a serem aplicados em cada avaliação elaborada pela Estratégia para Iniciar Melhoria de Processo de Software. A segunda (Figura 5) apresenta o modelo de objetos referente aos relatórios e gráficos fornecidos pela ferramenta. 


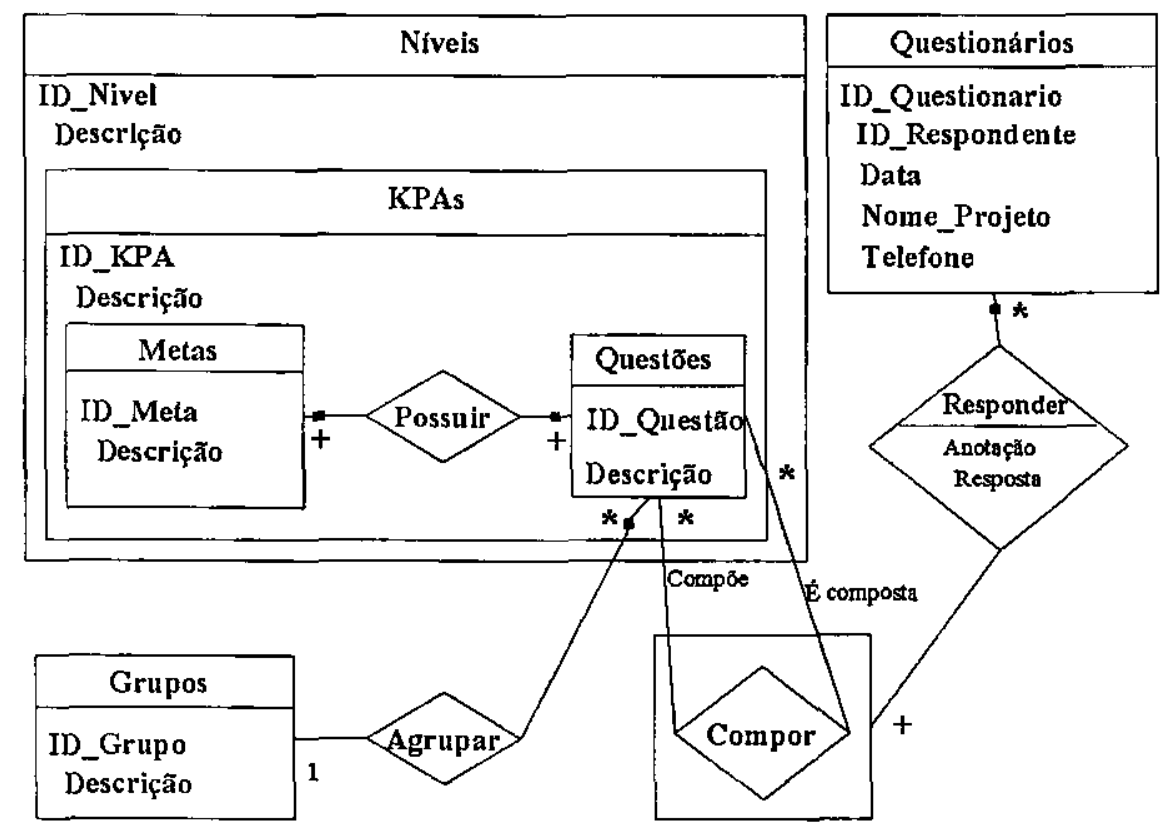

Figura 4 - Modelo de Objetos para os Questionários da ferramenta SProQ.

No modelo da Figura 4, a classe Níveis representa os níveis do SW-CMM, os quais são formados por várias áreas-chave de processo (representadas nesse modelo pela classe KPAs). As áreas-chave possuem metas (representadas nesse modelo pela classe Metas) a serem cumpridas. Para cumprir essas metas, são respondidas questões (representadas nesse modelo pela classe Questões), cujas respostas são depois avaliadas para indicar se a área-chave está ou não sendo cumprida pela organização sendo avaliada. As questões são classificadas em categorias de processos [Paulk et. al., 1993] (nesta modelagem representados pela classe Grupos) tais como Gerencial, Organizacional, de Engenharia, etc. E por fim a classe Questionário representa cada questionário aplicado a um indivíduo/setor da organização. Cada resposta dada a uma questão pode ainda receber uma anotação importante, a qual fica armazenada na base de dados para posterior consulta e análise.

Uma das grandes dificuldades encontradas por uma organização na implantação do modelo SW-CMM diz respeito à correta interpretação das questões por parte de quem as responde. Em outras palavras, nem todos os respondentes conseguem entender o real significado de todas as questões desse modelo. Existe um estudo sendo realizado na Universidade Federal de São Carlos no sentido de subdividir essas questões em sub-questões, mais compreensíveis e que, quando respondidas na sua totalidade, correspondem a uma questão do SW-CMM. Visando proporcionar uma ferramenta que seja o mais flexível possível para a inclusão de questōes do SW-CMM, inclusive em trabalhos futuros, mapeou-se a classe Questões em uma classe que possui um auto-relacionamento, ou seja, cada Questão pode ser decomposta em 
Questões menores, cujo significado seja mais facilmente entendido pelas pessoas sendo avaliadas dentro da organização.

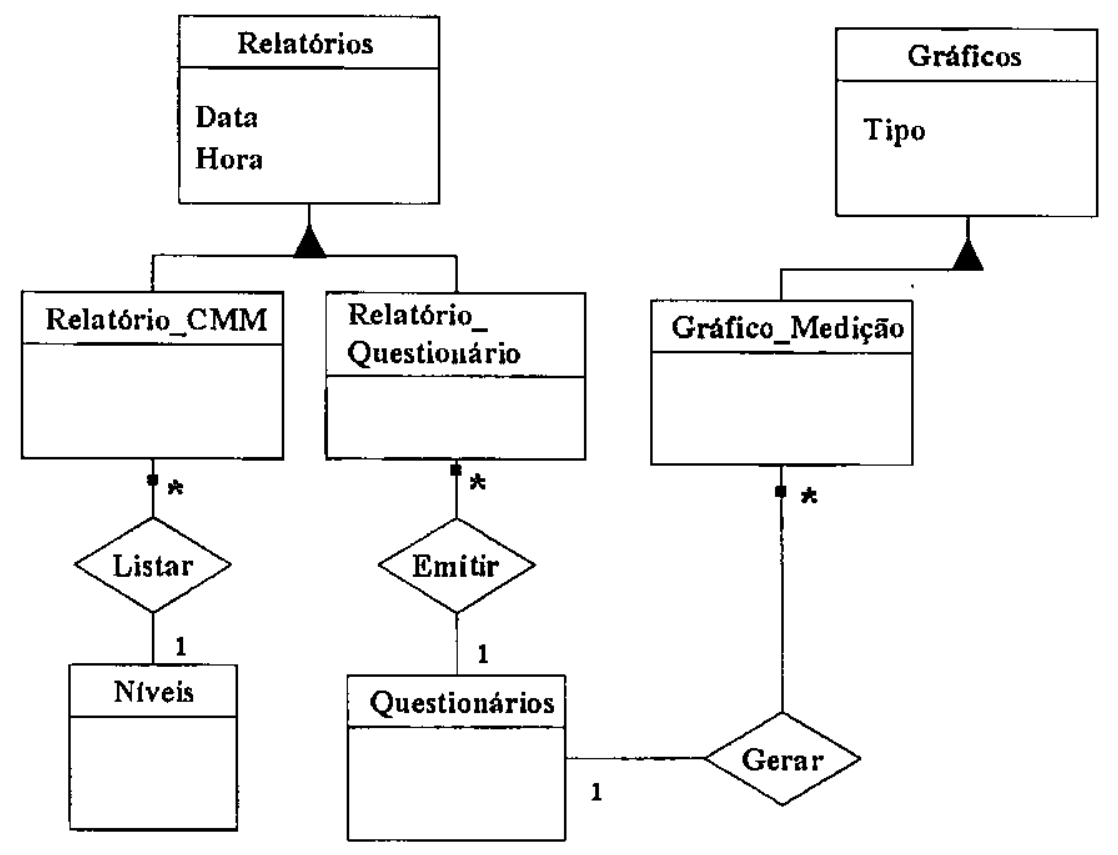

Figura 5 - Modelo de Objetos para os Relatórios e Gráficos da ferramenta SProQ.

Como observado na Figura 5; a ferramenta SProQ traz apenas um gráfico, chamado de Gráfico de Medição. Esse gráfico é o mesmo proposto na Estratégia para Iniciar Melhoria de Processo de Software. Porém, analisando o modelo de objetos anterior, pode-se perceber claramente que a ferramenta SProQ pode ser acrescida de novos gráficos, e foi esse o motivo pelo qual se criou nesse modelo uma super-classe denominada Gráficos.

\subsubsection{Modelo de Interfaces}

O modelo de interfaces do método Fusion descreve o comportamento de um sistema, através de seus eventos (de entrada e saída) e mudanças de estado. Esse modelo apresenta como as entidades interagem entre si dentro do sistema ou com outros sistemas de software ou hardware. As operações do sistema constituem os eventos de entrada e seus efeitos sobre 0 sistema, enquanto que os eventos de saída são aqueles gerados a partir de um evento de entrada. Uma técnica útil para se modelar a interface do sistema é montar cenários de utilização. Tais cenários compreendem eventos fluindo entre os agentes do sistema e o próprio 
sistema. A Figura 6 apresenta um dos cenários do Modelo de Interfaces da ferramenta SProQ. Todos os demais cenários encontram-se no apêndice $A$ desta dissertação.

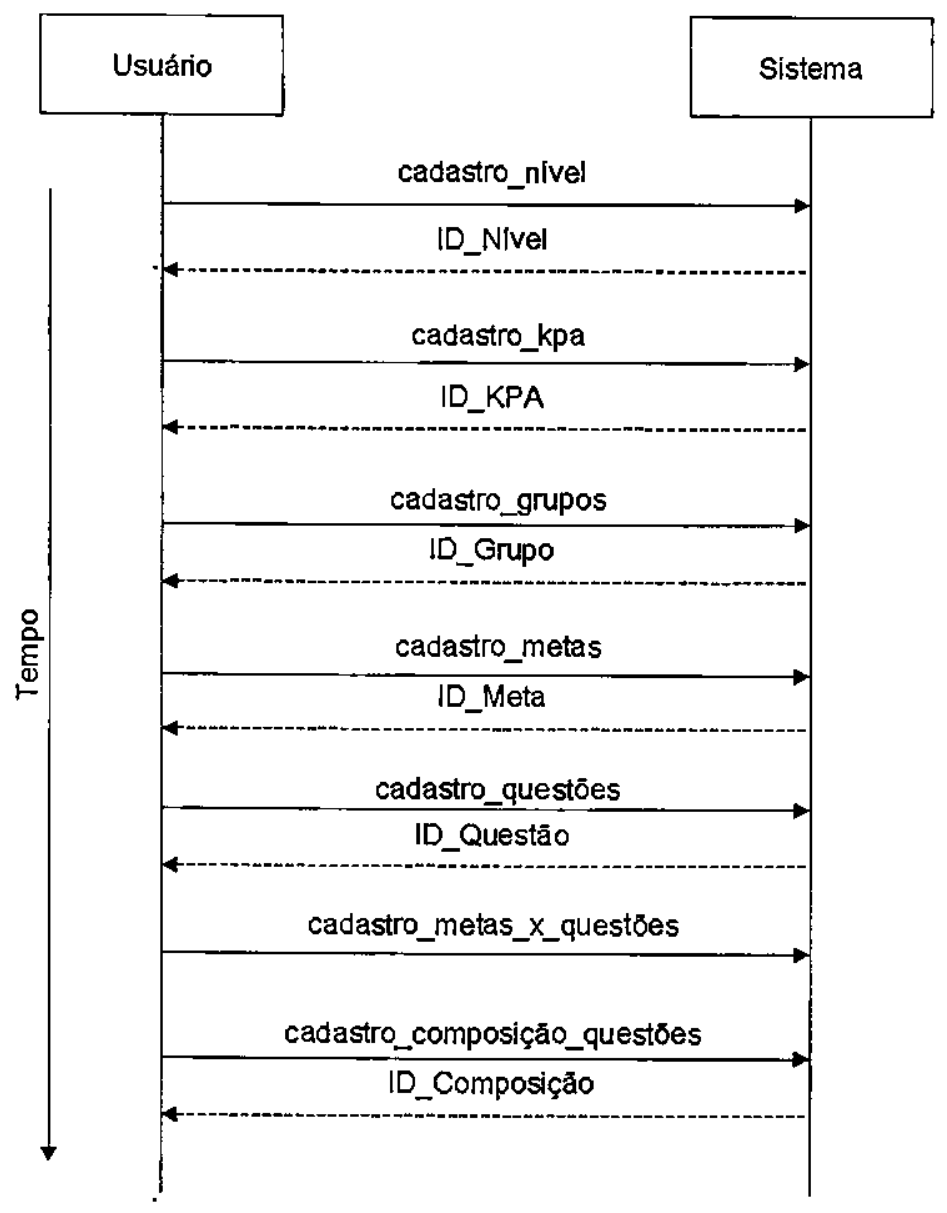

Figura 6 - Modelo de Interfaces: Cenário de Cadastramento de Questões do SW-CMM.

Para capturar aspectos diferentes do comportamento do sistema, o modelo de interfaces do método Fusion se utiliza de dois outros modelos: o Modelo de Ciclo de Vida e o Modelo de Operações.

\subsubsection{Modelo de Ciclo de Vida}

O modelo de ciclo de vida descreve o comportamento do sistema visto de uma perspectiva mais ampla, mostrando como o sistema se comunica com o seu ambiente desde o momento de sua criação até o seu término. Ele é composto de expressões ciclo de vida, as quais definem 
uma seqüência permissível de interações das quais um sistema pode participar dentro de seu período de existência.

Para a ferramenta SProQ foi gerado o seguinte modelo de ciclo de vida:

lifecycle SProQ: cadastramento_cmm.( avaliações.( [alteração_questionário*] II emissão_relatório_questões* || geração_gráfico_medição*) |l emissão_relatório_cmm*)

\begin{tabular}{|l|l|l|}
\hline cadastramento_cmm & $=$ & $\begin{array}{l}\text { (cadastro_nível.\#ID_Nível)+. (cadastro_kpa.\#ID_KPA)+. } \\
\text { (cadastro_grupos.\#ID_Grupo)+. } \\
\text { ((cadastro_metas.\#ID_Meta)+II } \\
\text { (cadastro_questões.\#ID_Questão)+). } \\
\text { (cadastro_metas_x_questões). } \\
\text { (cadastro_composição_questões.\#ID_Composição)+ }\end{array}$ \\
\hline Avaliações & $=$ & $\begin{array}{l}\text { (criar_questionário.\#ID_Questionário). } \\
\text { responder_questionário }\end{array}$ \\
\hline alteração_questionário & $=$ & alterar_questionário \\
\hline emissão_relatório_questões & $=$ & imprimir_relatório_questões. \#relatório_questões \\
\hline geração_gráfico_medição & $=$ & gerar_gráfico_medição. \#gráfico_medição \\
\hline emissão_relatório_cmm & $=$ & imprimir_relatório_cmm. \#relatório_cmm \\
\hline
\end{tabular}

Tabela 6 - Expressões do ciclo de vida da ferramenta SProQ.

\subsubsection{Modelo de Operações}

Esse modelo especifica o comportamento das operações de sistema de maneira declarativa, definindo assim seus efeitos em termos de mudanças de estado e eventos gerados. Em outras palavras, para cada operação do sistema, esse modelo mostra toda a transformação ocorrida no sistema durante essa operação, especificando inclusive as pré e pós-condições necessárias para que essa operação aconteça. Para se especificar esse modelo, o método Fusion define um Esquema utilizado para expressar cada uma das operações do sistema. A Figura 7 apresenta um dos Esquemas do Modelo de Operações da ferramenta SProQ. Todos os demais Esquemas encontram-se no apêndice A desta dissertação. 


\begin{tabular}{|r|l|}
\hline $\begin{array}{r}\text { Operation: } \\
\text { Description: }\end{array}$ & cadastro_nível \\
\hline Reads: & Supplastra um nivel do SW-CMM. \\
Changes: & New n: Nível \\
Sends: & Usuãório: $\{$ ID_Nível $\}$ \\
Assumes: nível) & \\
Resuit: & Foi cadastrado um novo nlvel do SW-CMM dentro do sistema. \\
& O identificador n.ID_Nível foi definido como um valor único. \\
\hline
\end{tabular}

Figura 7 - Esquema da operação cadastro_nível.

\subsection{A Fase de Projeto}

A realização desta fase consiste em traduzir as exigências da fase de análise numa representação do software que possa ser avaliada quanto à qualidade antes que a codificação se inicie. Nessa fase são incorporadas estruturas de software que satisfazem às definiçōes abstratas produzidas durante a fase de análise. $\mathrm{Na}$ fase de projeto é definido como será implementada a funcionalidade do sistema, a qual foi detalhada na fase análise. No método Fusion, o resuitado da fase de projeto é uma coleção de objetos que interagem entre si de modo a realizar o modelo de operações. Essa fase é composta por quatro modelos: grafos de interação de objetos, grafos de visibilidade, descrições de classes e grafos de herança.

\subsubsection{Grafos de Interação de Objetos}

Nesse modelo é descrito como os objetos interagem durante a execução do programa para que seja suportada a funcionalidade especificada no modelo de operações. Essa descrição é feita através da definição dos efeitos causados por cada operação do sistema em termos de mudança de estado do sistema e dos seus eventos. O grafo de interação de objetos define as seqüências de mensagens que ocorrem entre os objetos de um determinado grupo, quando realizam uma operaçāo em particular. A Figura 8 apresenta um dos grafos de interação da ferramenta SProQ. Todos os demais grafos de interação de objetos gerados para a ferramenta SProQ encontram-se no Apêndice $B$ desta dissertação. 


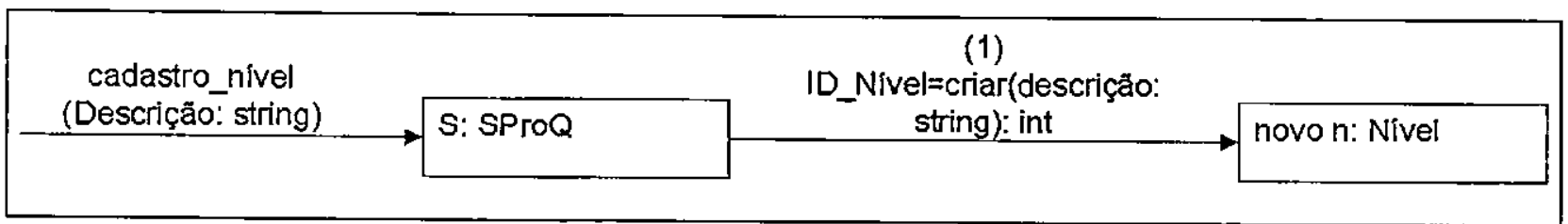

Descrição:

Operação cadastro_nível(Descrição: string)

Cadastrar novo Nível do SW-CMM, cujo nome é dado pelo parâmetro Descrição.

Figura 8 - Grafo de Interação do objeto Nível.

\subsubsection{Grafos de Visibilidade}

Nessa parte do modelo, são mostrados quais objetos do sistema são visíveis uns aos outros, para que sejam identificados os caminhos de comunicação realizados no sistema. Para que haja essa comunicação, os objetos precisam estar visíveis um para o outro, o que é demonstrado pelos grafos de visibilidade. $O$ objetivo de tais grafos é definir as estruturas de referência entre as classes existentes no sistema. A Figura 9 apresenta um dos grafos de visibilidade da ferramenta SProQ. Todos os demais grafos de visibilidade gerados para a ferramenta SProQ encontram-se no Apêndice B desta dissertação.

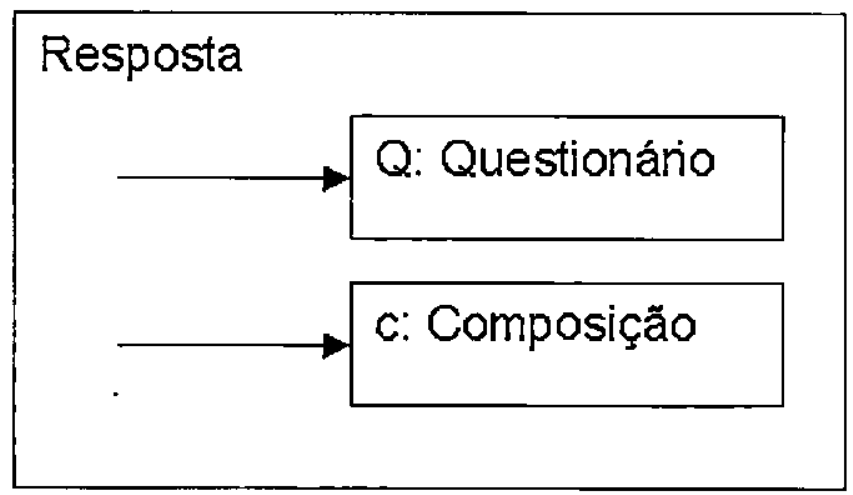

Figura 9 - Grafo de Visibilidade para os Questionários.

\subsubsection{Descrições de Classes}

Nessa parte do modelo são estabelecidas as classes que farão parte do sistema, bem como a composição de cada uma (métodos, atributos, atributos-objeto e herança). Em outras palavras, nessa fase do projeto desenvolve-se a estrutura de cada classe existente no sistema. Do 
modelo de objetos obtém-se os atributos de dados das classes; dos grafos de visibilidade, os atributos-objeto das classes; e dos grafos de interação de objetos, os métodos das classes. A seguir é apresentada a descrição de uma das classes da ferramenta SProQ. Todas as demais descrições de classes geradas para a ferramenta SProQ encontram-se no Apêndice B desta dissertaçăo.

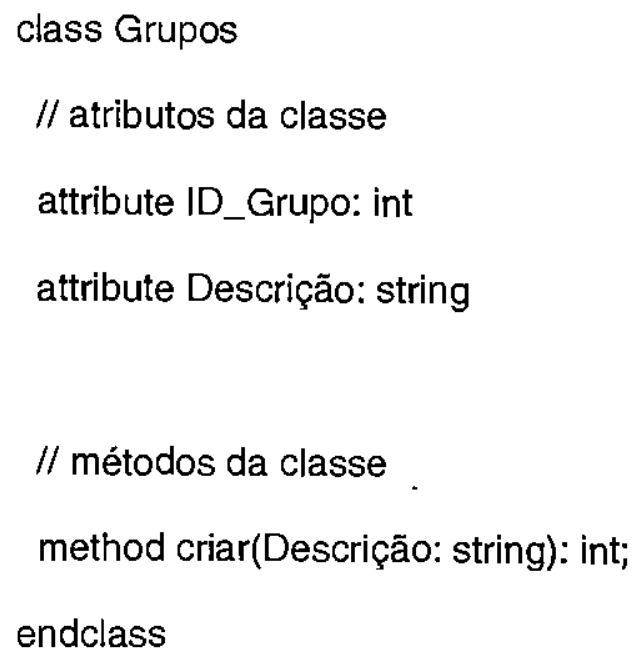

\subsubsection{Mapeamento do Modelo de Objetos para um Modelo Físico de Dados}

O modelo de objetos desenvolvido através do método Fusion trata-se de um modelo lógico de dados. O método Fusion não impõe restrições quanto ao modelo físico de dados a ser utilizado para mapear seu modelo de objetos. Atualmente, o Modelo Relacional [Silberschatz et. al., 1997] é o modelo físico de dados mais utilizado. Assim, para a ferramenta SProQ, optou-se por realizar o mapeamento do seu modelo de objetos para o Modelo Relacional [Rumbaugh et. al., 1994] (Figura 10). 


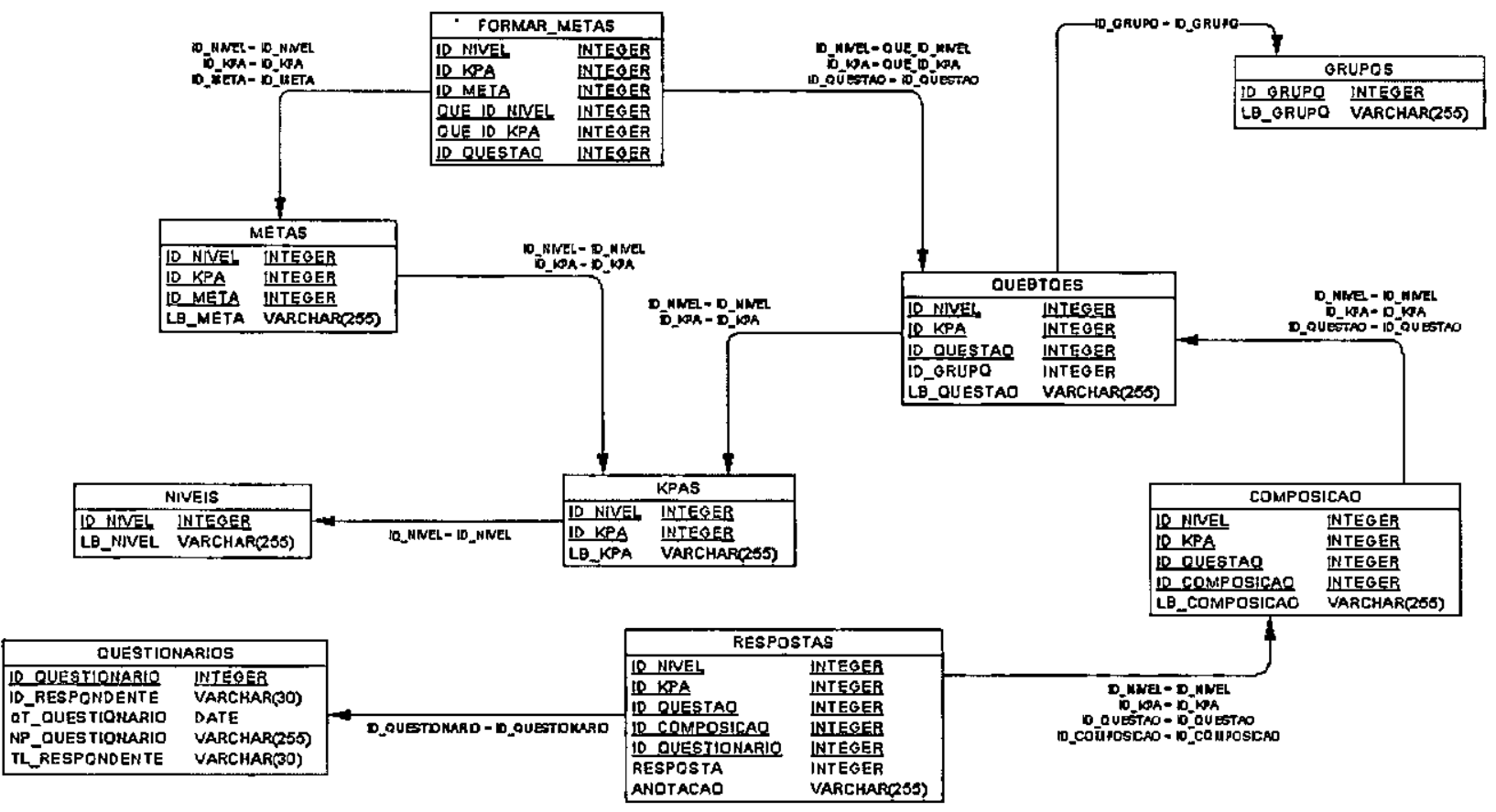

Figura 10 - O mapeamento do modelo de objetos da ferramenta SProQ para o Modelo Relacional.

\subsection{A Fase de Implementação}

A implementação da ferramentả SProQ foi desenvolvida utilizando-se a ferramenta Borland Delphi [Seraphim \& Fortes, 1999] [Blue, 1997]. Os principais motivos que levaram à escolha desse ambiente de programação foram:

- Trabalha dentro do ambiente Windows, o que é uma das restrições de projeto da ferramenta;

- Seu código (object Pascal) é $100 \%$ orientado a objetos, o que facilita na implementação de um sistema que foi modelado utilizando-se o método Fusion;

- O ambiente de um compilador object Pascal é um ambiente aceito e utilizado na maioria dos centros acadêmicos; o que significa que uma implementação adicional à ferramenta pode ser feita por qualquer pesquisador da área computacional;

- Possui componentes de acesso a bancos de dados, bem como acesso nativo aos principais Sistemas Gerenciadores de Bancos de Dados (SGBD) através de seu BDE (Borland Database Engine) [Borland, 1999]. 
A base de dados da ferramenta SProQ foi criada sob o Borland Interbase [Interbase, 1999], que é um Sistema Gerenciador de Bancos de Dados Relacional (SGBDR) [Date, 1986] e trabalha sobre uma base de dados criada segundo o Modelo Relacional. O Interbase oferece controle de acesso de usuários e integridade (de dados, de entidade e referencial), além de trabalhar em ambiente Cliente/Servidor. É importante lembrar que, apesar de ter sido utilizado - Interbase para gerenciar a base de dados da ferramenta SProQ, essa base de dados pode ser criada sob qualquer outro SGBDR. Para a criação da base de dados da ferramenta SProQ foi utilizada a ferramenta Q-Script [Gaspar et. al., 2000].

Quanto aos questionários utilizados em uma avaliação de processo de software, a ferramenta SProQ comporta:

- gerenciamento e manutenção dos questionários, através da inclusão e/ou remoção de suas questões;

- coleta e armazenamento das respostas aplicadas nas avaliações;

- reporte dos resultados obtidos em uma avaliação.

Gerenciamento e manutenção dos questionários é algo que não deve ser executado pelas pessoas sendo avaliadas, mas sim pelos responsáveis pela avaliação. Desse modo, a ferramenta SProQ foi dividida em dois módulos executáveis distintos, onde o primeiro módulo (MD_Manager) possui toda a parte de gerenciamento e manutenção dos questionários, enquanto que o segundo módulo (MD_Tool) agrega a coleta das respostas dos questionários e os relatórios e gráficos de avaliação.

A Figura 11 apresenta a interface com o usuário responsável pelo cadastramento das questōes do SW-CMM existentes nos questionários. 


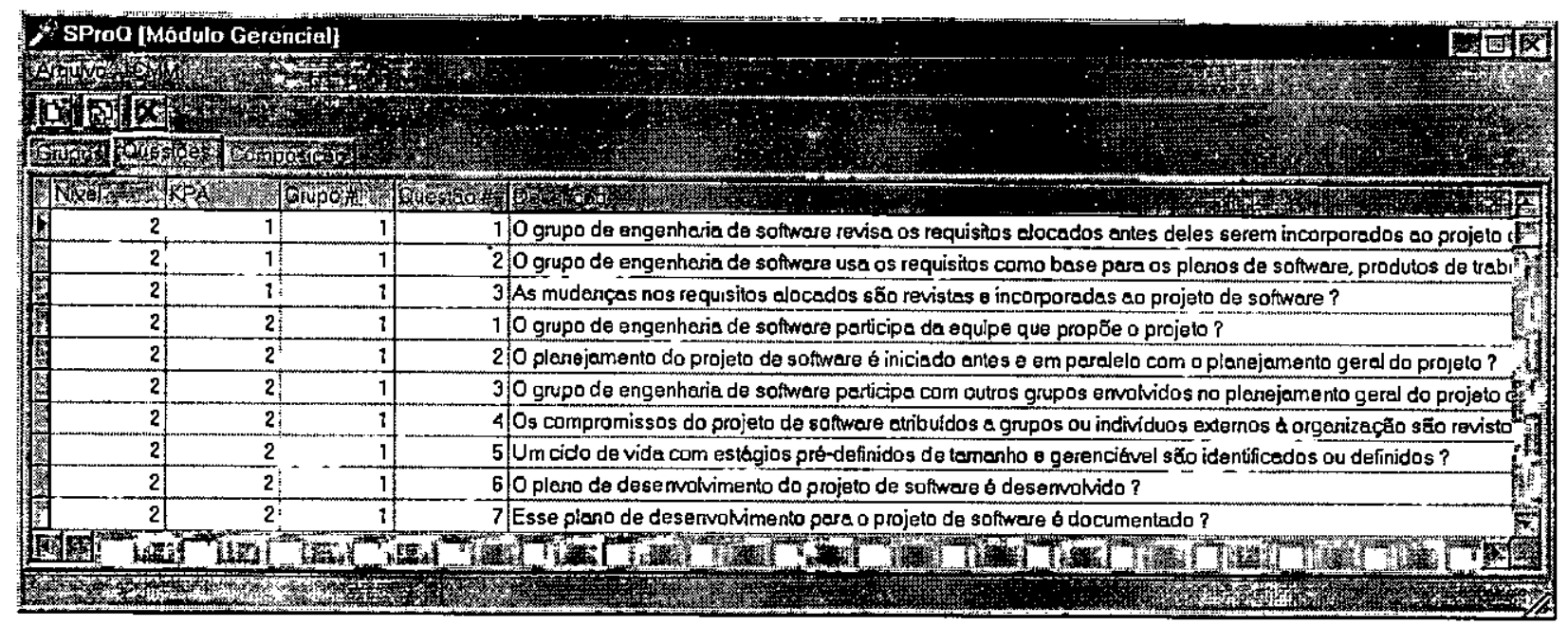

Figura 11 - Tela para Cadastramento das Questöes do SW-CMM.

Nessa tela observa-se a divisão do cadastramento em três partes: o cadastramento dos Grupos de Processo (sob a aba 'Grupos'), o cadastramento das Questões (sob a aba 'Questōes') e o cadastramento das Composições das questões (sob a aba 'Composição'). Além disso, para cada Questão, faz-se seu relacionamento com uma Meta da KPA a que a referida Questão pertence através do item de menu 'CMM'. As demais telas do módulo MD_Manager da ferramenta SProQ encontram-se no Apêndice B.

A Figura 12 apresenta a interface com o usuário responsável pelo cadastramento das respostas de um questionário de avaliação de processo de software. 


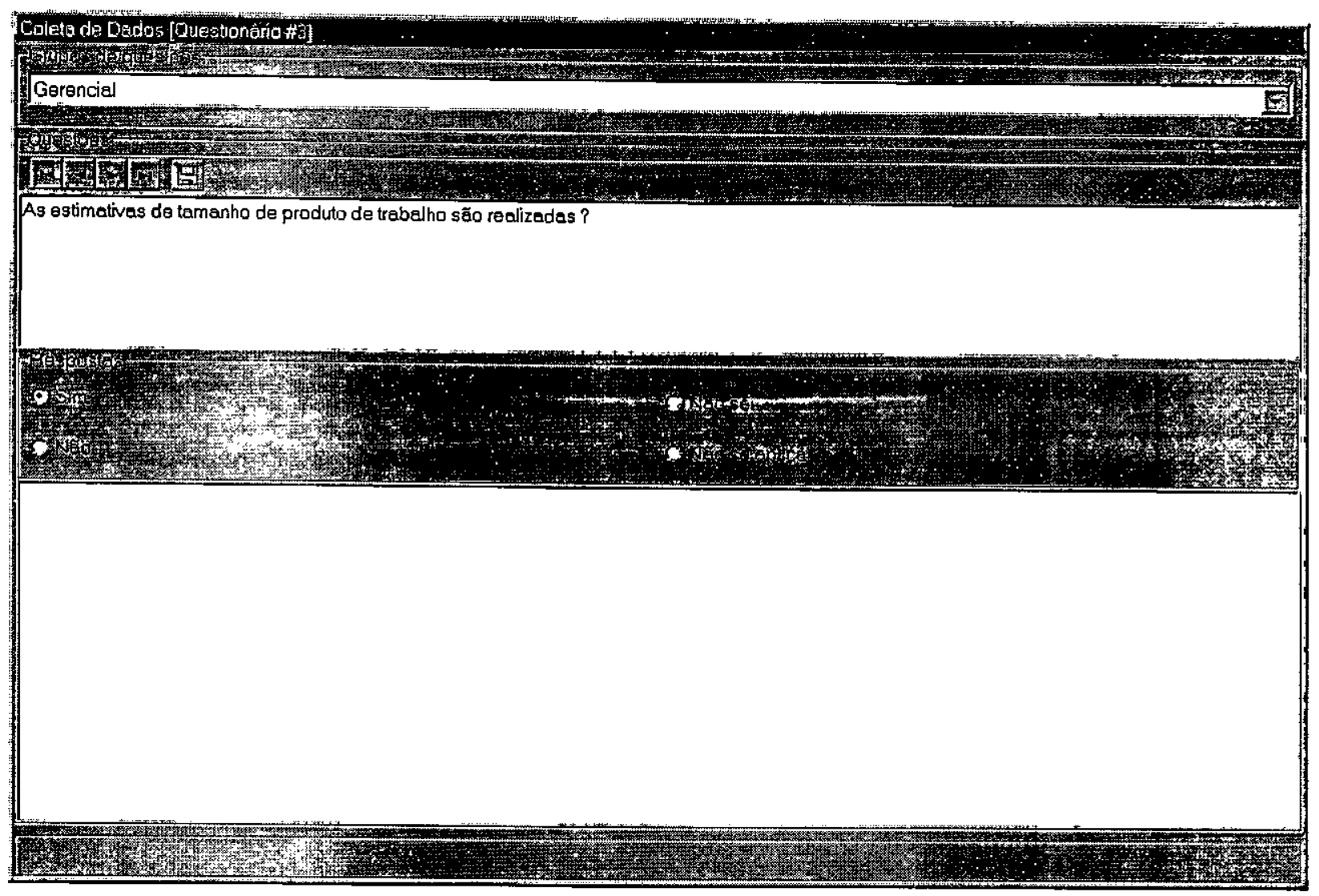

Figura 12 - Tela para Cadastramento das Respostas de uma Avaliação de Processo de Software.

Nessa tela observa-se que as questōes são apresentadas classificadas segundo ao Grupo de Processo a que pertencem e, para cada questão, suas possiveis respostas ('Sim', 'Não', 'Não sei' e 'Não se aplica') e a possibilidade de se incorporar-lhes quaisquer comentários. As demais telas do módulo MD_Tool da ferramenta SProQ encontram-se no Apêndice B.

\subsection{Considerações Finais}

Neste capítulo foi apresentado e documentado, de forma detalhada, todo o processo de construção da ferramenta SProQ. Foi mostrada a utilização do método Fusion para elaborar as fases de Análise e Projeto pertencentes ao ciclo de vida da ferramenta SProQ, bem como as considerações sobre a escolha da base de dados, do sistema gerenciador de banco de dados relacional e da linguagem de programação utilizados em sua elaboração. Todos os documentos complementares derivados do processo de construção da ferramenta SProQ encontram-se nos Apêndices. A e B. 
A seguir, são apresentadas as conclusões a que se chegou durante a elaboração desta dissertação de mestrado, e também sugestões para trabalhos futuros. 


\section{Capítulo 5}

\section{Conclusões e Trabalhos Futuros}

\subsection{Conclusões Finais}

Uma grande quantidade de empresas produtoras de software vem se preocupando com a melhoria de seus processos, no sentido de melhorar, por conseqüência, o seu produto final, perante um mercado cada vez mais exigente nesse aspecto. Torna-se difícil conseguir essa melhoria sem um modelo de qualidade. Nesse sentido, existem diversos estudos a nivel internacional que propōem modelos para a melhoria da qualidade de processo de software das organizações. Porém, eles tornam-se complexos de serem implantados nas pequenas e médias empresas brasileiras, principalmente pela falta de recursos (dinheiro, pessoal, etc.) que elas enfrentam.

Tendo em vista essas pequenas e médias empresas brasileiras, ENDO [Endo, 1998] desenvolveu uma Estratégia para Iniciar Melhoria de Processo de Software. Essa Estratégia é um instrumento de auxílio à fase de diagnóstico dentro de um programa de melhoria de processo de software em empresas de pequeno porte. A Estratégia utiliza um questionário para coleta de dados em sua fase de condução da avaliação, o qual avalia o processo de software com relação às atividades do nível 2 do SW-CMM.

\subsection{Contribuições}

Este trabalho de mestrado adicionou à Estratégia proposta por ENDO dois aspectos diferentes (Figura 13):

- Expandiu-se o questionário existente na Estratégia, selecionando e adicionando ao questionário as atividades do nível 3 (Repetível) do SW-CMM, tendo em vista que a maioria das empresas visam alcançar esse nível quando implantam tal modelo de melhoria de processo de software.

Com relação à seleção das atividades dos demais níveis do SW-CMM (que não as do nível 2) a serem adicionadas ao questionário da Estratégia, um ponto merece comentário. A idéia inicial era aplicar uma técnica de consenso, conhecida por Técnica Delphi [Dalkey, 1967] 
[Boehm, 1981] para se chegar a um consenso sobre quais atividades do SW-CMM seriam indispensáveis às pequenas empresas brasileiras de software. Participariam da pesquisa pessoas ligadas à área de processo de software, tanto relacionadas às pequenas empresas de software, como também pesquisadores de outras instituições de ensino nacionais. Porém, nenhum dos contatos que se tentou fazer junto a essas pessoas/empresas obteve resposta. Diante de tal dificuldade restringiu-se o estudo a revisões bibliográficas que culminaram com a seleção e inclusão das atividades do nível 3 do SW-CMM ao instrumento de pesquisa de ENDO.

- Uma segunda contribuição relaciona-se à elaboração da modelagem de uma base de dados para comportar o armazenamento dos dados coletados pelo questionário. Com base nessa modelagem, foi construída uma ferramenta automatizada para auxiliar a fase de diagnóstico da melhoria de processo de software, especificamente às etapas de Consolidação e Validação dos Dados, Realização do Julgamento das Medidas e Reporte dos Resultados.

- Este trabalho de mestrado fornece também, através da ferramenta elaborada, um auxílio à aplicação da Estratégia de ENDO, proporcionando às empresas uma forma de agilizar a avaliação de processo de software, propiciando o armazenamento dos dados coletados durante cada avaliação e fornecendo visualizações desses dados. 


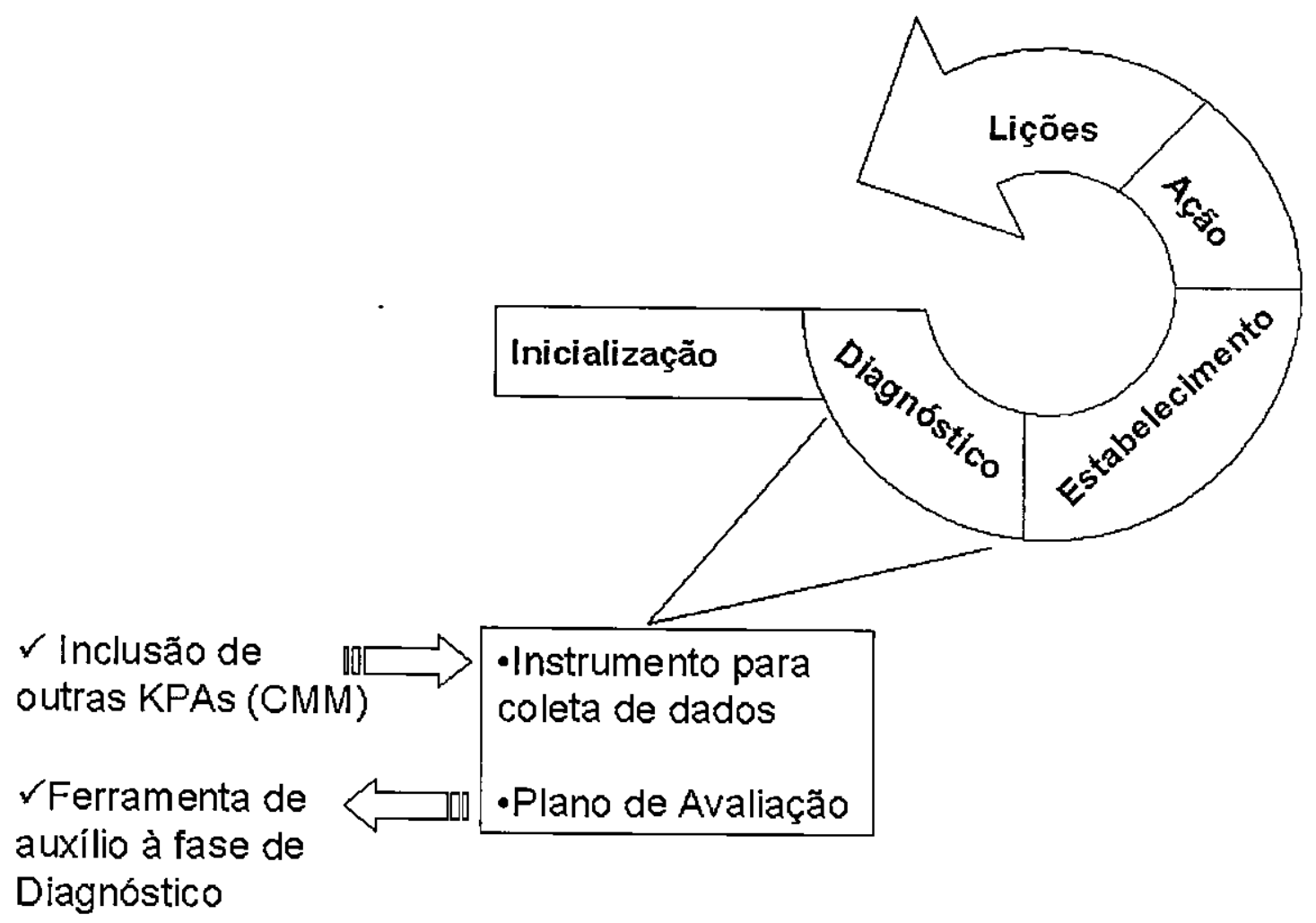

Figura 13 - Características a serem acrescentadas à Estratégia para Iniciar Melhoria de Processo de Software.

\subsection{Sugestões de Trabalhos Futuros}

- A ferramenta SProQ, apresentada neste trabalho de mestrado, foi desenvolvida de modo a permitir que outras KPAs do SW-CMM possam ser facilmente incluídas ou excluídas do instrumento de pesquisa, bastando para isso executar o módulo MD_Manager da ferramenta SProQ.

- Considerando-se ainda a inclusão e exclusão de KPAs ao instrumento de pesquisa, outra sugestão é que o estudo aplicando-se a Técnica Delphi seja preparado com antecedência e que a técnica possa ser efetivamente aplicada, onde os resultados seriam de grande importância para as empresas de pequeno porte.

- Atualmente está em desenvolvimento um trabalho de mestrado na UFSCar o qual modifica o questionário proposto por Endo, não no que se refere à inclusão ou exclusão de KPAs, mas no sentido de tornar as questões mais fáceis de serem compreendidas. Na verdade as questōes são expandidas em questões mais objetivas e mais fáceis de serem respondidas. Considerando-se esse trabalho (já em fase de conclusão), outra sugestão é primeiramente 
a modificação do questionário embutido na ferramenta SProQ e, posteriormente a utilização da ferramenta na aplicação do novo questionário em uma pesquisa de campo. Isso poderia mostrar mais rapidamente a situação real dos processos de software das empresas de pequeno porte. 


\section{Capítulo 6}

\section{Referências Bibliográficas}

[Andrade, 1996]

[Belloquim, 1998]

[Blue, 1997]

[Boehm, 1981]

[Borland, 1999]

[Brodman \& Johnson, 1994]

[Cavano, 1978]

[Coleman et. al., 1996]

[Curtis, 1998]

[Dalkey, 1967]

[Date, 1986]

[Deming, 1986]

[DoD - Std 2168]

[Endo, 1998]

[Endo, 1999]
ANDRADE, A. L.; e outros, Aplicação da norma ISO 12119 na Avaliação da Qualidade de Produtos de Software, VII CITS, Curitiba, 1996.

Belloquim, A. Qualidade de Software: Um Compromisso da Empresa Inteira, acessado em 20 de Dezembro de 1998. Disponivel na Internet:

$<$ http://www.ia.cti.br/-spin/QualComp.htm>

Blue, T.; Development Database in Delphi. First Edition, Makron Books, 1997

BOEHM, B. Software Engineering Economics Englewood Cliffs N.J.: PRENTICE-HALLL INC. 1981

Borland Corp., Borland Database Engine - BDE, online junho/1999, disponível na internet: http://www.borland.com/devsupport/bde/ti list

Judith G. Brodman, Donna L. Johnson: What Small Business and Small Organizations Say About the CMM: Experience Report. ICSE 1994: 331-340

CAVANO, J. P.; e J. A. MCCALL, A Framework for the Measurement of Software Quality, Proceeding ACM Software Quality Assurence Workshop, novembro, 1978.

Coleman, D.; Arnold, P.; Bodoff, S.; Dollin, C.; Gilchrist, H.; Hayes, F.; Jeremaes, P. Desenvolvimento Orientado a Objetos: Método Fusion. Editora Campus, 1996

CURTIS, B. Wich Comes First, the Organization or its Processes?, IEEE Software, v.15, n.6, p. 10-13, 1998.

Dalkey, N. C. The Delphi Method: An Experimental Study of Group Opinion, The Rand Corporation, RM-5888-PR, Junho, 1967

Date, C. J. Relacional Database: Selected Writings. Reading, Mass.: Addison-Wesley, 1986

DEMING, W. E. Out of the Crisis. Cambridge: MIT Press, 1986.

Dod-Std-2168, Department of Defense Standard of Software Quality Evaluation.

ENDO, C. Uma Estratégia para Iniciar Melhoria de Processo de Software. Dissertação de Mestrado, ICMC/USP - SC, 1998.

ENDO, C. Uma Estratégia para Iniciar Melhoria de Processo de Software. Anais do IV Simpósio de Teses e Dissertaçōes 
Defendidas, ICMC/USP - SC, 1999.

[Fox, 1997]

[Garmus, 1996]

[Gaspar et. al., 2000]

[Gillies, 1993]

[Ginsberg \& Quinn, 1995]

[Glass, 1998]

[Grady, 1997]

[Gremba, 1998]

[Haase, 1994]

[Horch, 1996]

[Humphrey, 1992]

[IEEE Std 729, 1983]

[Interbase, 1999]

[Ishikawa, 1993]

[Juran, 1993]

[Lowe, 1996]
FOX, C.; Frakes, W. The Quality approach: is it delivering? Communications of the ACM, vol. 40 n. 6 p. 25-29, June 1997.

GARMUS, D.,Measuring the Sofware Process: a practical guide to functional measurements, Prentice-Hall, Nova Jersey, 1996.

Gaspar, D. A.; Seraphim, E.; Traina, C. Junior (1999) Q-Script - A tool to Move Data Between two Relational Databases, VII Conference on Extending Database Technology - EDTB 2000, University of Konstanz, Alemanha, Março de 2000

GILLIES, A. Software Quality: Theory and Management, Chapman\&Hall, Longman, 1993

Mark P. Ginsberg, Lauren H. Quinn Process Tailoring and the the Software Capability Maturity Model (SEI-94-TR-024, ESC-TR-94024). Pittsburgh, PA: Software Engineering Institute, Carnegie Mellon University, November 1995.

GLASS, R. L. Defining Quality Intuitively, IEEE Software, v.15, n.3, p 103-104, 1998.

GRADY R. B. Successful Software Process Improvement. New Jersey: Prentice Hall, 1997.

GREMBA, J.; MYERS, C., The IDEAL Process Model: A Practical Guide for Improvement,

http://www.sei.cmu.edu/activities/ideal/ideal.bridge.html, [acessado em 25/04/99].

HAASE, V. et al. Bootstrap: Fine-Tuning Process Assessment, IEEE Software, v.11, n. 4, p. 25-35, 1994.

HORCH, J. W. Practical Guide to Software Quality Management, Artech House, 1996.

HUMPHREY, W. S. Introduction to Software Process Improvement. [on-line]. Techinical Report CMU/SEI-92-TR-7. Carnegie Mellon University: June 1993. Acessado em 10 de Fevereiro de 1999. Disponível na Internet:

$<$ http://www.sei.cmu.edu/publications/documents $>$.

IEEE Standard Glossary of Software Engineering Terminology, Software Engineering Technical Commitee of the IEEE Computer Society, 1983.

Interbase, Interbase: The OPEN source database, online junho/1999, disponível na internet: ftp://ftp2.interbase.com/pub/products/release/Windows/id55docs.z ip

ISHIKAWA, K. Controle da qualldade total à maneira japonesa. Rio de Janeiro: Campus, 1993.

JURAN, J. M. e GRYNA, F. Quality planning and analysis. New York: MacGraw Hill, 1993. p.2,

LOWE D. E.; COX G. M. Implementing the Capability Maturity 
[Maidantchik, 1997]

[Marciniat, 1994]

[Masters \& Bothwell, 1995]

[Melo, 1997]

[Paulk et. al., 1993]

[Paulk, 1992]

[Pressman, 1995]

[QUALIDADE, 1997]

[Rumbaugh et. al., 1994]

[Sanders, 1994]

[Seraphim \& Fortes, 1999]

[Silberschatz et al, 1997]

[Smith, 1989]
Model for Software Development. [on-line]. Hewlett-Packard Journal, v.47 n.4, p.6-9, August 1996. Acessado em 02 de Fevereiro de 99. Disponível na Internet:

$<$ http://www.searchbank.com/searchbanck/usp $>$.

MAIDANTCHIK, Carmen. Acessado em 20 de janeiro de 1999. Disponível na Internet: http://www.cos.ufri.br/ lodi/Publications/SPI WK/node2.htm

MARCINIAT, J. J., Encyclopedia of Software Engineering, Wiley Intersciense Publications, v.ll, p. 851-869, 1994.

Masters, Steve; Bothwell, Carol CMM Appraisal Framework, Version 1.0 (CMU-SEI-95-TR-01, ESC-TR-95-001). Pittsburgh, PA: Software Engineering Institute, Carnegie Mellon University, February 1995.

MELO, P. R. S; CASTELO BRANCO, C. E. Setor de Software: diagnóstico e proposta de ação para o BNDES. BNDES Setorial, n.5, p. 111-127, Março 1997.

Paulk, Mark C.; Weber, Charles V.; Garcia, Suzanne M.; Chrissis, Mary Beth, and Bush, Marilyn W. Key Practices of the Capability Maturity Model, Version 1.1 (CMU/SEI-93-TR-25, ADA 263432). Pittsburgh, PA: Software Engineering Institute, Carnegie Mellon University, February 1993.

PAULK, M.; CURTIS, B. ; CHRISSIS, M.; WEBER, C. The Capability Maturity Model for Software v. 1.1 [on-line]. [23/08/98]. Disponível na Internet:

$<$ http://www.sei.cmu.edu/publications/documents/93.reports/93.tr. 024html >

Pressman, Roger S. Engenharia de Software. São Paulo: Makron Books, 1995.

QUALIDADE, Qualidade no Setor de Software Brasileiro Brasilia. n.2, p.27, 1998.

Rumbaugh, J.; Blaha, M.; Premerlani, W.; Eddy, F.; Lorensen, W. Modelagem e Projetos Baseados em Objetos, Rio de Janeiro: Campus, 1994

SANDERS, J.; CURRAN, E., Software Quality - "A framework for success in software development and suport", Addison-Wesley, 1994.

Seraphim, E.; Fortes, R. P. M. Programação Delphi apoiando a construção de aplicativos de bases de dados, Série Notas Didáticas do ICMC No 42, dezembro de 1999, 61p

Silberschatz, Abraham; Korth, Henry F.; Sudarshan S. Database System Concepts. Third Edition, McGraw-Hill, 1997

SMITH, D. J.; WOOD, K. B., Engineering Quality Software - "A review of current practices standards and guidelines including new methods and development tool', Elsevier Science Publishers Ltd., 1989.

[SPICE1]
SPICE. ISO/iEC Software Process Assesment - Part 1: Concepts and Introductory Guide, Version 1.00. [on-line]. [20/08/98]. Disponivel na Internet:

$<$ http://www.sqi.cit.gu.edu.au/spice/suite download.shtml $>$. 
[SPICE7, 1997]

[Tsukumoto, 1995]

[Valente, 1999]

[Werkema, 1995]
SPICE. ISO/iEC Software Process Assesment - Part 7: Guide for use in process improvement, Version 1.00. Acessado em 20 de Agosto de 1998. Disponível na Internet:

$<$ http:/www.sqi.cit.gu.edu.au/spice/suite download.shtml $>$.

TȘUKUMOTO, N. A.; e outros, Modelos de Processo de Software: Visão Global e Análise Comparativa, Fundação CTI Brasil, Campinas, 1995.

Valente, Fábio F. R. A Implantação do CMM de Qualidade de Software na Xerox. Developers Magazine, Ano 3, № 35, pp. 42 a 44, 1999

WERKEMA, M. C. C., Ferramentas industriais básicas para o gerenciamento de processos, Fundação Christiano Ottoni, 1995. 


\section{Apêndices}

\section{Apêndice A - Documentos da Fase de Análise da Ferramenta \\ SProQ}

\section{Dicionário de Dados da Ferramenta SProQ}

O método Fusion propõe que seja criado um Dicionário de Dados, utilizado durante todo o ciclo-de-vida de um software. Tal dicionário de dados serve como um repositório central de termos e conceitos, cujas informações servirão como conteúdo semântico para os modelos gerados por esse método. A seguir, então, é dado o Dicionário de Dados da ferramenta SProQ.

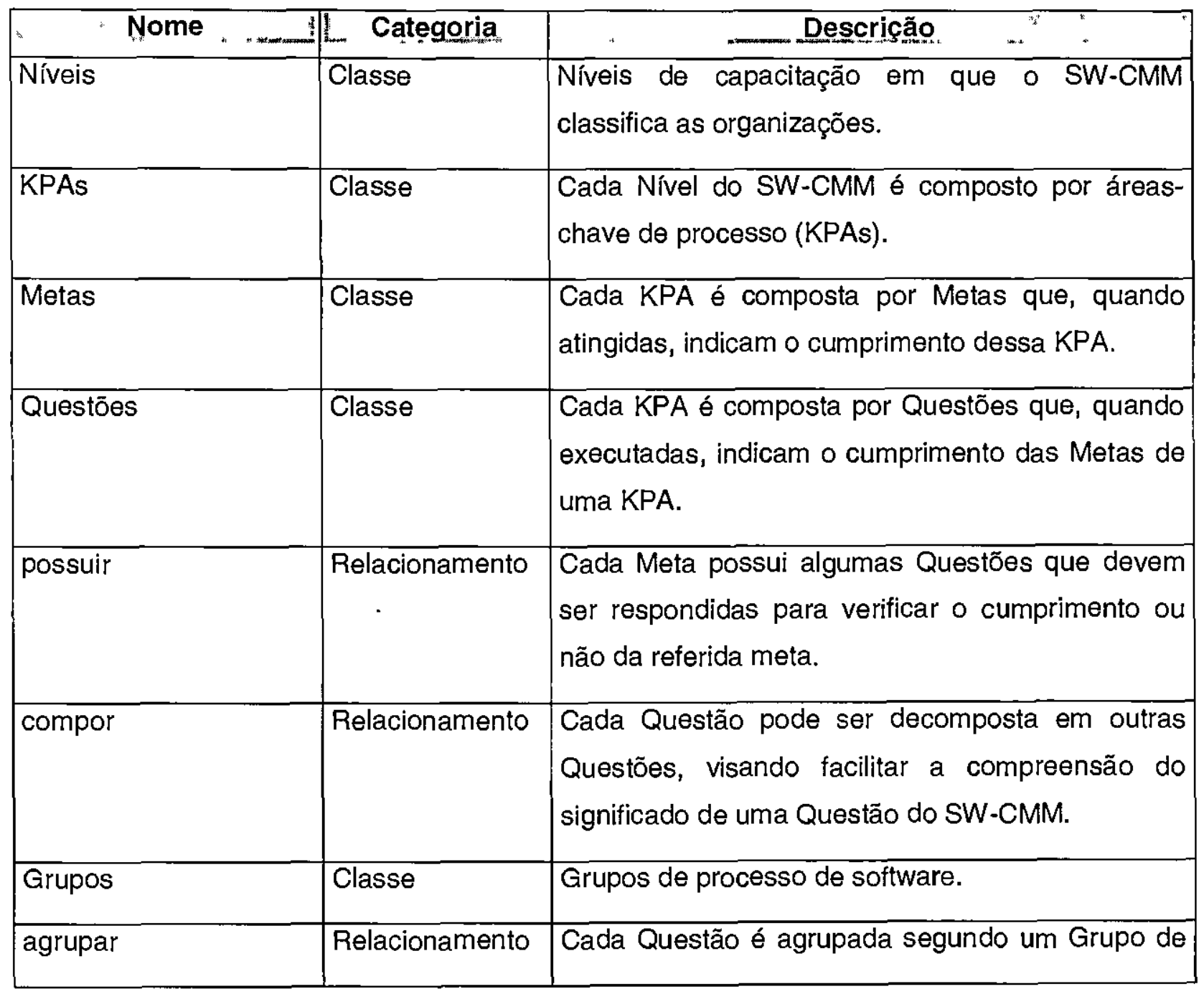




\begin{tabular}{|c|c|c|}
\hline & & processo a que pertencem. \\
\hline Questionário & Classe & $\begin{array}{l}\text { Cada avaliação é realizada utilizando-se um } \\
\text { Questionário, o qual conterá as Questōes do SW- } \\
\text { CMM e suas respectivas respostas. }\end{array}$ \\
\hline responder & Relacionamento & $\begin{array}{l}\text { Cada Questionário de avaliação responde às } \\
\text { Questões do SW-CMM. }\end{array}$ \\
\hline Relatórios & Classe & Classe-base para os relatórios. \\
\hline Relatório_CMM & Subclasse & $\begin{array}{l}\text { Relatório que lista as Questões do SW-CMM, } \\
\text { agrupadas em Niveis e KPAs. }\end{array}$ \\
\hline Relatório_Questionário & Subclasse & $\begin{array}{l}\text { Relatório que lista as Questões a serem } \\
\text { respondidas por uma avaliação. }\end{array}$ \\
\hline Gráficos & Classe & Classe-base para os gráficos. \\
\hline Gráfico_Medição & Subclasse & $\begin{array}{l}\text { Gráfico que apresenta as medições feitas em uma } \\
\text { avaliação. }\end{array}$ \\
\hline Listar & Relacionamento & $\begin{array}{l}\text { As Questões constantes nas KPAs dos Niveis SW- } \\
\text { CMM são listadas em um relatório. }\end{array}$ \\
\hline Emitir & Relacionamento & $\begin{array}{l}\text { Um relatório contendo O Questionário de uma } \\
\text { avaliação é emitido. }\end{array}$ \\
\hline Gerar & Relacionamento & $\begin{array}{l}\text { Um gráfico de medição de uma avaliação é } \\
\text { gerado. }\end{array}$ \\
\hline ID_Nível & Atributo & Identificador de um Nível SW-CMM. \\
\hline ID_KPA & Atributo & Identificador de uma KPA SW-CMM. \\
\hline ID_Meta & Atributo & Identificador de uma Meta SW-CMM. \\
\hline ID_Questão & Atributo & Identificador de uma Questão SW-CMM. \\
\hline ID_Questionário & Atributo & Identificador de um Questionário SW-CMM. \\
\hline ID_Grupo & Atributo & Identificador de um Grupo SW-CMM. \\
\hline Descrição & Atributo & $\begin{array}{l}\text { Níveis }=>\text { nome do Nível } \\
\text { KPAs } \Rightarrow>\text { nome da KPA } \\
\text { Metas } \Rightarrow>\text { nome da Meta }\end{array}$ \\
\hline
\end{tabular}




\begin{tabular}{|c|c|c|}
\hline & & $\begin{array}{l}\text { Questões } \Rightarrow>\text { descrição da questão } \\
\text { Grupos } \Rightarrow>\text { nome do grupo. }\end{array}$ \\
\hline ID_Respondente & Atributo & Identificação de quem respondeu ao Questionário. \\
\hline Data & Atributo & $\begin{array}{l}\text { Questionários } \Rightarrow>\text { data de criação do Questionário. } \\
\text { Relatórios } \Rightarrow>\text { data de emissão do Relatório. }\end{array}$ \\
\hline Hora & Atributo & Relatórios $=>$ horário de emissão do Relatório. \\
\hline Tipo & Atributo & Gráficos $\Rightarrow>$ tipo de gráfico a ser gerado. \\
\hline Nome_Projeto & Atributo & Nome do Projeto sendo avaliado. \\
\hline Telefone & Atributo & $\begin{array}{l}\text { Telefone para contato } r \\
\text { organização/responsável/respondente do } \\
\text { sendo avaliado. }\end{array}$ \\
\hline resposta & Atributo & $\begin{array}{l}\text { Resposta dada a uma Questão, sendo que seus } \\
\text { valores possíveis são: Sim, Não, Não sei, Não se } \\
\text { aplica. }\end{array}$ \\
\hline anotação & Atributo & $\begin{array}{l}\text { Anotações que podem ser feitas para cada } \\
\text { Questão respondida. }\end{array}$ \\
\hline
\end{tabular}

Tabela 7 - Dicionário de Dados do Modelo de Objetos da Ferramenta SProQ.

\begin{tabular}{|l|l|l|l|}
\hline \multicolumn{1}{|c|}{ Nome } & \multicolumn{1}{|c|}{ Categonia } & \multicolumn{1}{|c|}{ Agente } & \multicolumn{1}{c|}{ Descriçãó } \\
\hline Cadastro_nível & Op. do sistema & Usuário & $\begin{array}{l}\text { Cadastra um Nível do SW- } \\
\text { CMM. }\end{array}$ \\
\hline Cadastro_KPA & Op. do sistema & Usuário & $\begin{array}{l}\text { Cadastra uma KPA } \\
\text { pertencente a um dos níveis } \\
\text { do SW-CMM. }\end{array}$ \\
\hline Cadastro_Meta & Op. do sistema & Usuário & $\begin{array}{l}\text { Cadastra uma meta de uma } \\
\text { KPA do SW-CMM. }\end{array}$ \\
\hline Cadastro_Questões & Op. do sistema & Usuário & $\begin{array}{l}\text { Cadastra uma questão de uma } \\
\text { KPA. }\end{array}$ \\
\hline
\end{tabular}




\begin{tabular}{|c|c|c|c|}
\hline Cadastro_Grupos & Op. do sistema & Usuário & $\begin{array}{l}\text { Cadastra um novo grupo de } \\
\text { processos. }\end{array}$ \\
\hline Cadastro_metas_x_questões & Op. do sistema & Usuário & $\begin{array}{l}\text { Cadastrar um relacionamento } \\
\text { entre Metas e Questōes do } \\
\text { SW-CMM. }\end{array}$ \\
\hline Cadastro_composição_questões & Op. do sistema & Usuário & $\begin{array}{l}\text { Cadastra um item de } \\
\text { composição de uma Questão. }\end{array}$ \\
\hline Criar_Questionário & Op. do sistema & Usuário & $\begin{array}{l}\text { Cria um novo Questionário, a } \\
\text { partir das Questões existentes } \\
\text { no sistema. }\end{array}$ \\
\hline Responder_Questionário & Op. do sistema & Usuário & $\begin{array}{l}\text { Resposta às Questōes de uma } \\
\text { avaliação. }\end{array}$ \\
\hline Alterar_Questionário & Op. do sistema & Usuário & $\begin{array}{l}\text { Altera os dados cadastrais de } \\
\text { um Questionário. }\end{array}$ \\
\hline Imprimir_relatório_cmm & Op. do sistema & Usuário & $\begin{array}{l}\text { Solicitação para impressão de } \\
\text { um relatório com as Questões } \\
\text { do SW-CMM, agrupadas de } \\
\text { acordo com os Níveis/KPAs a } \\
\text { que pertencem. }\end{array}$ \\
\hline Imprimir_relatório_questões & Op. do sistema & Usuário & $\begin{array}{l}\text { Solicitação para impressão de } \\
\text { um relatório com um } \\
\text { Questionário completo a ser } \\
\text { respondido. }\end{array}$ \\
\hline Gerar_gráfico_medição & Op. do sistema & Usuário & $\begin{array}{l}\text { Solicitação para geração de } \\
\text { um gráfico com os resultados } \\
\text { obtidos pela avaliação de um } \\
\text { Questionário. }\end{array}$ \\
\hline Relatório_cmm & Evento & Usuário & $\begin{array}{l}\text { Emissão de um relatório } \\
\text { contendo as Questões do SW- } \\
\text { CMM, agrupadas de acordo } \\
\text { com os Níveis/KPAs a que } \\
\text { pertencem. }\end{array}$ \\
\hline
\end{tabular}




\begin{tabular}{|l|l|l|l|}
\hline Relatório_questões & Evento & Usuário & $\begin{array}{l}\text { Emissão de um relatório com } \\
\text { um Questionário completo a } \\
\text { ser respondido. }\end{array}$ \\
\hline Gráfico_medições & Evento & Usuário & $\begin{array}{l}\text { Emissão de um gráfico com os } \\
\text { resultados obtidos pela } \\
\text { avaliação de um Questionário. }\end{array}$ \\
\hline
\end{tabular}

Tabela 8 - Dicionário de Dados: A Interface do Sistema da Ferramenta SProQ.

\section{Modelo de Interfaces}

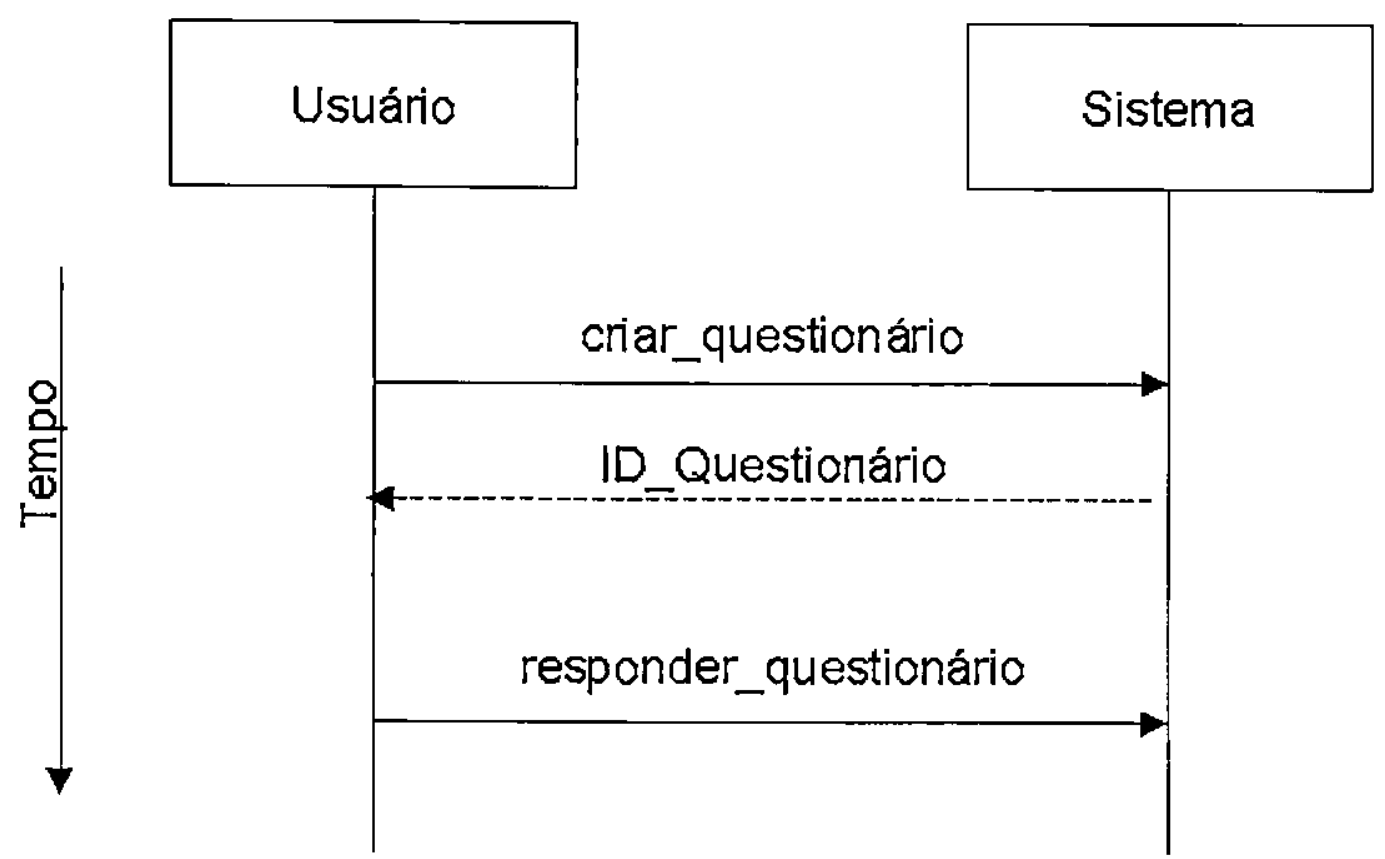

Figura 14 - Modelo de Interfaces: Cenário de Avaliações. 


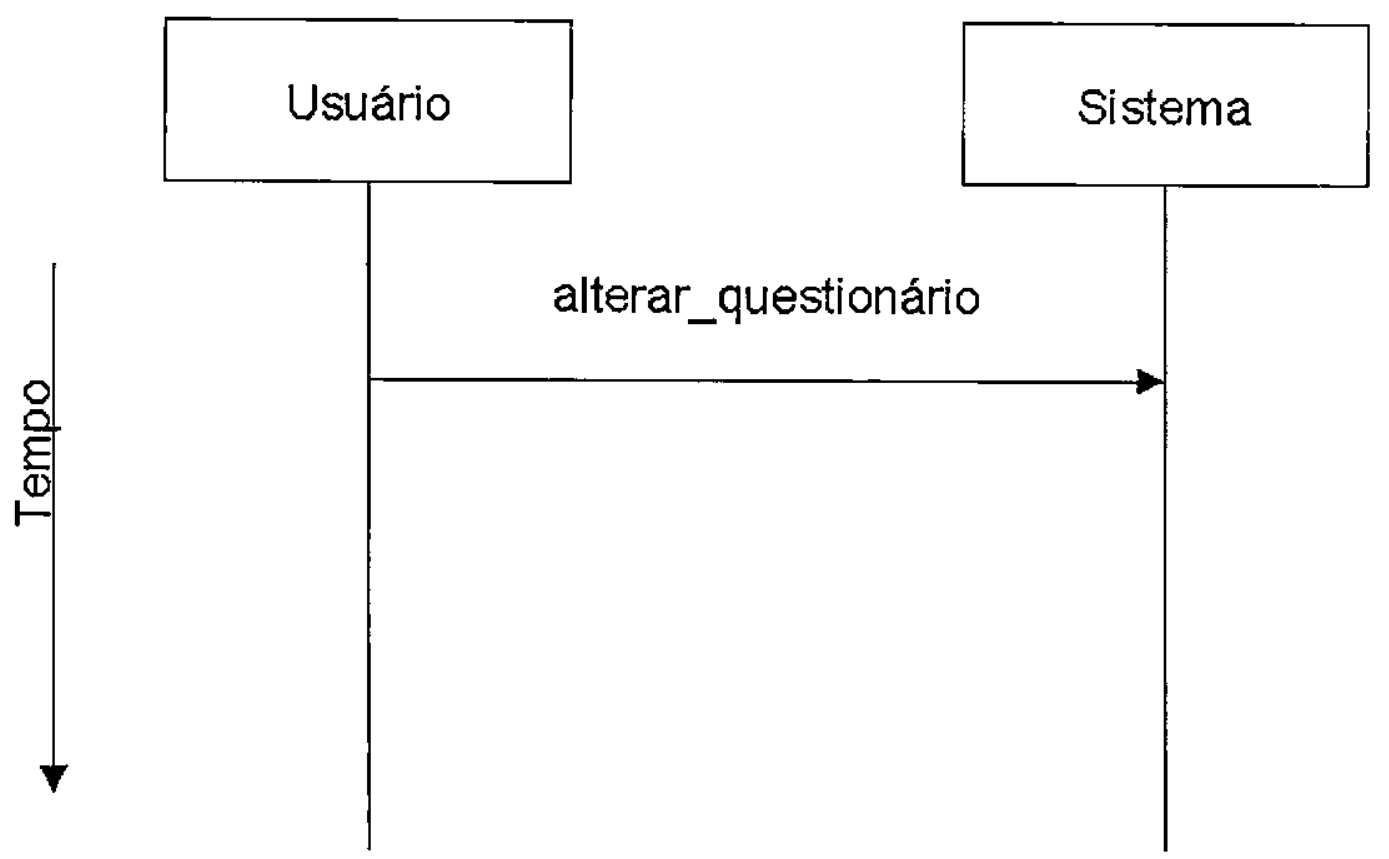

Figura 15 - Modelo de Interfaces: Cenário de Alteração de Questionário. 


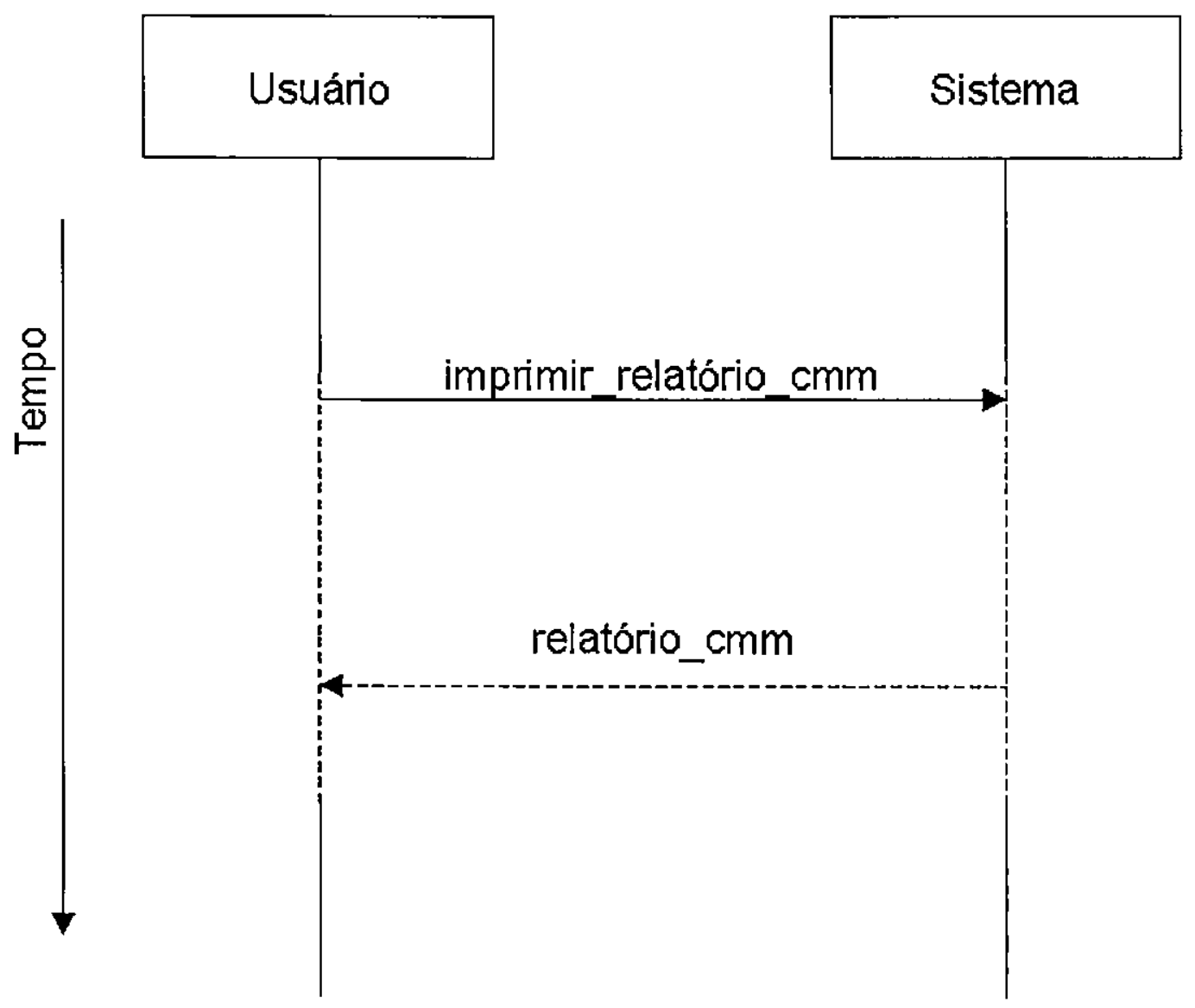

Figura 16 - Modelo de Interfaces: Cenário de Emissão de Relatório SW-CMM. 


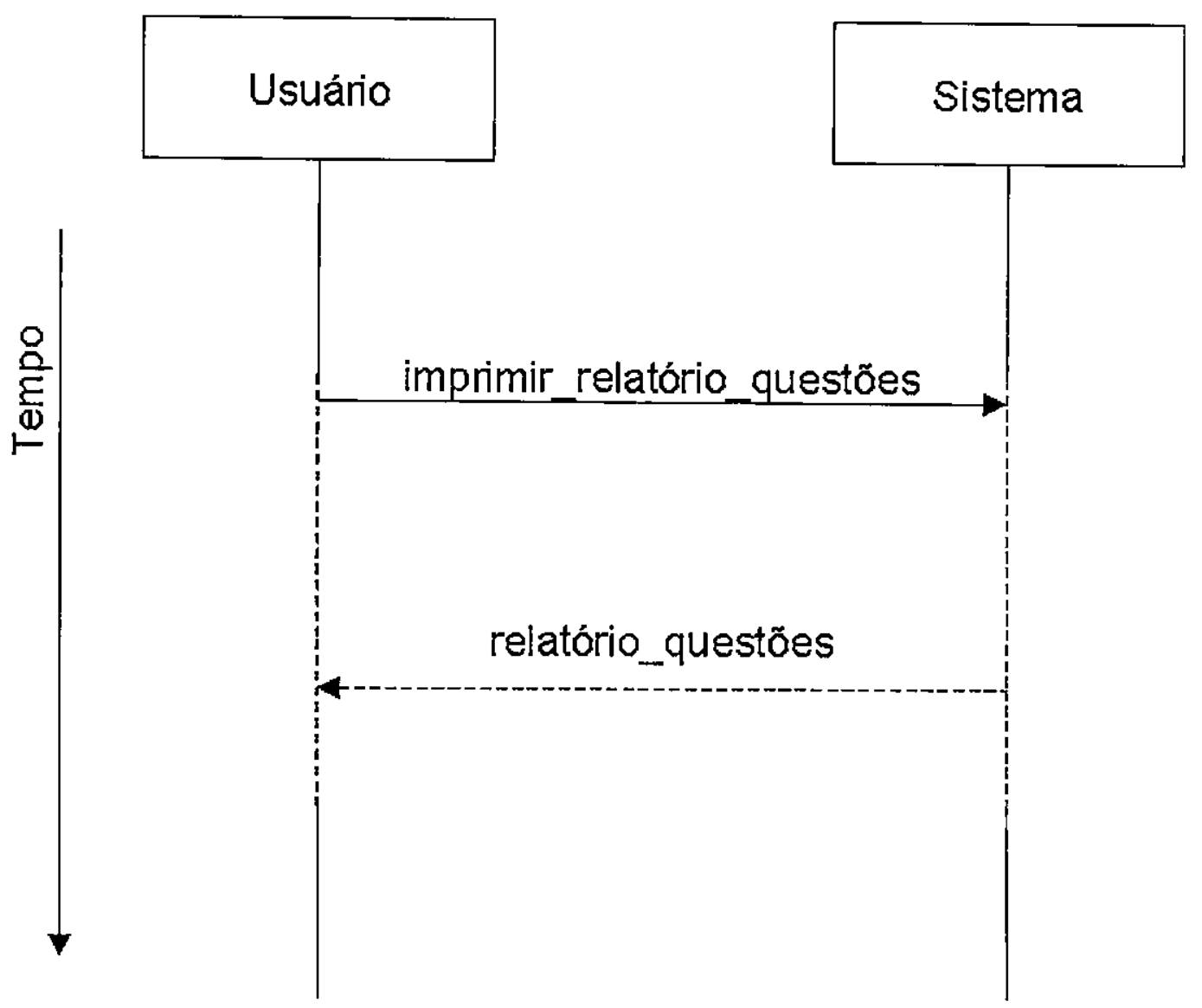

Figura 17 - Modelo de Interfaces: Cenário de Emissão de Relatório dos Questionários. 


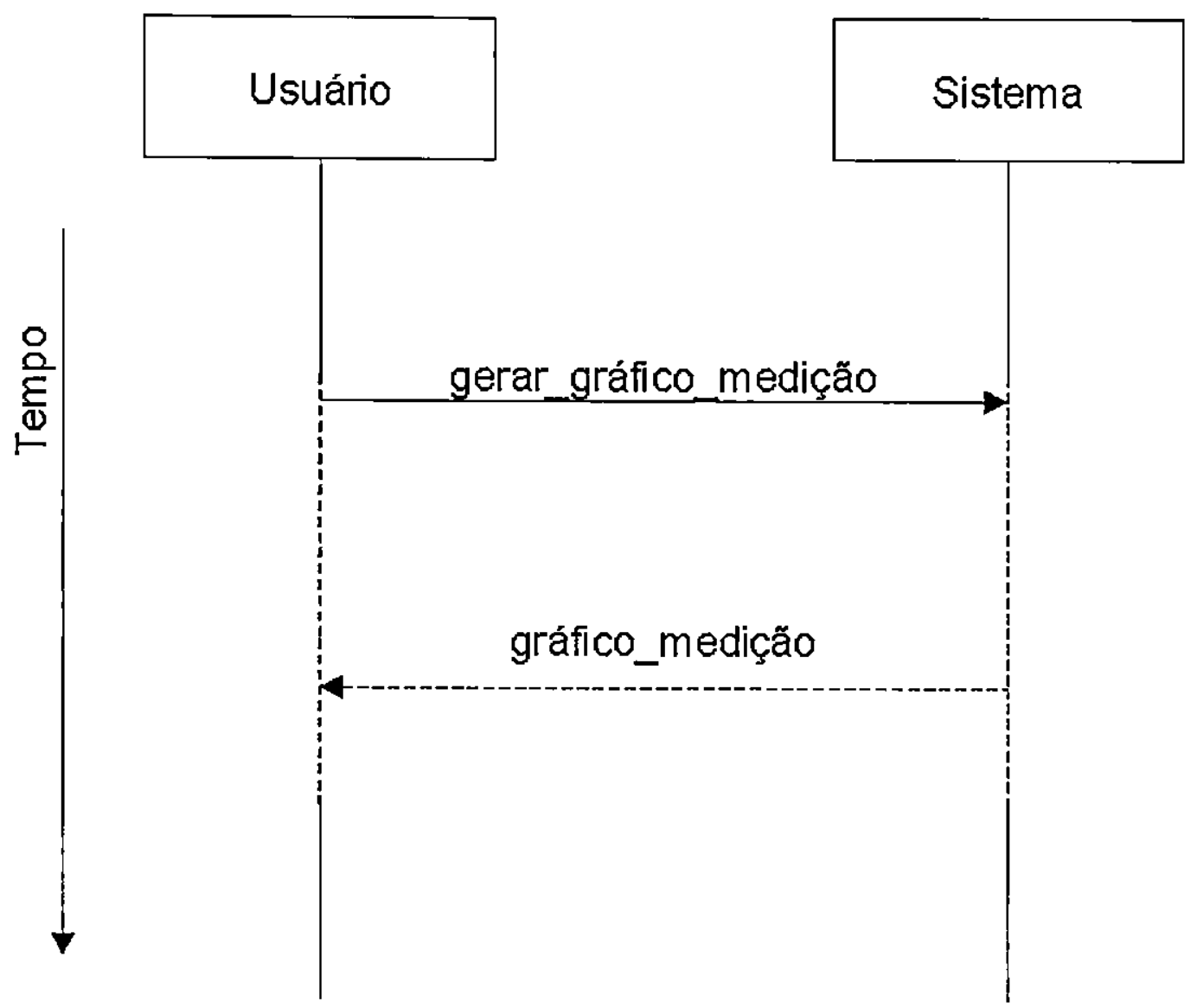

Figura 18 - Modelo de Interfaces: Cenário de Geração de Gráfico de Mediçōes.

\section{Modelo de Operaçōes da Ferramenta SProQ}

$\mathrm{Na}$ fase de Análise do método Fusion é gerado um Modelo de Operaçōes, visando definir o a semântica de cada operação que faz parte da interface do sistema. A seguir, é dado o Modelo de Operações da ferramenta SProQ.

\begin{tabular}{|r|l|}
$\begin{aligned} \text { Operation: } \\
\text { Description: }\end{aligned}$ & Cadastro_kpa \\
\hline Reads: & Supplied $\{$ ID_Nível, Descrição (da KPA) $\}$ \\
Changes: & New k: KPA, n: Níveis \\
Sends: & ID_KPA \\
Assumes: & O ID_Nível está cadastrado no sistema.
\end{tabular}




\begin{tabular}{|l|l|}
\hline Result: & $\begin{array}{l}\text { Foi cadastrada uma nova KPA para um dos níveis do SW-CMM. } \\
\text { O identificador k.ID_KPA foi definido como um valor único para esse ID_Nível. }\end{array}$ \\
\hline
\end{tabular}

Figura 19 - Operação: Cadastramento de KPAs.

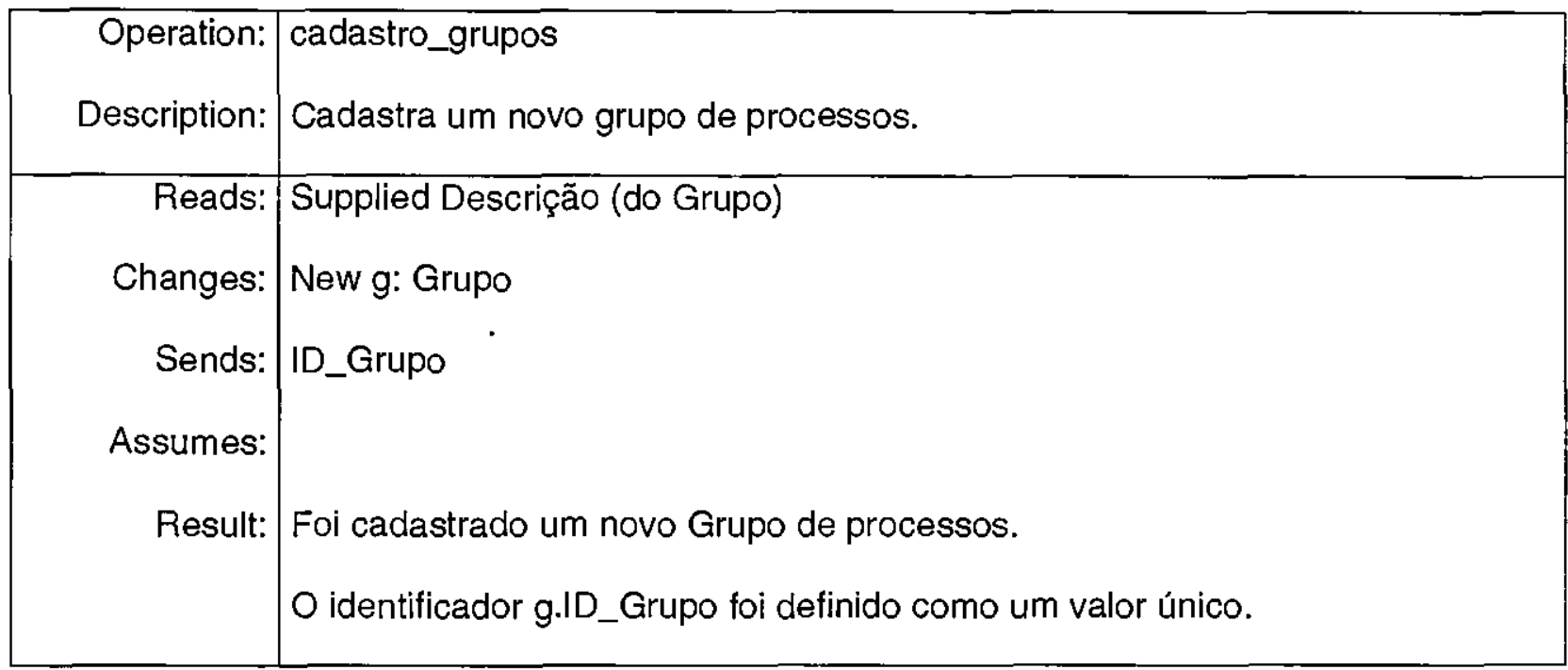

Figura 20 - Operação: Cadastramento de Grupos.

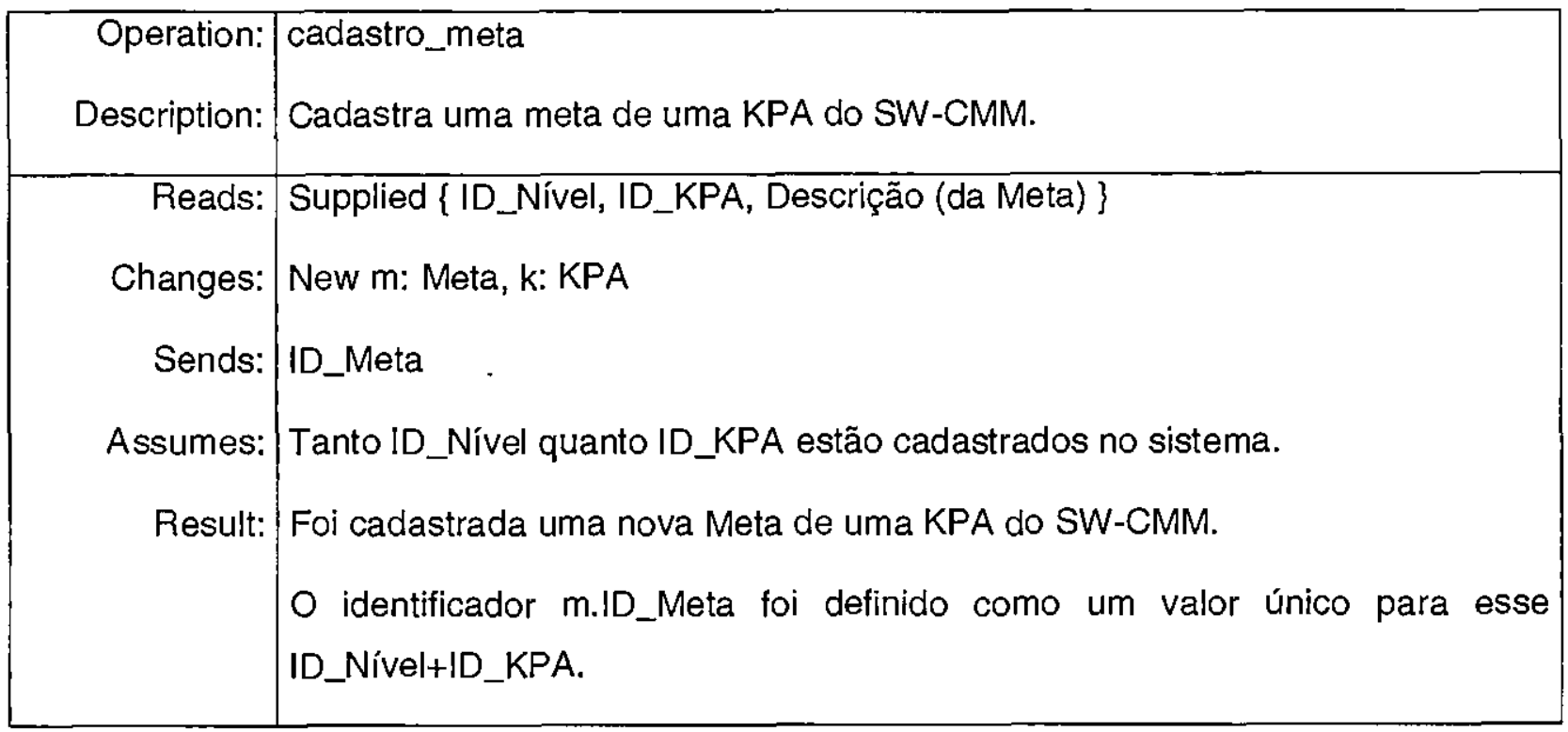

Figura 21 - Operação: Cadastramento de Metas.

Operation: cadastro_questões 


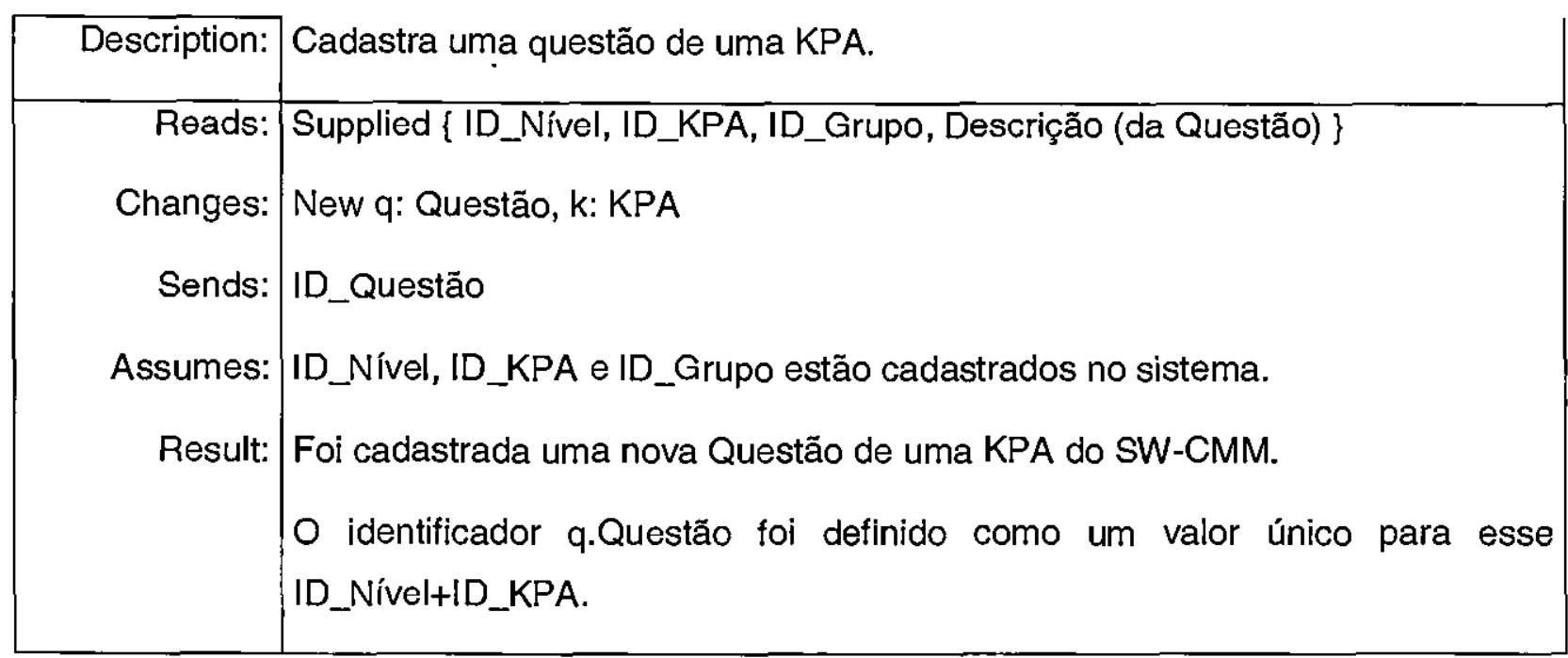

Figura 22 - Operação: Cadastramento de Questões.

\begin{tabular}{|r|l|}
$\begin{array}{r}\text { Operation: } \\
\text { Description: }\end{array}$ & cadastro_metas_x_questões \\
\hline Reads: & Supplied \{ ID_Nível, ID_KPA, ID_Meta, ID_Questão \} \\
Changes: & New f: Formar_Metas, m: Meta, q: Questão \\
Sends: & $\begin{aligned} \text { Assumes: } \\
\text { ID_Nível, ID_KPA, ID_Meta e ID_Questão estão cadastrados no sistema. } \\
\text { Não existe relacionamento previamente cadastrado entre ID_Meta e } \\
\text { ID_Questão } \\
\text { Result: }\end{aligned}$ \\
Um novo relacionamento entre Metas e Questões foi cadastrado.
\end{tabular}

Figura 23 - Operação: Cadastramento de Relacionamentos Metas x Questões.

\begin{tabular}{|r|l|}
\hline $\begin{array}{r}\text { Operation: } \\
\text { Description: }\end{array}$ & $\begin{array}{l}\text { cadastro_composição_questões } \\
\text { Cadastra umi item de composição de uma Questão. }\end{array}$ \\
\hline Reads: & $\begin{array}{l}\text { Supplied \{ ID_Nível, ID_KPA, ID_Questão, Descrição (do item de composição) } \\
\} \\
\text { Changes: }\end{array}$ \\
Nends: & $\begin{array}{l}\text { New composição, q: Questão } \\
\text { ID_Composição }\end{array}$
\end{tabular}




\begin{tabular}{r|l} 
Assumes: & ID_Nivel, ID_KPA e ID_Questão estão cadastrados \\
Result: & $\begin{array}{l}\text { Um novo item de composição de uma Questão foi cadastrado. } \\
\text { O identificador c.ID_Composição foi definido como um valor único para esse } \\
\text { ID_Nível+ID_KPA+ID_Questão. }\end{array}$
\end{tabular}

Figura 24 - Operação: Cadastramento de Composição de Questōes.

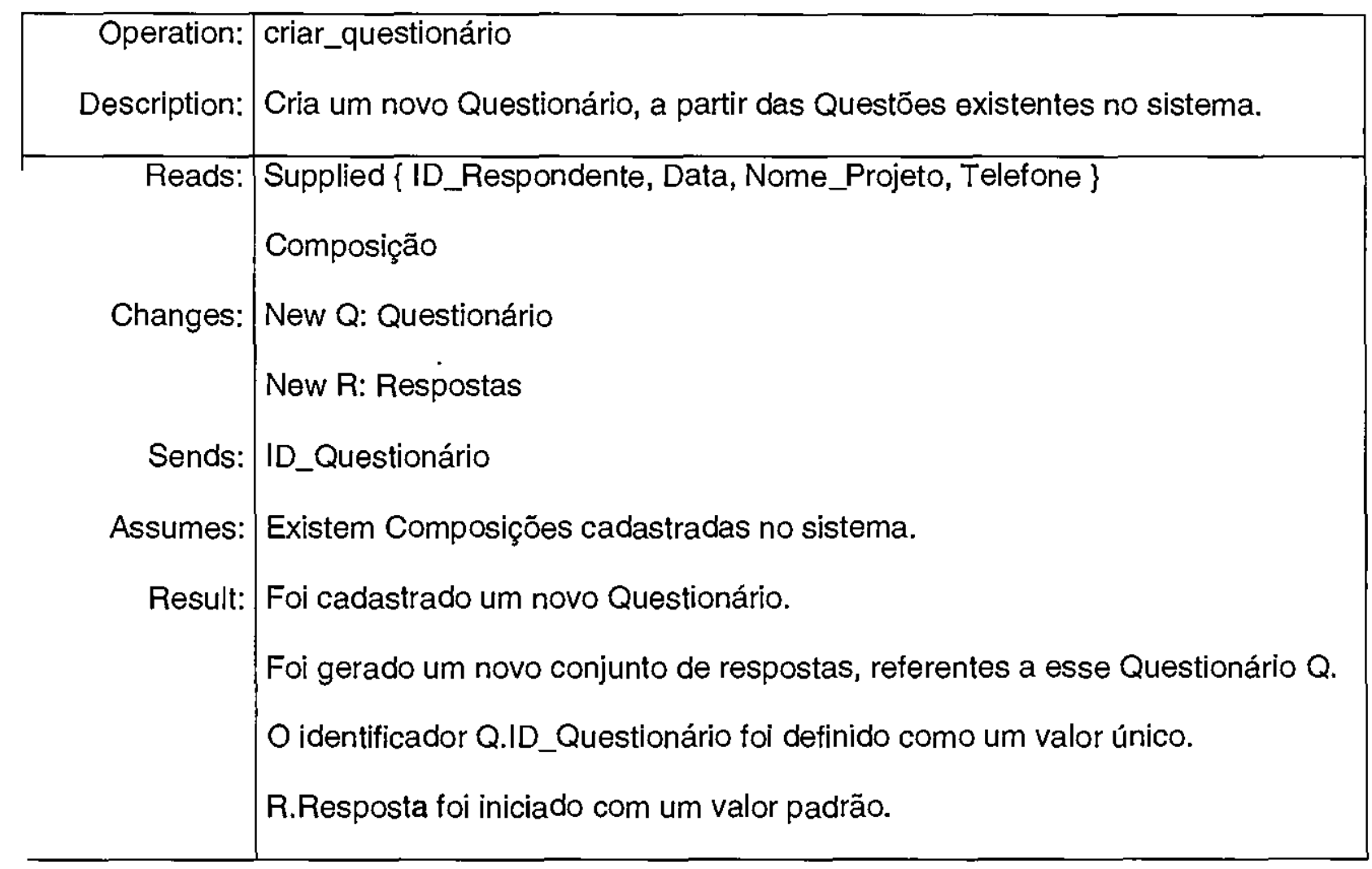

Figura 25 - Operação: Criação de Questionários.

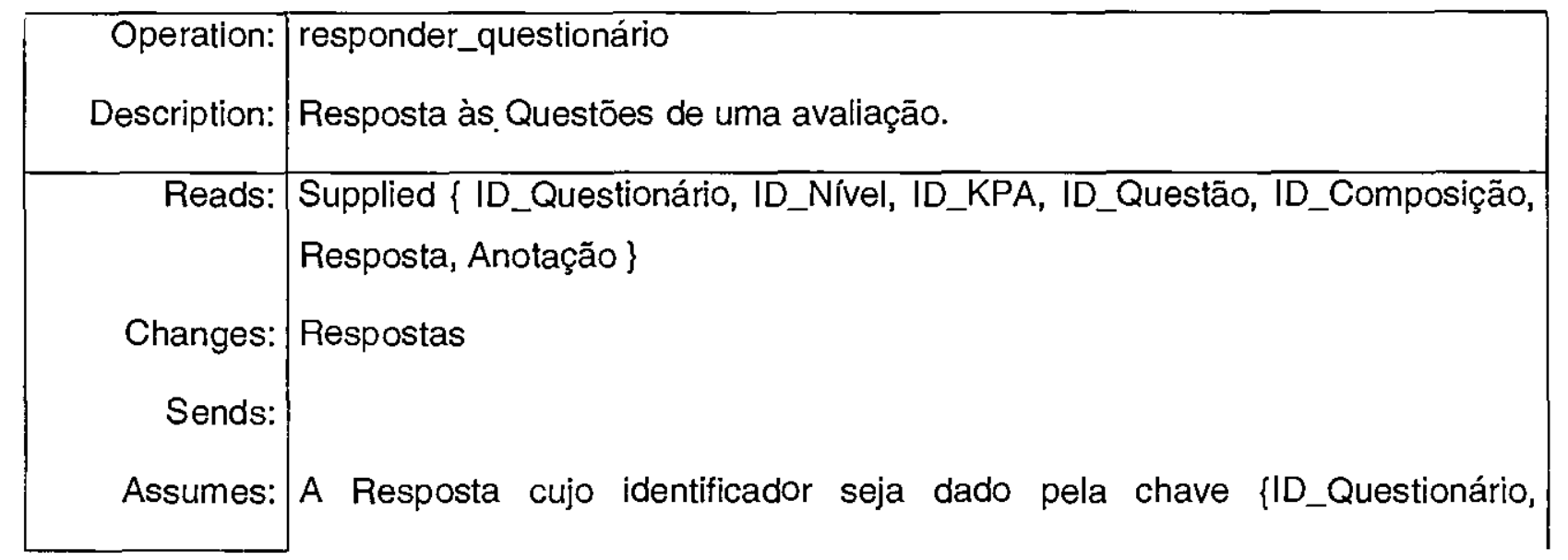




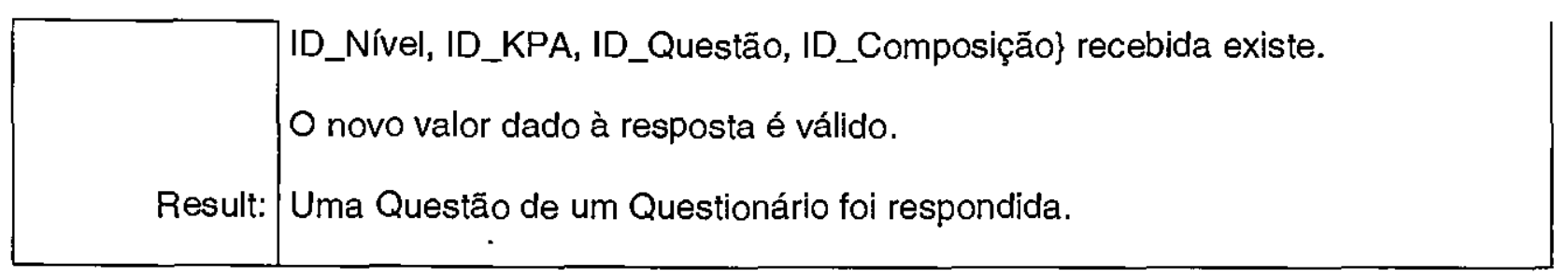

Figura 26 - Operação: Responder Questionário.

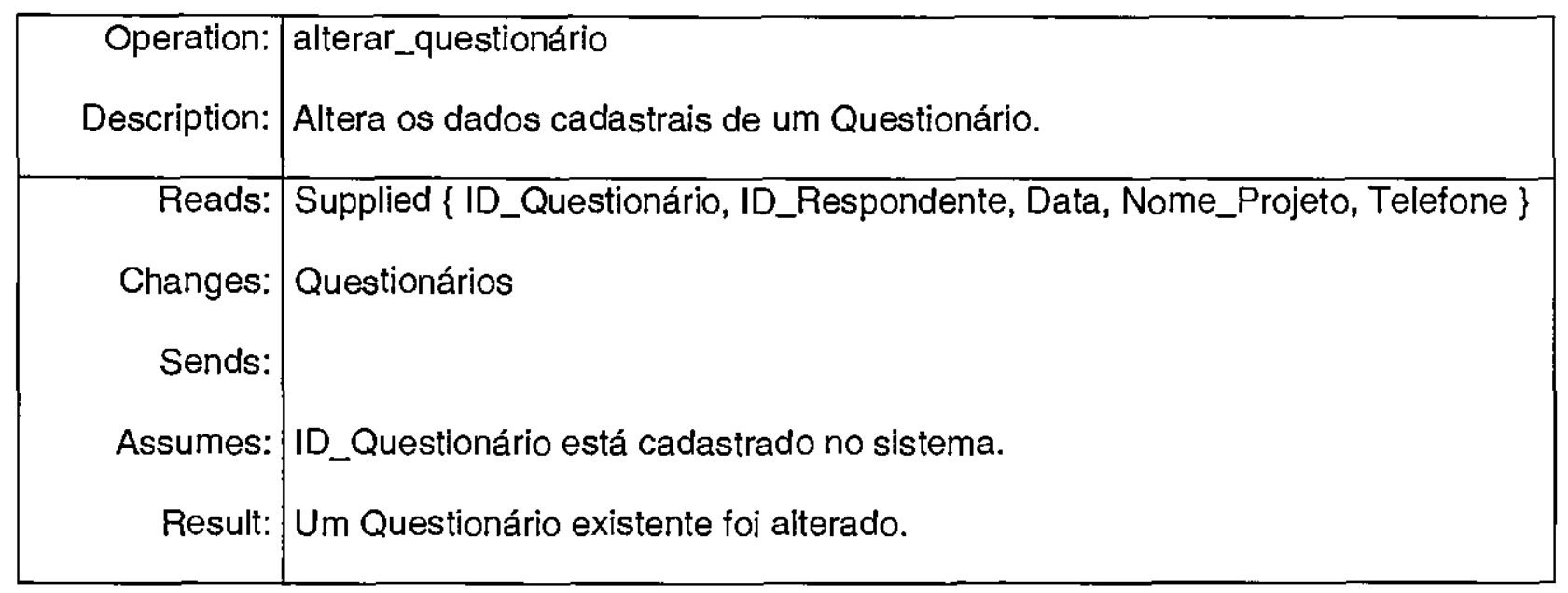

Figura 27 - Operação: Alterar Questionário.

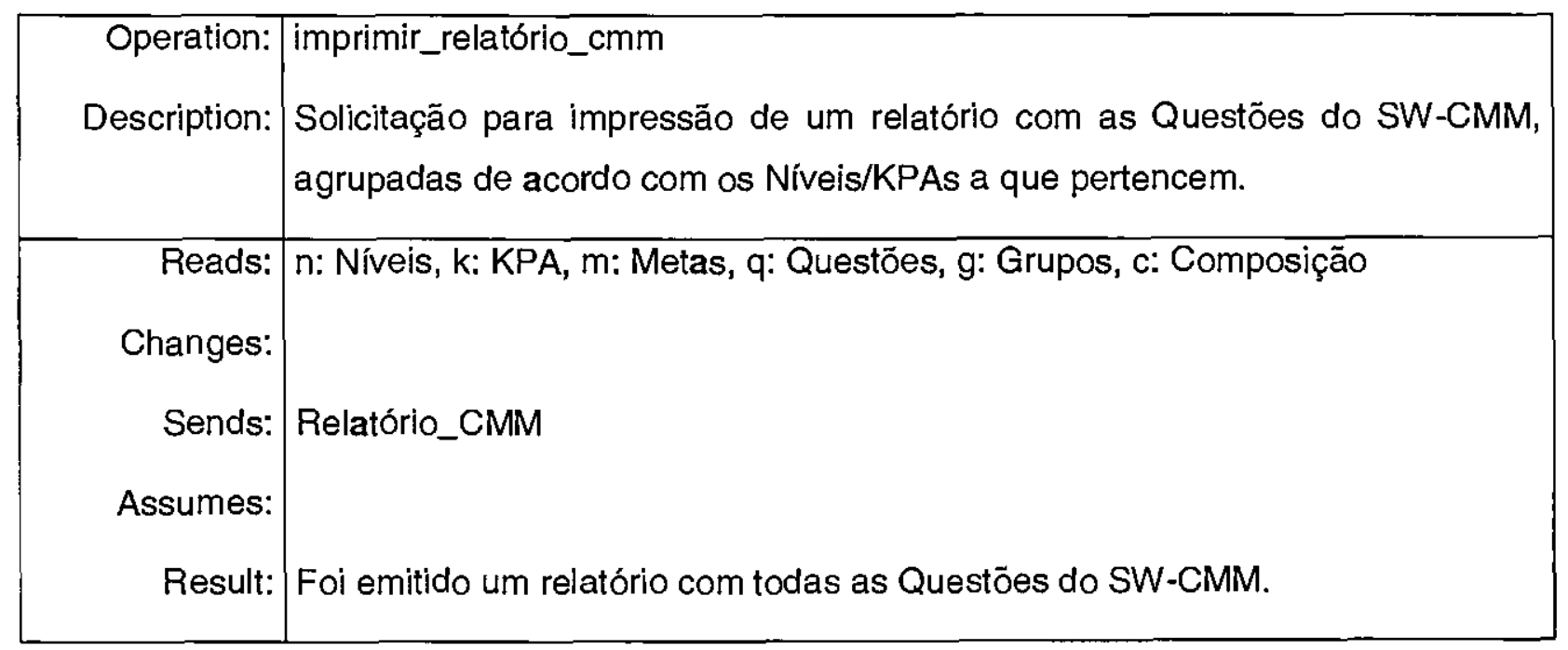

Figura 28 - Operação: Imprimir Relatório SW-CMM. 


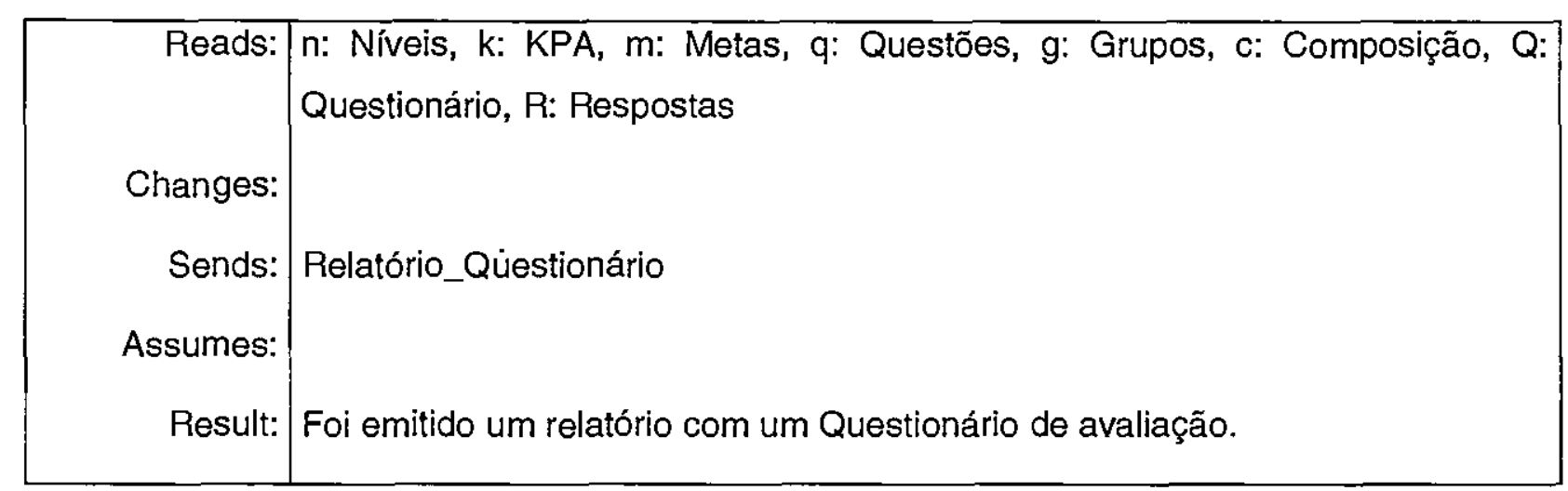

Figura 29 - Operação: Imprimir Relatório de Questões.

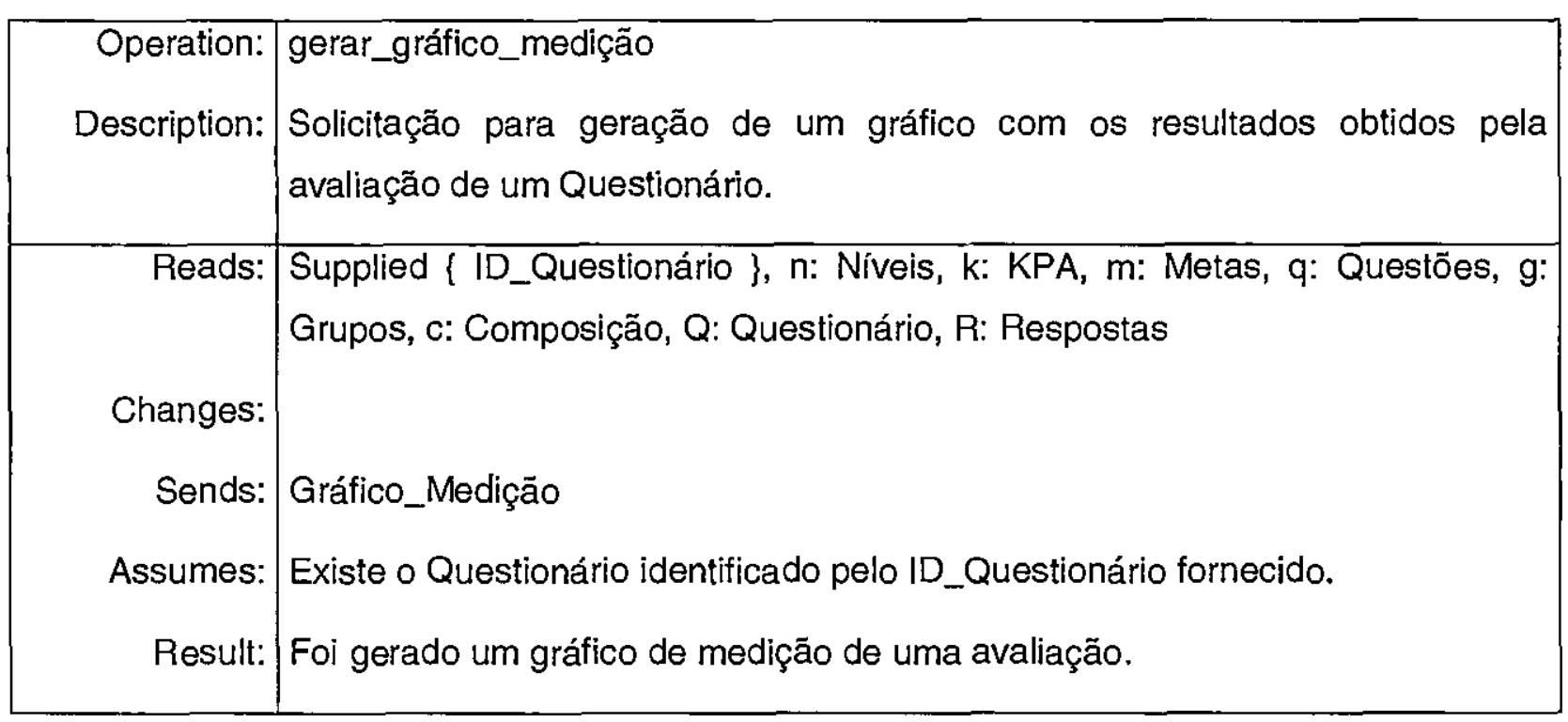

Figura 30 - Operação: Gerar Gráfico de Medição. 


\section{Apêndice B - Documentos da Fase de Projeto da Ferramenta \\ SProQ}

\section{Etapa de Projeto da Ferramenta SProQ}

Este apêndice apresenta os grafos gerados na parte de Projeto do método Fusion aplicado à ferramenta SProQ.

\section{Grafos de Interação de Objetos}

cadastro_kpa

(ID_Nivel: int, Descrição: string)
(1)

ID_KPA=criar(ID_Nivel: Int, Descrição: string): int novo k: KPA

\section{Descrição:}

Operação cadastro_kpa(ID_Nível: int, Descrição: string)

Cadastrar uma nova KPA para o nível dado pelo parâmetro ID_Nível, cujo nome da KPA é dado pelo parâmetrỏ Descrição.

cadastro_grupos

(Descrlção: string)
S: SPROQ
ID_Grupo=criar(Descrição: string) int novo g: Grupo

\section{Descrição:}

Operação cadastro_grupo(Descrição: string)

Cadastrar um novo Grupo, cujo nome é dado pelo parâmetro Descrição.

cadastro_meta

(ID_Nivel: int, ID_KPA: int, Descrição: string) k: KPA novo m: Meta

Descrição: 
Operação cadastro_meta(ID_Nível: int, ID_KPA: int, Descrição: string)

Cadastrar uma nova Meta para a KPA ID_KPA do nível ID_Nível, cujo nome da Meta é dado pelo parâmetro Descrição.

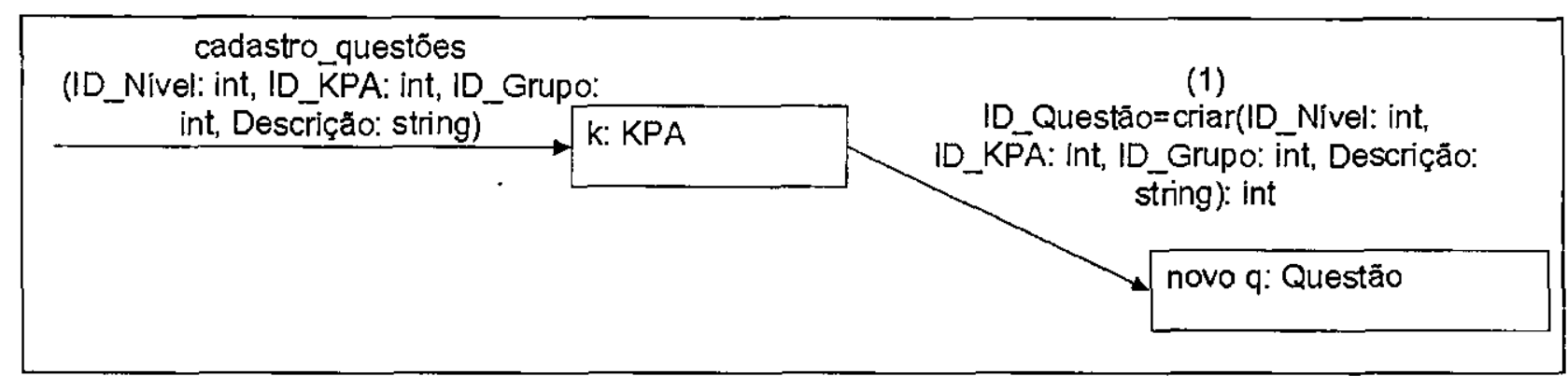

\section{Descrição:}

Operação cadastro_questões(ID_Nível: int, ID_KPA: int, ID_Grupo: int, Descrição: string)

Cadastrar uma nova Questão para a KPA ID_KPA do Nível ID_Nivel, cujo texto da Questão é dado pelo parâmetro Descrição e cujo Grupo é dado pelo parâmetro ID_Grupo.

\section{Descrição:}

Operação cadastro_metas_x_questões(ID_Nível: int, ID_KPA: ID_Meta: int, ID_Questão: int)

Cadastrar um novo relacionamento entre uma Meta e uma Questão, ambas pertencentes a um mesmo Nível (ID_Nível) e KPA (ID_KPA). 
cadastro_composiçăo questōes

(ID_Nivel: int, ID_KPA: int, ID_Questäo: int,

Descrição: string)

q: Questōes

novo c: Composição
(1)

ID_Composiçăo= criar(ID_Nivel: int, ID_KPA: int, ID_Questão: int, Descrição: string): int

\section{Descrição:}

Operação cadastro_composição_questōes(ID_Nivel: int, ID_KPA: int, ID_Questão: int, Descrição: string)

Cadastrar uma nova Composição de uma Questão (ID_Questão) de uma KPA (ID_KPA) do nível ID_Nível, cujo nome texto dessa Composição é dado pelo parâmetro Descrição.

criar_questionário

(ID_Resondente: string, Data: date, Nome_Projeto, Telefone: string)

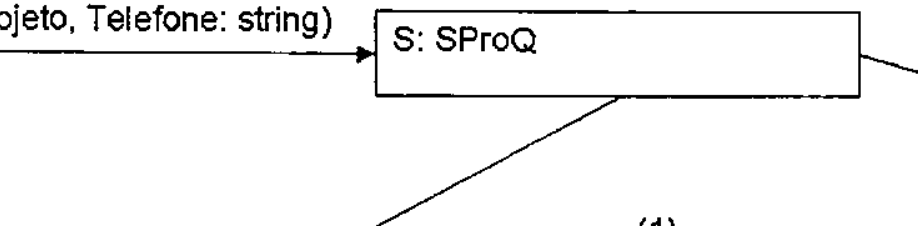

(1)

ID_Questionanio = criar(ID_Resondente: string, Data: date, Nome_Projeto,

novo Q: Questionário

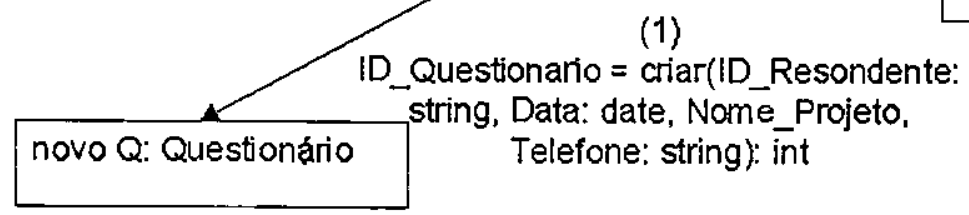

(2)

Instanciar_questరes( ID_Questionário: int) novo r: Resposta

Descrição:

Operação criar_questionário(ID_Respondente: string, Data: date, Nome_Projeto, Telefone: string)

Cadastrar um novo Questionário, onde o respondente é dado pelo parâmetro ID_Respondente, a data é dada pelo parâmetro Data, o nome do projeto é dado pelo parâmetro Nome_Projeto e o telefone de contado do respondente é dado pelo parâmetro Telefone.

Após a criação de um novo registro Questionário, é necessário instanciar cada uma das Questōes cadaștradas no sistema para esse novo Questionário, a fim de que o mesmo possa ser respondido. 


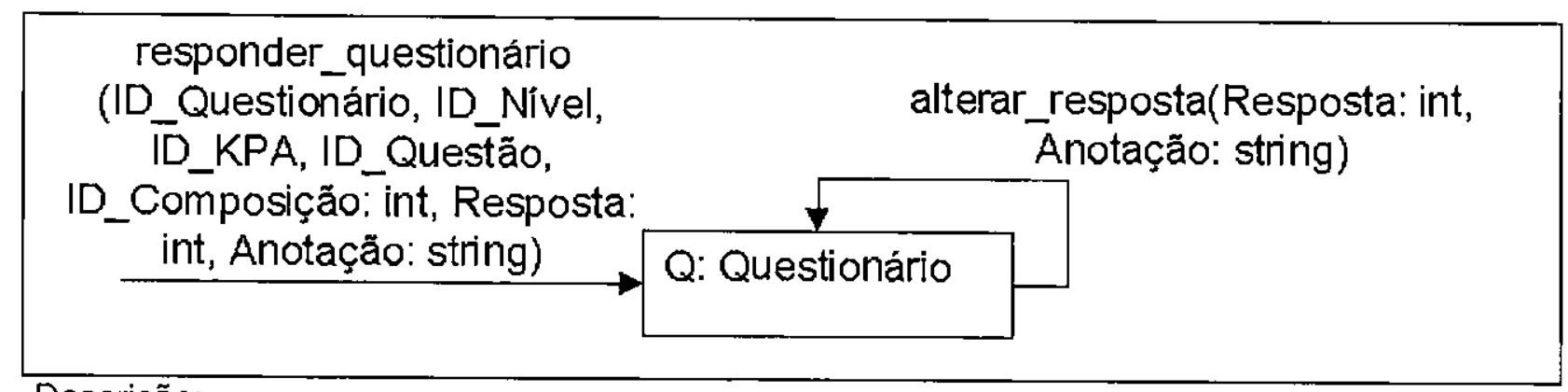

Descrição:

Operação responder_questionário(ID_Questionário, ID_Nível, ID_KPA, ID_Questão, ID_Composição: int, Resposta: int, Anotação: string)

Responder a uma quiestão (ID_Nível, ID_KPA, ID_Questão, ID_Composição) de um questionário (ID_Questionário), onde a resposta à essa questão é dada pelo parâmetro Resposta, e uma possível anotação a ser feita com relação a essa resposta é dada pelo parâmetro Anotação.

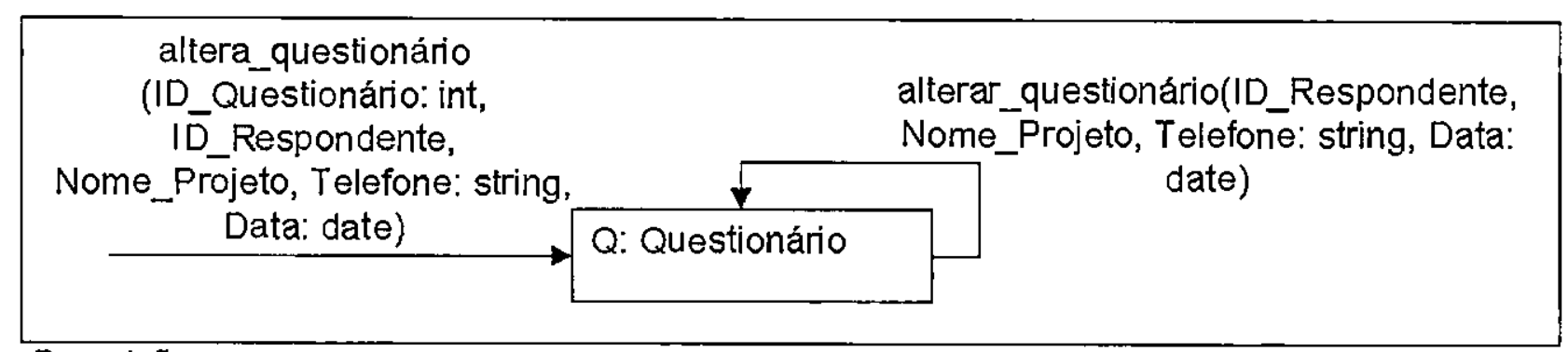

\section{Descrição:}

Operação altera_questionário(ID_Questionário: int, ID_Respondente, Nome_Projeto, Telefone: string, Data: date)

Alterar os dados cadastrais de um Questionário (ID_Questionário), onde o respondente é dado pelo parâmetro ID_Respondente, a data é dada pelo parâmetro Data, o nome do projeto é dado pelo parâmetro Nome_Projeto e o telefone de contado do respondente é dado pelo parâmetro Telefone. 


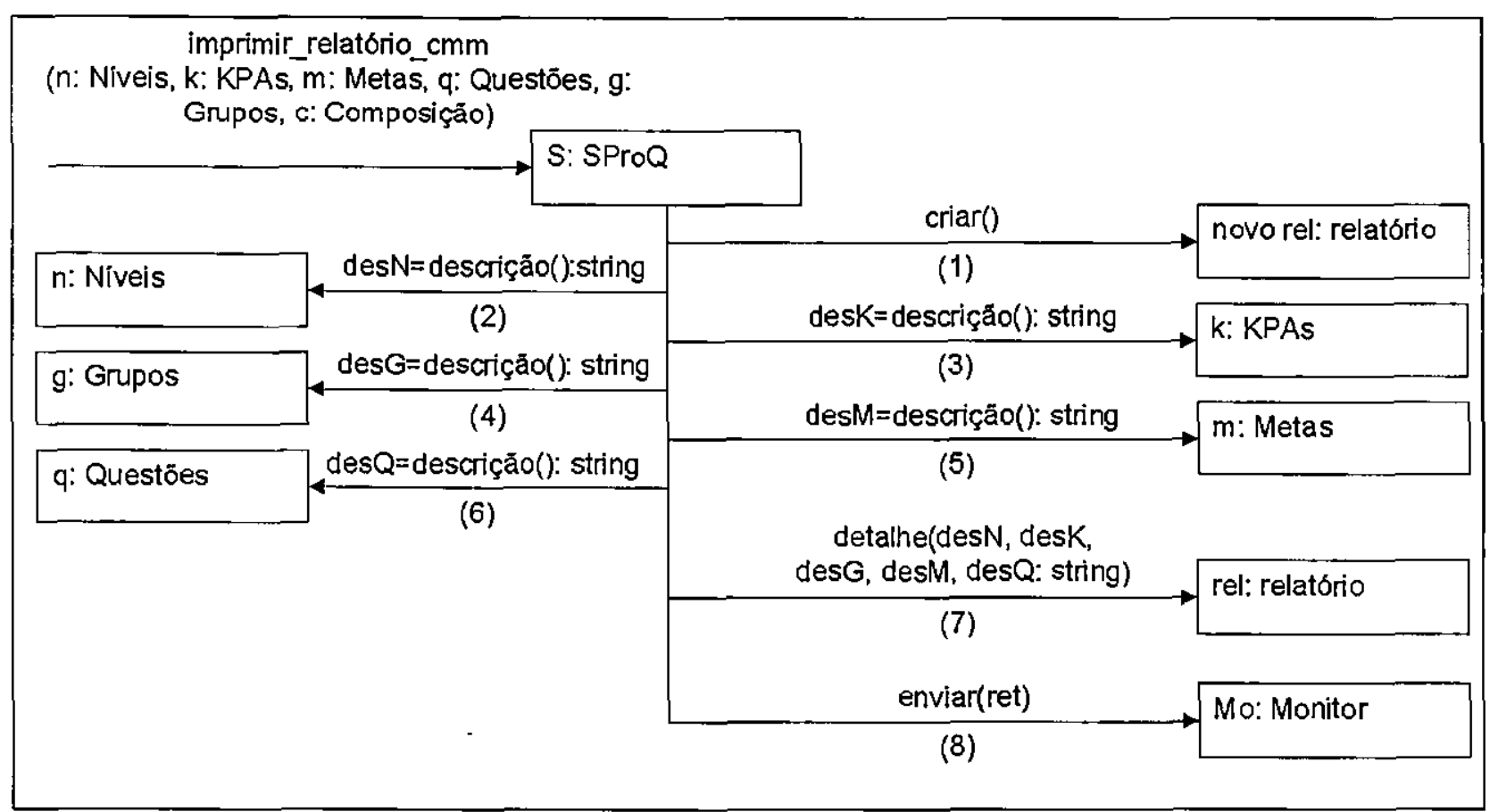

Descrição:

Operação imprimir_relatório_cmm(n: Níveis, k: KPAs, m: Metas, q: Questões, g: Grupos, c: Composição)

Imprimir um relatório com todas as questões do SW-CMM cadastradas, seguindo-se a classificação proposta pelo SEl (Nível $\rightarrow$ KPA $\rightarrow$ Meta $\rightarrow$ Questão). 


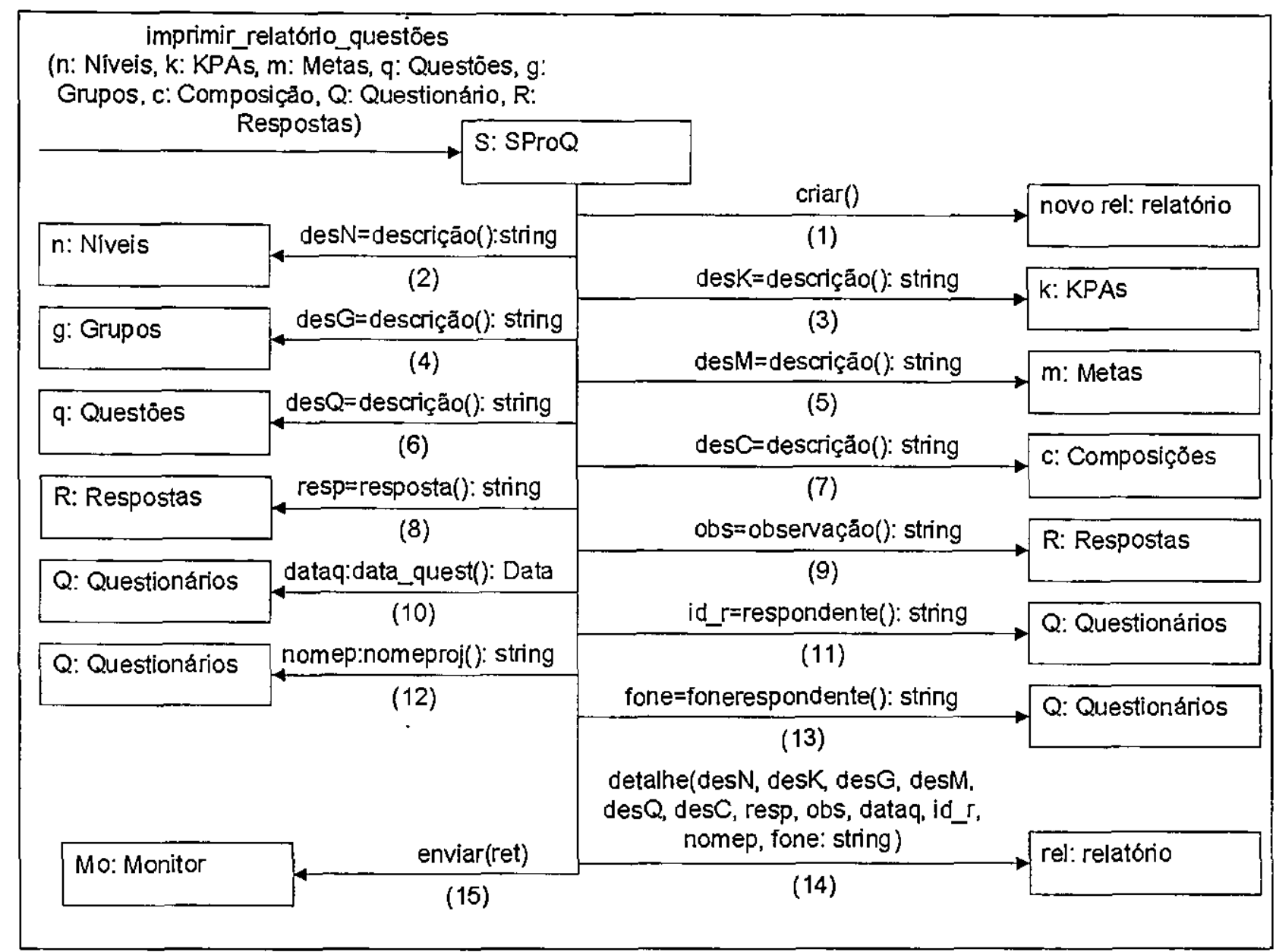

\section{Descrição:}

Operação imprimir_relatório_questões(n: Níveis, k: KPAs, m: Metas, q: Questões, g: Grupos, c: Composição, Q: Questionários, R: Respostas)

Imprimir um relatório com um Questionário de avaliação 


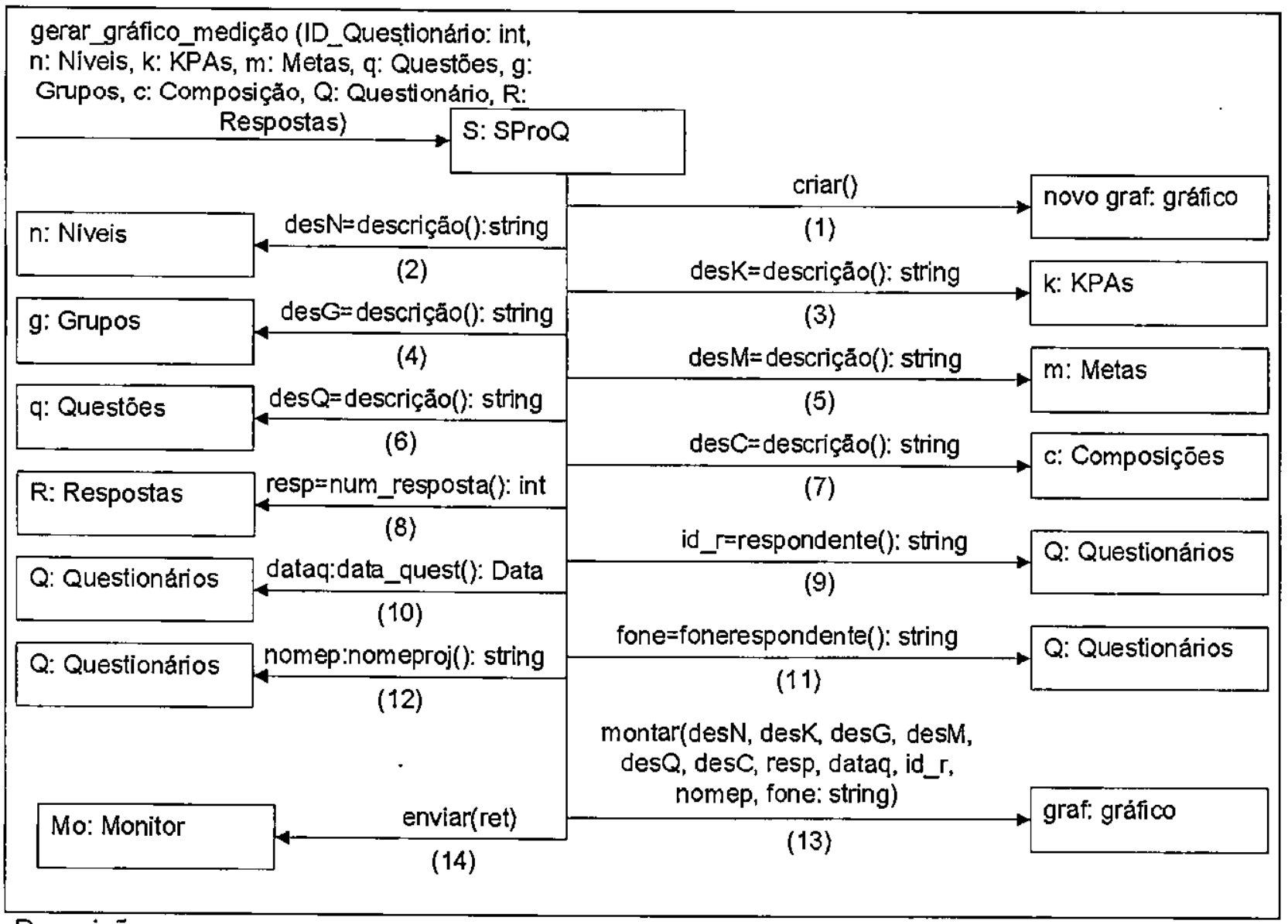

Descrição:

Operação gerar_gráfico_medição(ID_Questionário: int, n: Níveis, k: KPAs, m: Metas, q: Questões, g: Grupos, c: Composição, Q: Questionários, R: Respostas)

Gerar um gráfico de medição sobre uma avaliação feita por um Questionário, indicada pelo parâmetro ID_Questionário.

\section{Grafos de Visibilidade}



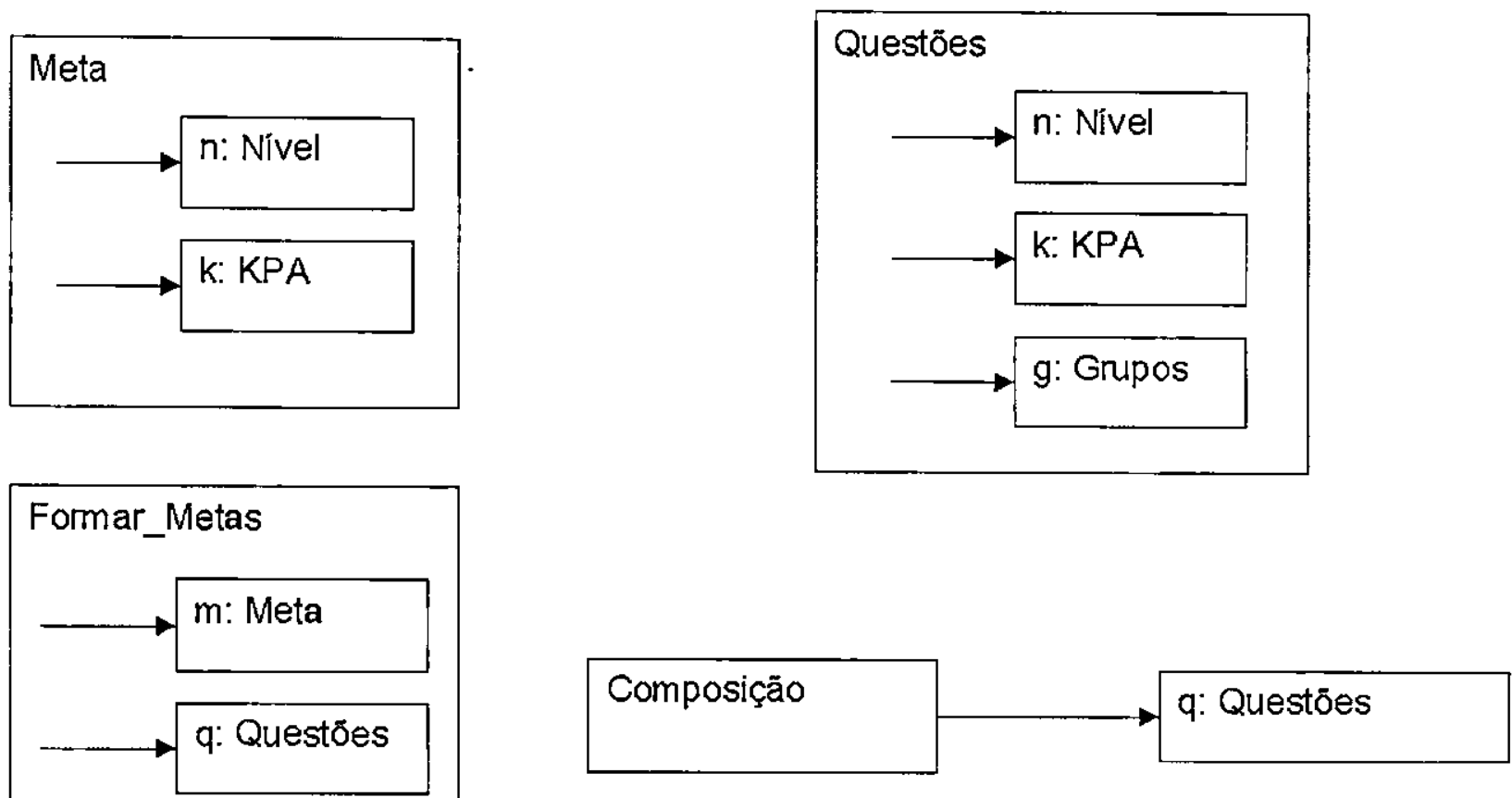

Figura 31 - Grafo de Visibilidade para as Questões do SW-CMM.

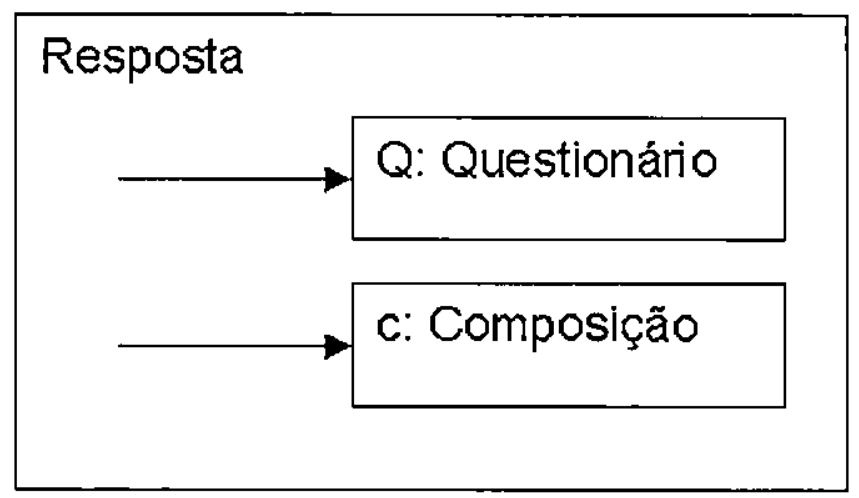

Figura 32 - Grafo de Visibilidade para as Respostas. 


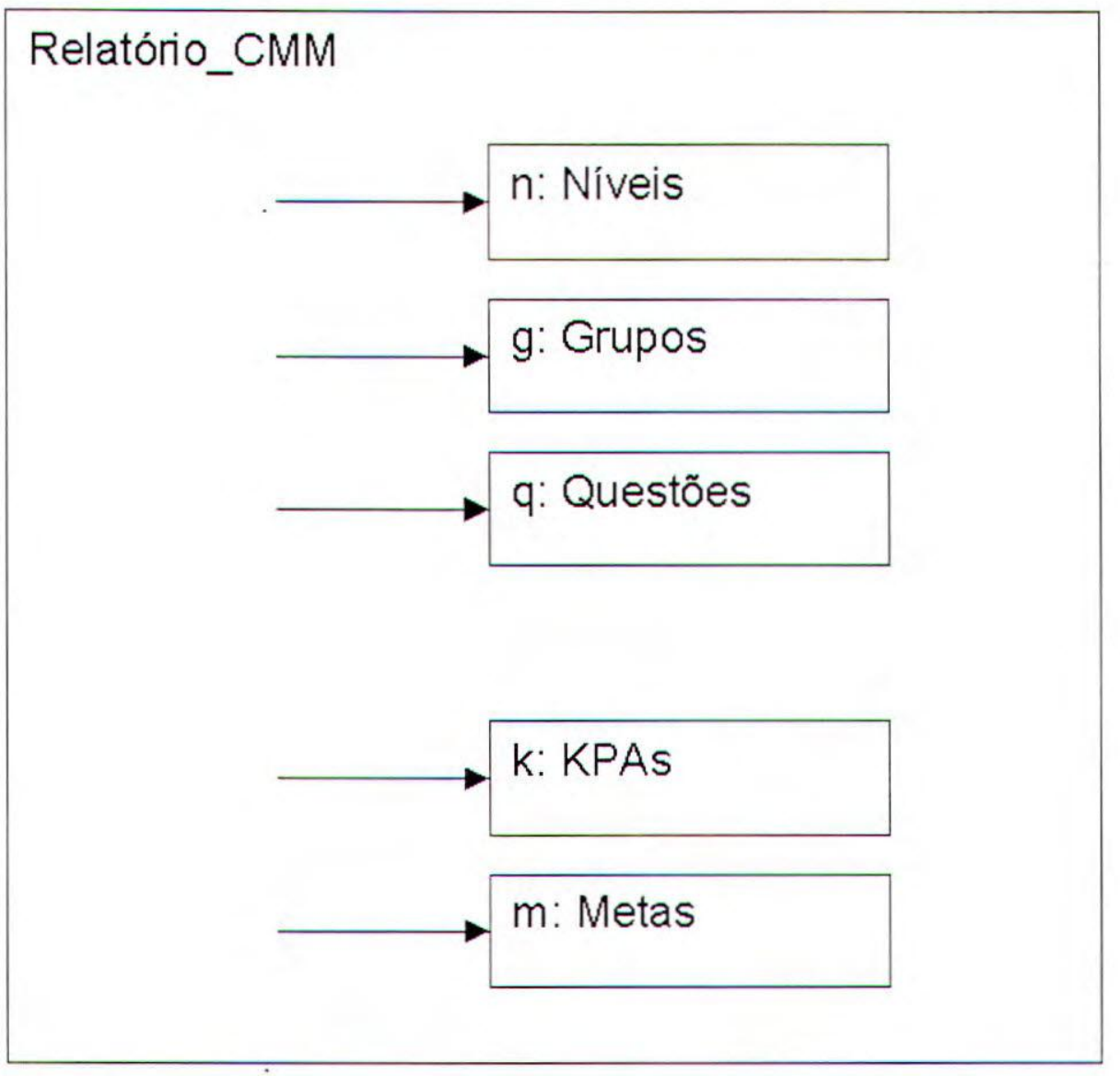

Figura 33 - Grafo de Visibilidade para o Relatório SW-CMM. 


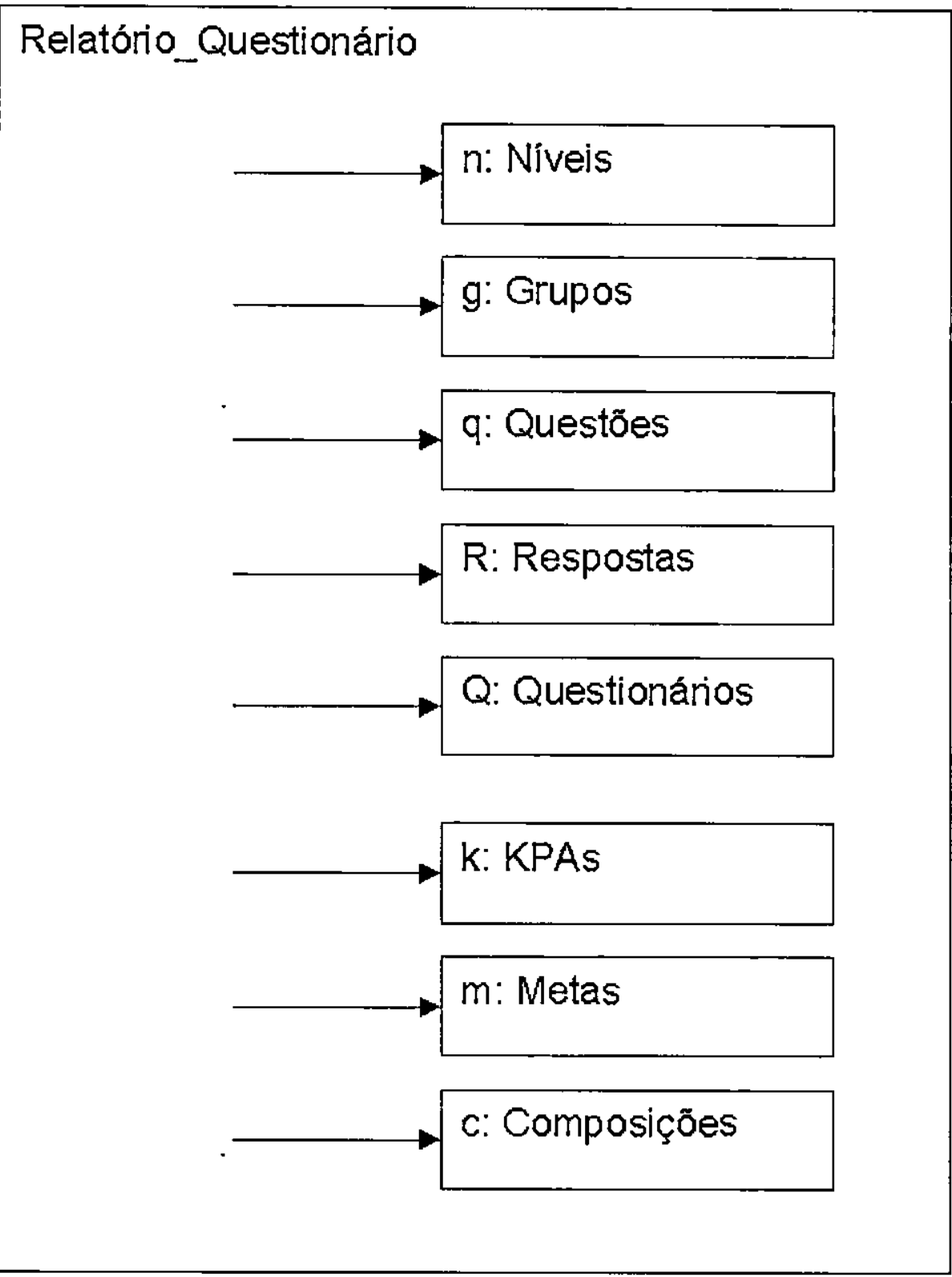

Figura 34 - Grafo de Visibilidade para o Relatório de Questionários. 


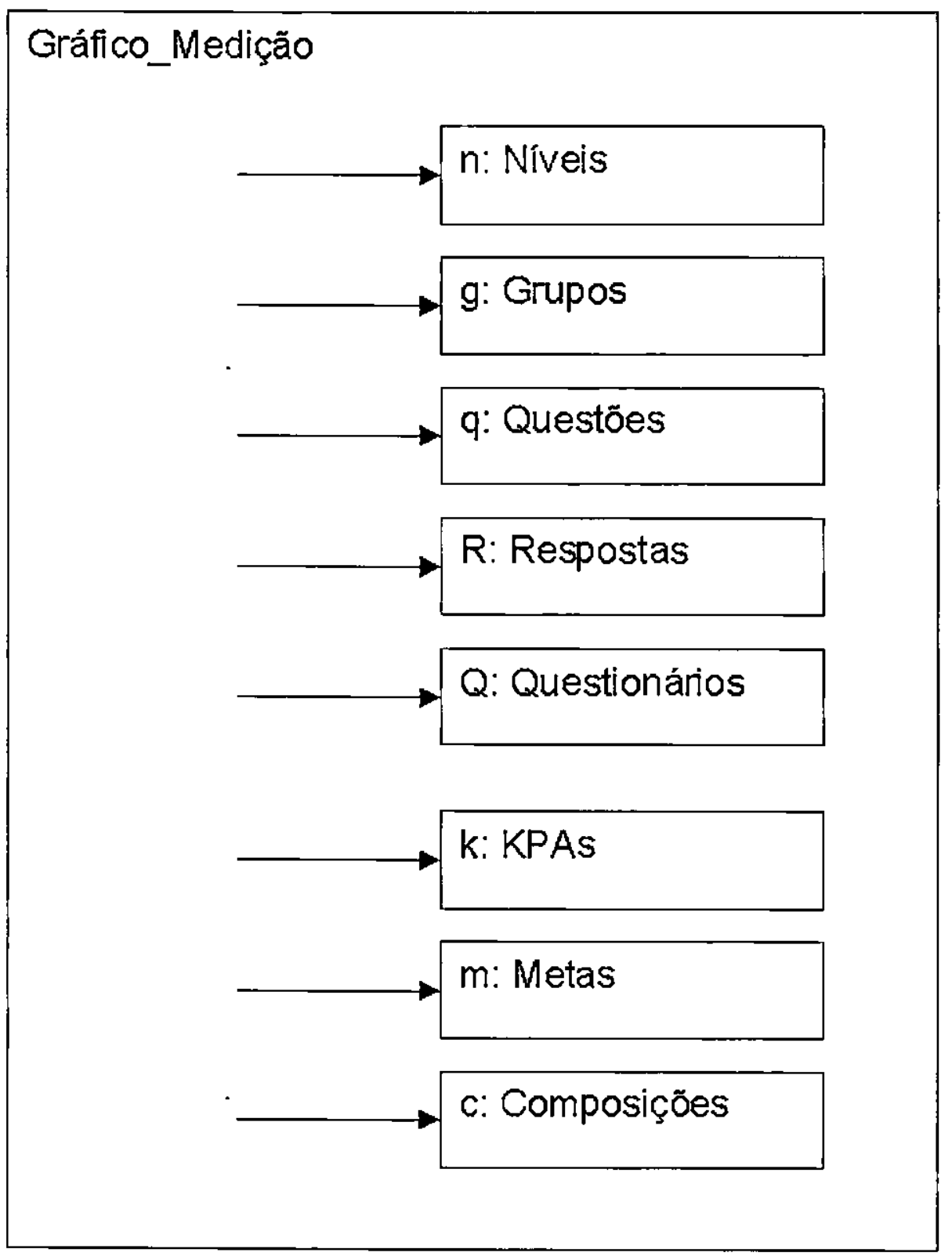

Figura 35 - Grafo de Visibilidade para os Gráficos.

\section{Descrições de Classes}

class Questionários

// atributos da classe

attribute ID_Questionário: int

attribute ID_Respondente: string 
attribute Data: date

attribute Nome_Projeto: string

attribute Telefone: string

// métodos da classe

method criar(ID_Respondente: string, Data: date, Nome_Projeto, Telefone: string): int method instanciar_questōes(ID_Questionário: int)

endclass

class Níveis

// atributos da classe

attribute ID_Nível: int

attribute Descrição: string

// métodos da classe

method criar(Descrição: string): int;

endclass

class KPAs

// atributos da classe

attribute $\mathrm{n}$ : bound Niveis

attribute ID_KPA: int

attribute Descrição: string

$/ /$ métodos da classe

method criar(ID_Nível: int, Descrição: string): int;

endclass 


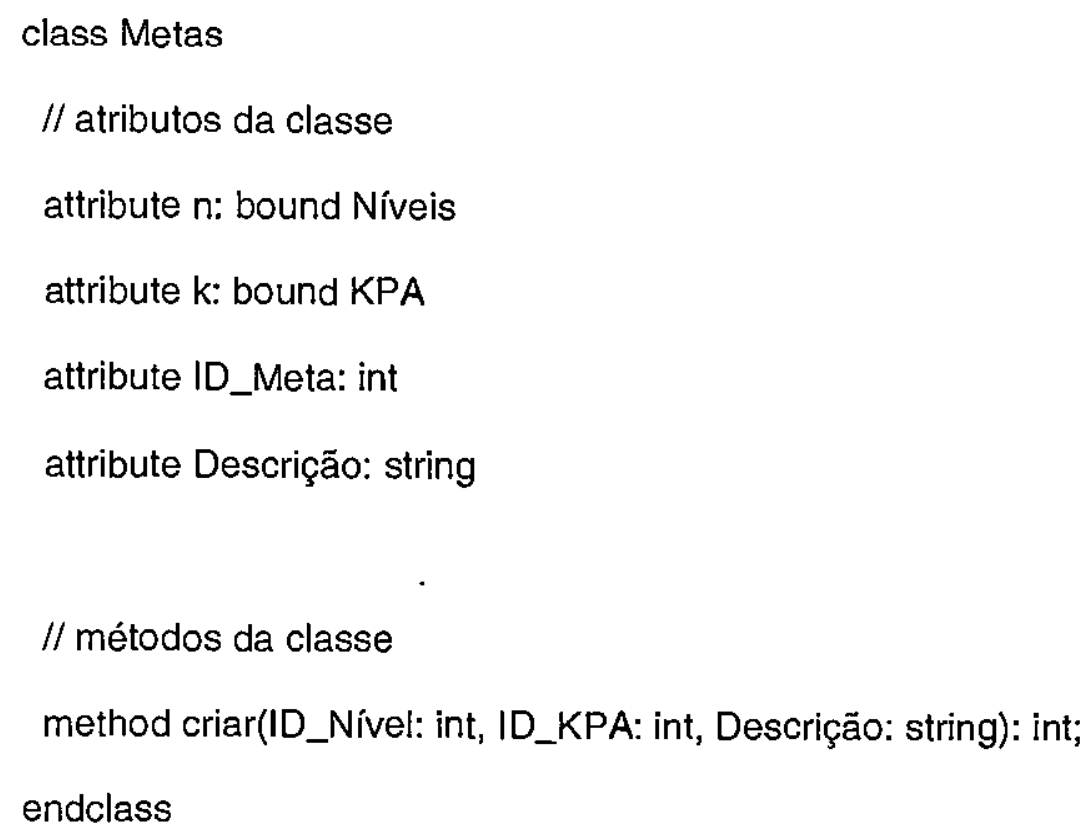

\section{Telas de Interface com o Usuário}

A seguir são apresentadas algumas das telas presentes na interface da ferramenta SProQ. 


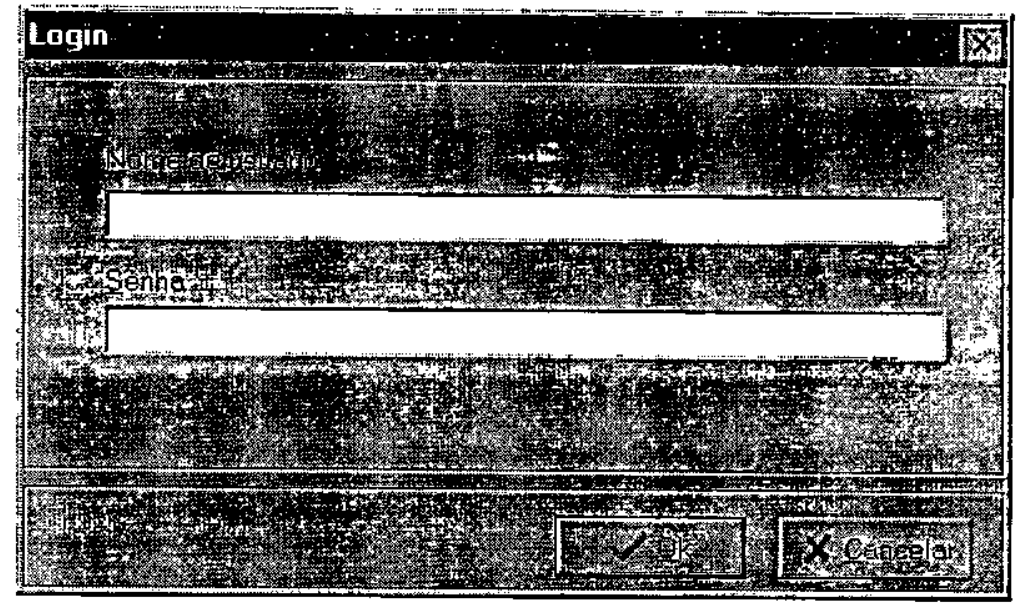

\section{Figura 36 - Tela de Login.}

É utilizada para a digitação do nome e senha do usuário, para que o mesmo possa ser validado pelo sistema gerenciador de banco de dados da ferramenta SProQ.

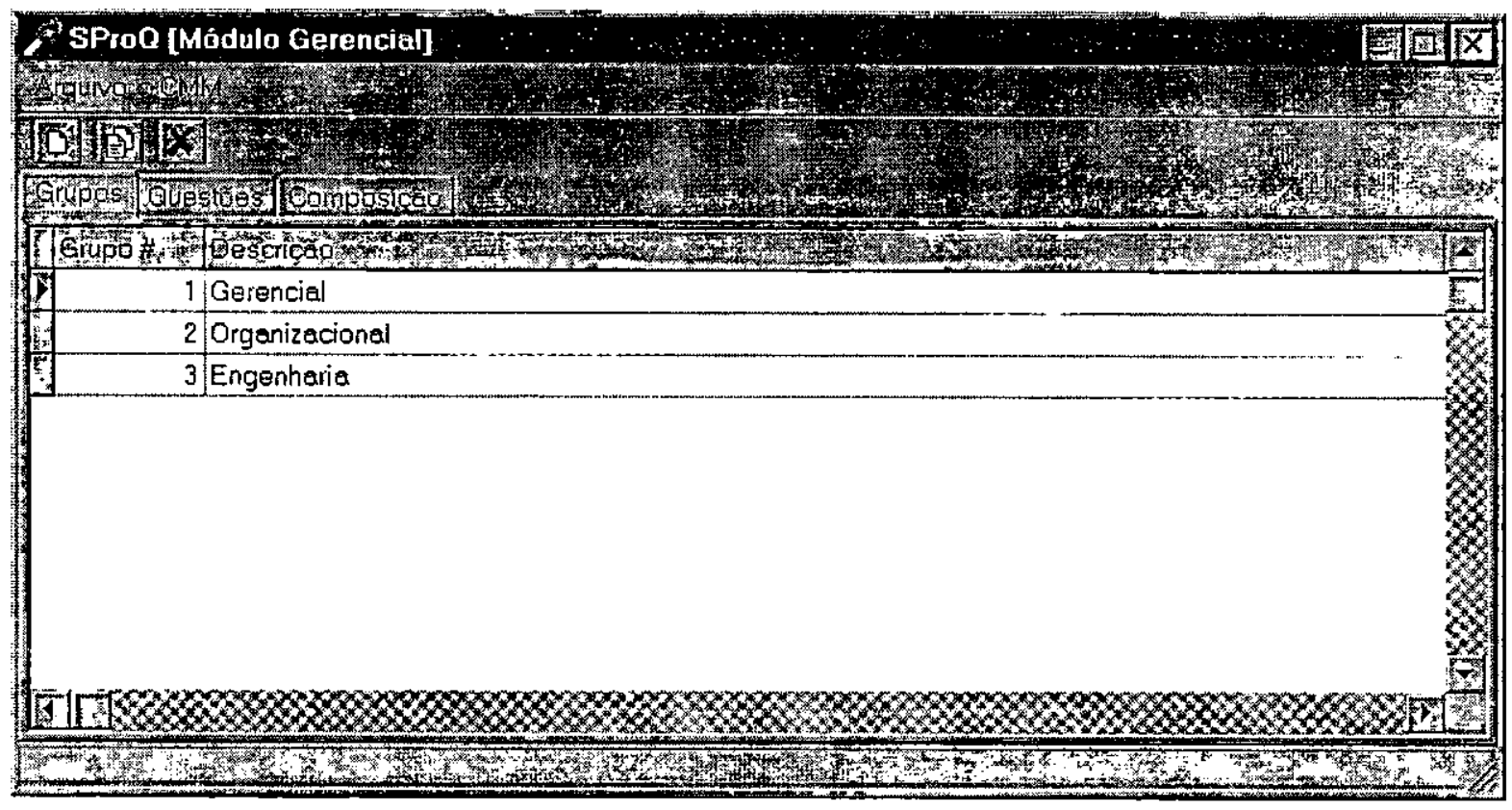

Figura 37 - Tela de Visualização de Grupos de Processo.

Utilizada para visualizar os grupos de processo do SW-CMM. 


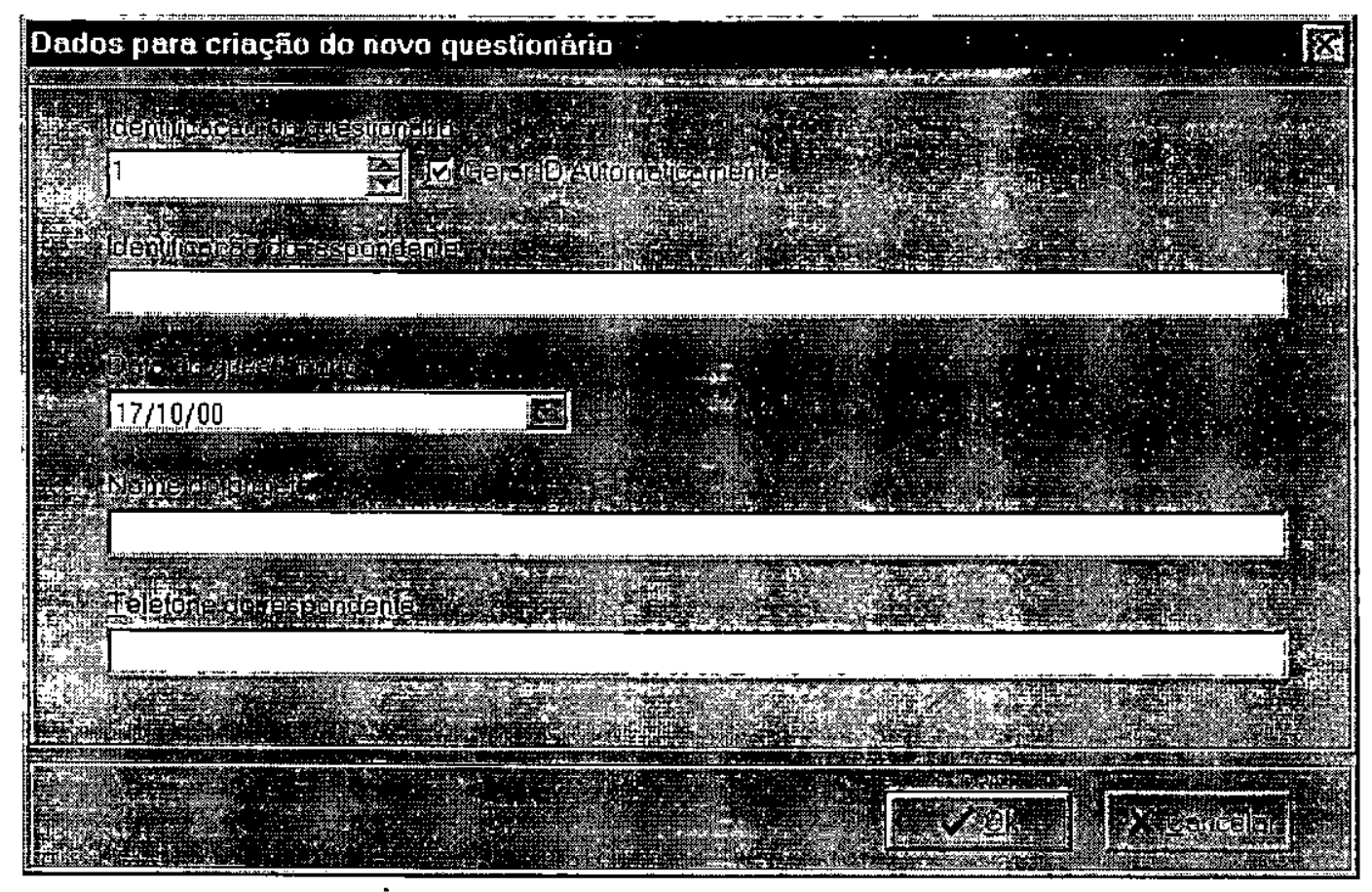

Figura 38 - Tela de Cadastramento de um novo Questionário.

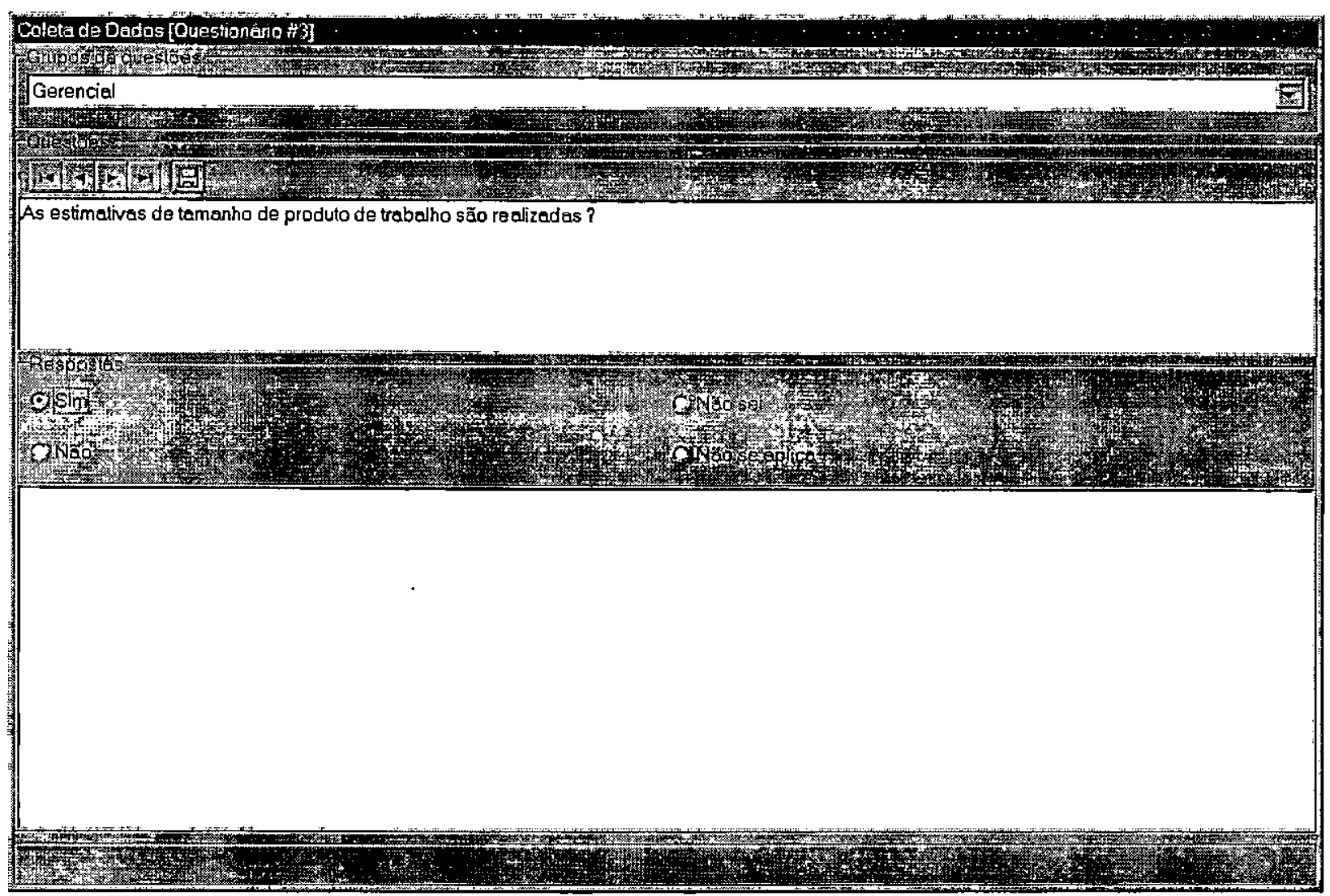

Figura 39 - Tela de Visualização/Alteração das Respostas dos Questionários. 


\section{Apêndice C - O Plano de Avaliação da Estratégia para Iniciar \\ Melhoria de Processo de Software}

1. Introdução

1.1 Objetivo

1.2 Escopo

1.3 Papéis e Responsabilidades

- Patrocinador

- Gerente Sênior

- Participantes

- Avaliadores

1.4 Termos-Chave

1.5 Referências

2. Atividades de Avaliação

2.1 Condução da Avaliação

2.2 Consolidação e Validação dos Dados

2.3 Realização do Julgamento das Medidas

3. Reporte dos Resultados

3.1 Reporte dos Resultados da Avaliação

3.2 Proteção de Informações Confidenciais

3.3 Preservação das Gravações

4. Estimativas de Cronograma e Recursos

4.1 Cronograma

4.2 Recursos

Plano de Avaliação de Processo de Software

1. Introdução do Plano

1.1 Objetivo 
O objetivo deste plano é orientar a realizaçāo de avaliação de processo de software visando melhoria interna. Este plano contém informaçōes que auxiliam a organizar, conduzir e acompanhar as tarefas necẹssárias para que uma avaliação de processo de software seja realizada.

O plano proposto auxilia a identificação de pontos fortes e fracos de uma organização em relação a um modelo de referência: Nível 2 do SW-CMM.

\subsection{Escopo}

O plano é proposto para ser utilizado por pequenas empresas ou por organizaçōes grandes que possuam seus próprios centros de desenvolvimento de sistemas, para utilização interna. $\mathrm{Na}$ identificação do Escopo é necessário definir um projeto dentro da organização que deve ser avaliado. Esse projeto é uma instância do processo de software que tenha seu próprio orçamento e cronograma.

\subsection{Papéis e Responsabilidades}

Apresenta-se nessa subseção as responsabilidades atribuídas para cada parte envolvida na avaliação:

- Patrocinador. é responsável pelo respaldo financeiro da avaliação. Muitas vezes esse papel é desempenhado pelo próprio responsável pela organização como o seu dono ou o diretor de uma empresa;

- Gerente sênior. é responsável pela garantia do andamento da avaliação, fornecendo todos os recursos, a disponibilidade da equipe avaliada e outros tipos de suportes que não sejam a parte financeira. Muitas vezes o patrocinador e o gerente sênior se confundem numa mesma pessoa. Isso não impede que a avaliação tenha sucesso.

- Participantes da Avaliação: são aqueles envolvidos com o projeto que participarão do processo de avaliação, respondendo aos questionários e fornecendo qualquer outro tipo de informação. Devem ser escolhidos de maneira a serem representativos dentro do projeto. A preparação desses participantes deve ser realizada ministrando-se palestras sobre o SWCMM e sobre o contexto de melhoria de processo;

- Avaliadores: são os responsáveis pela avaliação. Geralmente é necessário montar uma equipe de avaliadores com um líder. Esse avaliador pode ser uma pessoa, devidamente treinada da própria organização. $O$ avaliador deve ter conhecimento prévio de conceitos de engenharia de software, do modelo SW-CMM e o modelo IDEAL.

\subsection{Termos-Chave}


- Áreas-chave: práticas do modelo SW-CMM que evidenciam cumprimento de atividades de engenharia de software;

- SW-CMM: Capability Maturity Model, modelo de maturidade de processo de software;

- Garantia de qualidade: atividade de engenharia de software que oferece gerenciamento do processo que está sendo usado e do produto que está sendo construído;

- Gerenciamento de configuração: atividade de engenharia de software que tem como função manter a integridade dos produtos de software;

- GQM: Goal-Question-Metric abordagem que auxilia a condução de uma pesquisa

- IDEAL: Initiating, Diagnosing, Acting, Establishing, Learning, abordagem de melhoria de processo de software proposta pela SEl;

- Nível de maturidade: cada uma das categorias que o SW-CMM classifica as organizações;

- Metas: os objetivos que devem ser cumpridos para implementação de cada área-chave;

- Práticas-chave: tarefas que devem ser cumpridas em cada área-chave. Elas podem ser classificadas como: compromisso para realizar, condições para desempenhar, tarefas, medições e análise verificação;

- Processo de software: envolve políticas, responsabilidades, custos, cronogramas, enfim todas as variáveis que influenciam o desenvolvimento de um software;

- SEl: Software Engineering Institute, orgão governamental dos EUA com a sede na Universidade de Carnegie-Mellon.

\subsection{Referências}

- Engenharia de Software

- PRESSMAN, R. S., Engenharia de Software, 3ed, Rio de Janeiro, Makron Books, 1995;

- Qualidade de Software

- KAN, S. H., Metrics and Models in Software Quality Engineering, Addison-Wesley, EUA, 1995;

- PAULK, M. C.; CURTIS, B.; CHRISSIS, M. B., Capability Maturity Model for Software, versão 1.1, CMU/SEI-93-TR-24, fevereiro, 1993;

- GREMBA, J.;MYERS, C., The IDEAL Process Model: A Practical Guide for Improvement, http://www.sei.cmu.edu/activities/ldeal/ideal.bridge.Html, [acessado em 25/08/98];

- MASTERS S.; BOTHWELL C., CMM Appraisal Framework versão1.0, Relatório Técnico TR-95-001, Software Engineering Institute, 1995. 
- Elaboração de Planos

- ANSI/IEEE Standard for Software Project Management Plans, IEEE Software Engineering Standards Collection, primavera, 1991; .

- PACHECO, R. F.; SANCHES R., Gerenciamento de Configuração de Software, Relatório Técnico - ICMSC, n. 57, junho, 1997.

2. Atividades de Avaliação

\subsection{Condução da Avaliação}

É proposta a utilização do questionário elaborado (com base no nível 2 do SW-CMM e nas métricas propostas pelo Questionário de Maturidade da SEI), que tem como função capturar as informações necessárias para os objetivos da avaliação e pertinentes ao escopo escolhido na seção 1.1 e seção 1.2 deste plano, respectivamente.

Propõe-se que a aplicação do questionário seja realizada através de entrevistas individuais com os participantes da avaliação definidos na seção 1.3 deste plano. $O$ tempo de duração de cada entrevista não deve exceder uma hora. As informações que necessitam ser comprovadas através de documentos devem ser conferidas pessoalmente pelo avaliador.

\subsection{Consolidação e Validação dos Dados}

A validação consiste em verificar se as repostas dos questionários não apresentam dados inconsistentes, se não existem questões que não foram respondidas, ou que tenham mais de uma resposta e verificar possíveis ocorrências de erros.

Os dados coletados devem ser agrupados por área-chave, isso é realizado automaticamente pela disposição das questōes no questionário. Cada conjunto de respostas deve ser analisado para verificar o cumprimento ou não de cada área-chave do nível 2.

\subsection{Realização do Julgamento das Medidas}

A partir das informações da atividade anterior é possivel julgar cada área-chave segundo os valores: satisfeito, não satisfeito, não aplicável e não medido. No questionário proposto, todas as perguntas de cada área-chave devem ser respondidas sim para que a área-chave seja considerada satisfeita.

3. Reporte dos Resultados 


\subsection{Reporte dos Resultados da Avaliação}

Nesta seção deve ser explicitada a maneira como os resultados serão reportados. Um relatório com informações como o escopo, objetivos, data, local e informações sobre os resultados da avaliação, bem como análise dos resultados deve ser apresentada.

Os resultados podem ser apresentados graficamente através de diagramas de barras, de pizza, gráficos ou mesmo dispostos em tabelas para facilitar a sua visualização. Além do relatório, os resultados podem também ser relatados em forma de uma apresentação expondo todas as informações que sejam de interesse dos patrocinadores e gerente sênior.

\subsection{Proteção de Informações Confidenciais}

A confidencialidade das informações deve ser garantida. É importante que sejam definidos o que pode e como podem ser divulgadas essas informações através de publicações e outros meios. Além disso, a confidencialidade das informações entre os membros da própria organização deve ser estabelecida, para garantir a individualidade de cada participante.

\subsection{Preservação das Gravações}

É importante realizar um histórico das anotações, observações, qualquer informação que possa ser útil: para os avaliadores para aperfeiçoar o processo de avaliação, e para os avaliados e patrocinadores para poder realizar pesquisas posteriores.

\section{Estimativas de Cronograma e Recursos}

\subsection{Cronograma}

O cronograma deve conter o tempo requerido para cada atividade da avaliação, separadamente. Como exemplo, o período para coleta de dados e tempo requerido para realizar a análise das informações.

O cronograma pode ser apresentado em forma de diagrama de tarefas que permite visualizar paralelismo entre as atividades, se houver.

\subsection{Recursos}

Descreve os recursos que devem estar disponiveis para realizar a avaliação. Como exemplo, podemos citar, sala de reuniões, recursos áudio-visuais para palestras, salas para realizar entrevistas individuais e outros. 



\section{Apêndice D - O Questionário de Avaliação da Estratégia para Iniciar Melhoria de Processo de Software}

\section{Informações Gerais}

Este documento apresenta um questionário para avaliar aspectos gerenciais do processo de software tomando como base o nivel 2 do Modelo CMM (Capability Maturity Model).

O questionário deve ser preenchido durante entrevistas, quando também serão realizadas orientações explicativas sobre as questões nele contidas.

Esse questionário faz parte de um processo de avaliação baseado num plano de avaliação para processo de software e pretende caracterizar o processo de software segundo as 6 áreaschaves propostas pelo nível 2 do SW-CMM.

\section{Elaboração do Questionário}

Para a elaboração do questionário utilizou-se um método denominado Goal-Question-Metric (GQM) [Basili], o qual já foi empregado em muitos projetos de pesquisas em Engenharia de Software [Rombach]

Esse método fornece um mecanismo que orienta a determinação dos objetivos de interesse da análise e o refinamento de cada objetivo em um conjunto de questões como propósito para quantificar os mesmos. Tais questöes definem um conjunto específico dos dados a serem coletados.

\subsection{Objetivos da Coleta de Dados}

\begin{tabular}{|l|l|}
\hline Objeto & Processo de Software \\
\hline Propósito & Verificar a qualidade do Processo \\
\hline Foco de Qualidade & Áreas-chave do nível 2 do SW-CMM \\
\hline Ponto de Vista & Administrativo \\
\hline Ambiente & Grupo de Desenvolvimento de Software \\
\hline
\end{tabular}

\subsection{Lista de Questões}


O questionário contém questōes que dizem respeito a implementação e institucionalização das áreas-chave propostas pelo nível 2 do SW-CMM. Essas questões estão organizadas, em grupos, segundo as metas de cada uma das 6 (seis) áreas-chave desse nível. As perguntas são baseadas nas tarefas que devem ser realizadas para atingir cada meta proposta.

As respostas serão consideradas informações confidenciais.

3. Instruções para Preenchimento do Questionário

1. As quatro possiveis respostas para cada questão são: Sim, Não, Não se Aplica e Não Sei.

A reposta Sim deve ser assinalada quando:

A prática é bem estabelecida e desempenhada consistentemente.

(A prática pode ser desempenhada quase sempre e permite considerar bemestabelecida e consistentemente desempenhada como um procedimento padrão)

A resposta Não deve ser assinalada quando:

A prática não é bem estabelecida ou é realizada inconsistentemente.

(A prática pode até ser desempenhada, mas é omitida diante de alguma dificuldade)

A resposta Não se Aplica deve ser assinalada quando:

A prática em questão não se aplica ao contexto avaliado.

(Por exemplo, todas as questões em relação ao Gerenciamento de Subcontratados de Software, quando não existe parte do projeto sob responsabilidade de um subcontratado)

A resposta Não Sei deve ser assinalada quando:

Não está seguro da resposta

2. Qualquer tipo de anotação em relação às questões pode ser acrescentada nos espaços assinalados reservados no fim de cada meta.

3. Todas as questões devem ser respondidas assinalando apenas uma opção. 
4. Referências

1. Capability Maturity Model Pratices, CMU/SEI-93-TR-25, Web-site da SEl em http://www.sei.cmu.edu/

2. Capability Maturity Model Appraisal Framework Version 1.0, CMU/SEl-95-TR-001, Web-site da SEl em http://www.sei.cmu.edu/

3. Capability Maturity Model - Based Appraisal for Internal Process Improvement (CBA IPI): Method Description, CMU-96-TR-007, Web-site da SEI http://www.sei.cmu.edu

4. BASILI, V.R.; CALDEIRA,G. e ROMBACH, H.D.Goal-Question-Metric Paradigm, Encyclopedia os Software Engineering, John Wiley \& Sons, Nova York, v.1, p.527-532, 1995

5. ROMBACH, H. D., A Controled Experiment on the Impact of Software Structure on Maintainability, IEEE Transaction on Software Engineering, v.SE-13, 1987. 


\section{Questionário}

\section{Informações sobre o Respondente}

Identificação do Respondente:

Data: 1

Nome do Projeto:

Telefone:

\section{Questões}

\section{Gerenciamento de Requisitos}

A finalidade dessa área-chave é estabelecer um entendimento comum entre o cliente e a equipe do projeto sobre os requisitos alocados ao software. Isso envolve documentar e controlar os requisitos do cliente e manter os planos, produtos e atividades consistentes com esses requisitos.

\section{Meta1}

Os requisitos do software serem controlados por uma linha de referência (baseline) para o uso da engenharia de software e no gerenciamento.

Sim Não Não se aplica Não sei

1: O grupo de engenharia de software revisa os requisitos alocados antes deles serem incorporados
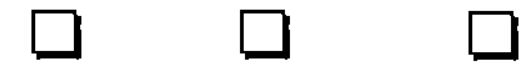
ao projeto de software? 
Anotaçōes:

\section{Meta2}

Os planos de software, produtos e atividades serem mantidos consistentes com os requisitos do software.

\section{Sim Não Não se aplica Não sei}

2: O grupo de engenharia de software usa os requisitos como base para os planos do software, produtos de trabalhos e atividades?

3: As mudanças nos requisitos alocados são revistas e incorporadas ao projeto de software?

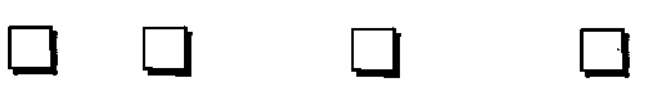

Anotações:

\section{Planejamento de Projeto de Software}

A finalidade dessa área-chave é estabelecer planos razoáveis para desenvolver e gerenciar o processo de software. Isso envolve desenvolver estimativas, determinar os compromissos e definir um plano para realizar o trabalho. Esse plano deve conter o ciclo de vida do projeto de software, uma lista de produtos a serem entregues ao cliente, prazos, estimativas para o nível de esforço, recursos, ferramentas de suporte e riscos do projeto.

\section{Meta1}


As estimativas de software serem documentadas para serem utilizadas no planejamento e acompanhamento do projeto de software.

Sim Não Não se aplica Não sei

9: As estimativas de tamanho de produto de trabalho são realizadas ?

10: As estimativas de esforço e custos de projeto de software são realizadas ?

11: As estimativas para o projeto de recursos computacionais críticos são realizadas ?

12: O cronograma do projeto de software é estabelecido?
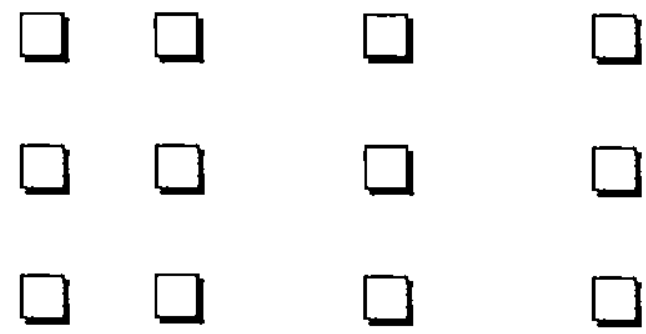

$\square$

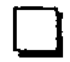

15: Todas as informações obtidas durante o planejamento de software são registradas ?

Anotações:

\section{Meta2}

As atividades de projeto de software e compromissos serem planejados e documentados.

Sim Não Não se aplica Não sei

2: O planejamento do projeto de software é iniciado antes e em paralelo com o planejamento geral do
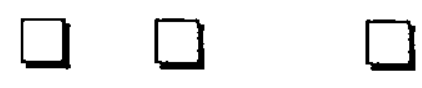
projeto?

5: Um ciclo de vida com estágios pré-definidos de tamanho e de gerenciável são identificados ou
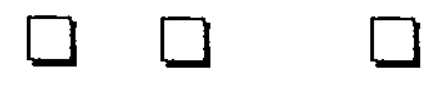
definidos?

6: O plano de desenvolvimento do projeto de software é desenvolvido?

7: Esse plano de desenvolvimento para o projeto de software é documentado? 
8: Identificam-se os produtos de trabalhos de software que são necessários estabelecer e manter controle no projeto de software?

13: Os riscos de software associados aos custos, recursos, cronograma e aspectos técnicos do projeto

são identificados, avaliados e documentados?

14: Os planos para as atividades de engenharia de software e ferramentas de suportes são preparados?
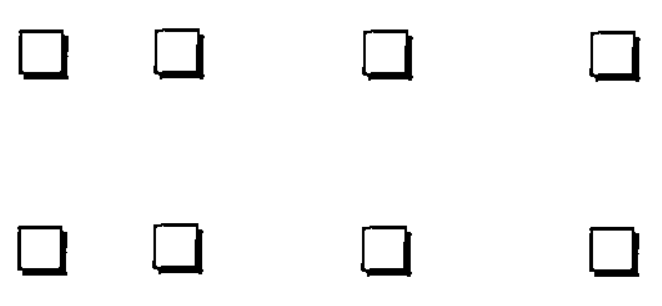

Anotações:

\section{Meta3}

Os grupos e os indivíduos envolvidos obedecerem aos seus compromissos relacionados ao projeto de software.

Sim Não Não se aplica Não sei

1: O grupo de engenharia de software participa da equipe que propõe o projeto?

3: O grupo de engenharia de software participa com outros grupos envolvidos no planejamento geral do
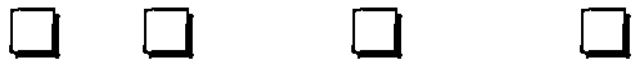
projeto durante toda a vigência do projeto?

4: Os compromissos do projeto de software atribuídos a grupos ou indivíduos externos à organização são revistos pelo gerente sênior?

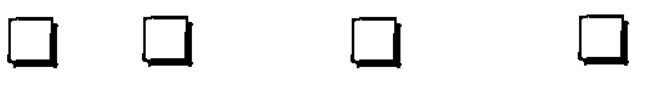

Anotaçōes: 


\begin{abstract}
Acompanhamento e Supervisão de Projeto de Software
A finalidade dessa área-chave é oferecer visibilidade adequada do progresso real do projeto, de modo que o gerenciamento possa tomar medidas efetivas quando o desempenho se desvia significativamente do plano. Isso envolve acompanhar e revisar os resultados e as realizações do software confrontando com as estimativas documentadas, compromissos e planos. Envolve, também, ajustar os planos com base nos resultados e realizações efetivamente alcançados. Os mecanismos utilizados para isso podem ser revisões internas e revisões formais com clientes. Quando ocorre um desvio entre os planos e os resultados efetivos, deve-se alterar a forma como o trabalho está sendo feita e/ou ajustar os planos.
\end{abstract}

\title{
Meta1
}

Os resultados reais e desempenho do projeto serem acompanhados em relação ao plano de software.

Sim Não Não se aplica Não sei

1: Um plano de desenvolvimento de software documentado é usado para acompanhar as atividades de software e para comunicar a situação atual?

5: O tamanho do produto de trabalho de software (ou o tamanho da mudança no produto e trabalho de software) são acompanhados e ações corretivas são realizadas se necessário?

6: O esforço e o custo do projeto de software são acompanhados e ações corretivas são tomadas se necessário?

7: Os recursos críticos do projeto são acompanhados e ações corretivas são tomadas se necessário?

8: O cronograma do projeto de software é acompanhado e ações corretivas são tomadas se necessário?

9: As atividades técnicas de engenharia de software
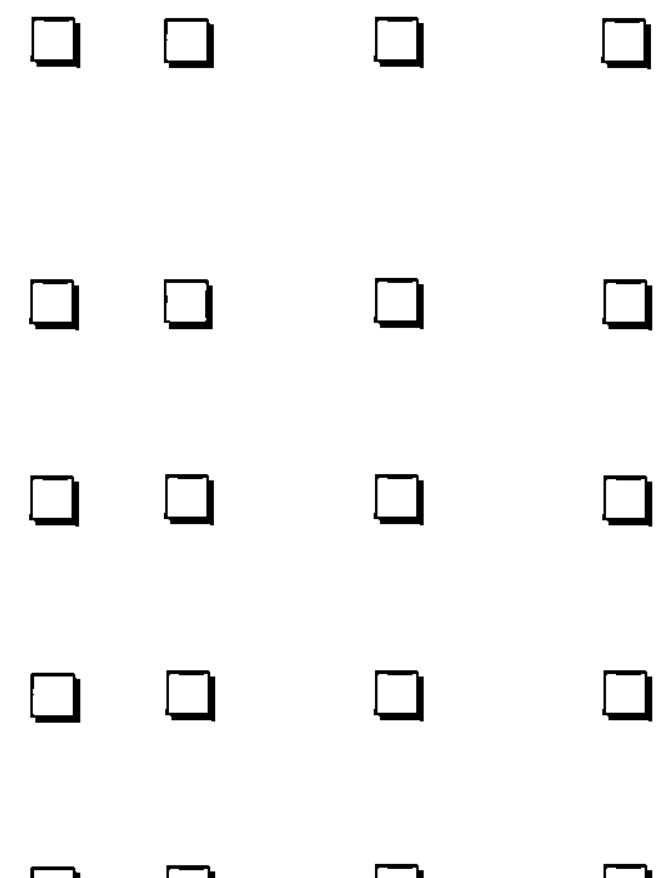
são acompanhadas e ações corretivas são tomadas se necessário?

10: Os riscos de software associados ao custo, recursos, cronogramas e aspectos técnicos do projeto são acompanhados?

11: Os dados de medidas reais e dados para o replanejamento do projeto de software são gravados?

12: $O$ grupo de engenharia de software conduz periodicamente uma revisão interna para acompanhar o progresso técnico, planos, desempenho e questões em relação ao plano de desenvolvimento de software?

13: As revisões formais para verificar o cumprimento e resultado do projeto de software são conduzidos
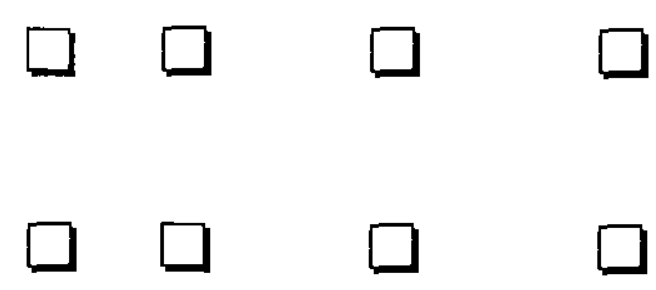
nos marcos estabelecidos?

Anotações:

\section{Meta2}

As açōes corretivas serem realizadas e gerenciadas quando os resultados reais e 0 desempenho desviarem significativamente do plano de software.

Sim Não Não se aplica Não sei

2: O plano de desenvolvimento de software é revisado?
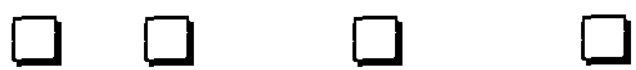

Anotações: 


\section{Meta3}

As mudanças nos compromissos de software serem obedecidas pelos indivíduos e grupos envolvidos.

Sim Não Não se aplica Não sei

3: Os compromissos do projeto de software e mudanças nesses compromissos associados a indivíduos ou grupos externos a organização são revisados com o gerente sênior?

4: As mudanças de compromissos aprovados que afetam o projeto de software são comunicadas aos membros do grupo de engenharia de software $e$ outros grupos relacionados?

Anotaçōes:

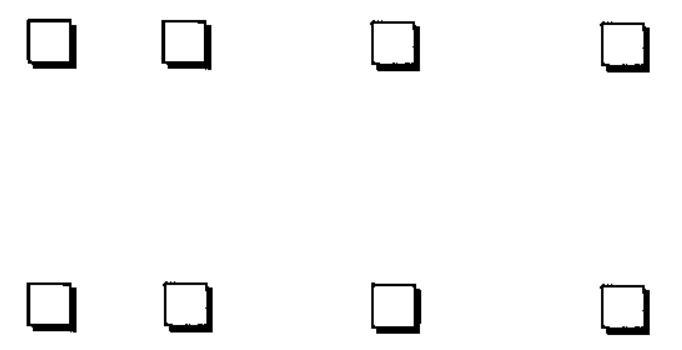

\section{Gerenciamento de Subcontratos de Software}

A finalidade dessa área-chave é selecionar fornecedores (que se responsabilizam por parte do trabalho) qualificados e gerenciá-los eficazmente. Isso envolve selecionar o fornecedor, estabelecer compromissos, acompanhar e revisar o desempenho e os resultados obtidos. $\mathrm{Na}$ seleção e gerenciamento do fornecedor são necessários documentos como: cláusula de contrato, requisitos do projeto, produtos a serem entregues, padrões e procedimentos a serem seguidos.

\section{Meta1}


O contratante selecionar os subcontratado de software qualificado.

Sim Não Não se aplica Năo sei

1: O trabalho a ser realizado pelo subcontratado é definido e planejado ?

2: O subcontratado de software é selecionado baseandose numa avaliaçāo da habilidade de desempenhar o trabalho proposto pelo subcontratado?

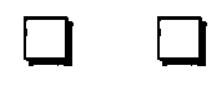

$\square$
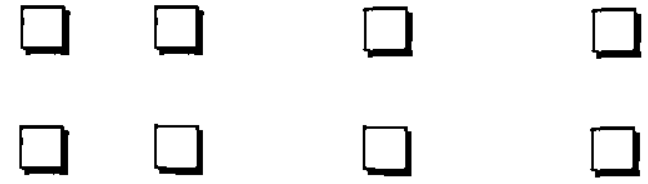

Anotações:

\section{Meta2}

O contratante e o subcontratado de software concordarem com os compromissos de ambas as partes.

\section{Sim Não Não se aplica Não sei}

3: A concordância contratual entre o contratante e o subcontratado de software é usada como uma base para gerenciamento do subcontrato?

4: Um plano de desenvolvimento de software do subcontratado é documentado revisto e aprovado pelo contratante?

6: As mudanças na estrutura de trabalho do subcontratado de software, termos do subcontrato,

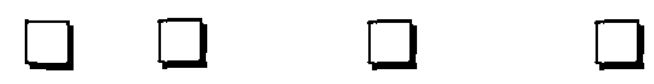
condiçōes e outros compromissos são resolvidos em comum acordo com ambas as partes envolvidas: contratante e subcontratado?

Anotações: 


\section{Meta3}

O contratante e o subcontratado de software manterem comunicação.

Sim Não Não se aplica Não sei

7: O gerente do contratante conduz periodicamente uma revisão da situação e da coordenação com os gerentes

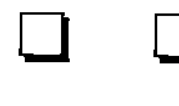
do subcontratados?

8: As revisões técnicas periódicas e troca das informações são realizadas com o subcontratado de software?

9: As revisões formais para verificar o cumprimento das atividades de engenharia de software por parte do
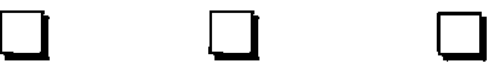
subcontratado de software são conduzidos e os marcos são selecionados?

13: O desempenho do subcontratado de software é avaliado periodicamente e revisado com o subcontratado?
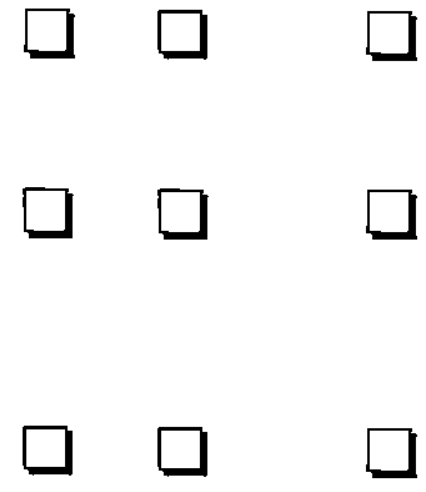
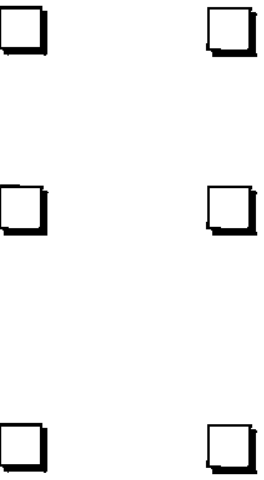

Anotações:

\section{Meta4}

O contratante acompanhe o resultado real e desempenho do subcontratado de software em relação aos seus compromissos.

\section{Sim Não Não se aplica Não sei}

5: Um plano de desenvolvimento de software do subcontratado documentado e aprovado é usado para

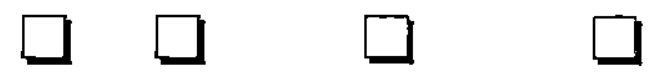
acompanhar as atividades de software e comunicar a situação?

10: O grupo de garantia de Qualidade do contratante
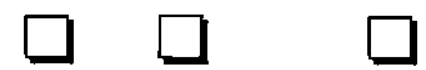
monitora as atividades de garantia de qualidade do subcontratado para verificar se os planos, padrões e procedimentos estão sendo seguidos ?

11: O grupo de gerenciamento de configuração de software monitora as atividades de gerenciamento de

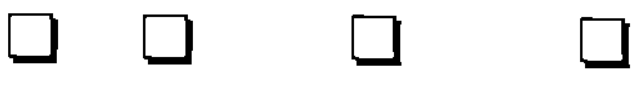
configuraçāo de software do subcontratado para verificar se os planos, padrões e procedimentos estāo sendo seguidos?

12: O contratante conduz o teste de aceitação da parte do produto de liberação de software do subcontratado ?

Anotaçōes:

\section{Garantia de Qualidade de Software}

A finalidade dessa área-chave é oferecer gerenciamento, com visibilidade apropriada, do processo que está sendo utilizado e dos produtos que estão sendo construfdos. Isso envolve revisões e auditorias nos produtos de software e nas atividades para assegurar que estão em conformidade com os padrōes e procedimentos aplicados. Envolve também fornecer esses resultados para os gerentes envolvidos.

\section{Meta1}

As atividades de garantia de qualidade de software serem planejadas.

Sim Não Não se aplica Não sei

1: Um plano para Garantia de Qualidade de Software é preparado para o projeto de software?

2: As atividades do grupo de Garantia de Qualidade de Software são desempenhadas de acordo com o plano?

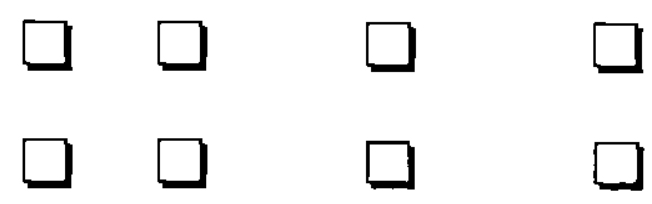

Anotações: 


\section{Meta2}

A conformidade dos produtos de software e atividades ao padrão aplicado, aos procedimentos e aos requisitos ser verificada objetivamente.

\section{Sim Não Não se aplica Não sei}

3: O grupo de Garantia de Qualidade de Software participa da preparação e revisão do: plano de

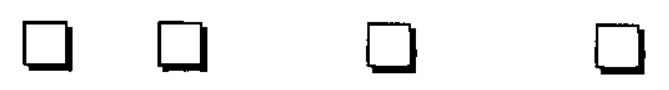
desenvolvimento de software, padrōes e procedimentos? 4: $O$ grupo de Garantia de Qualidade de Software revisa as atividades de engenharia de software para verificar seu cumprimento?

5: O grupo de Garantia de Qualidade de Software dá auditoria a produtos de trabalhos de software para

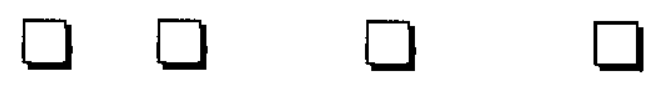
verificar seu cumprimento?

Anotações:

\section{Meta3}

Os grupos e indivíduos envolvidos serem informados sobre as atividades de garantia de qualidade e de seus resultados.

Sim Não Não se aplica Não sei

6: O grupo de Garantia de Qualidade de Software reporta periodicamente os resultados das atividades ao grupo de

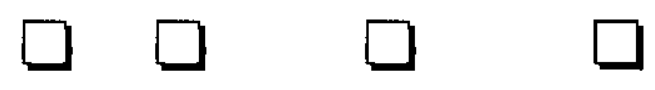
engenharia de software?

7: Os desvios identificados nas atividades de software e nos produtos de trabalhos de software são documentados

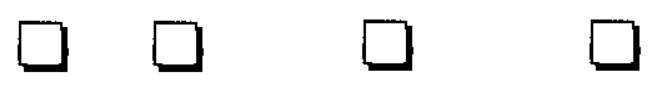


e manipulados?

8: O grupo de Garantia de Qualidade de Software conduz revisōes periódicas das atividades e das descobertas com - pessoal de Garantia de Qualidade de Software do cliente, apropriadamente?

Anotações:

\section{Meta4}

Os problemas de questões-que não podem ser resolvidos no projeto de software serem encaminhados ao gerente sênior.

\section{Sim Não Não se aplica Não sei}

7: Os desvios identificados nas atividades de software e nos produtos de trabalhos de software são documentados

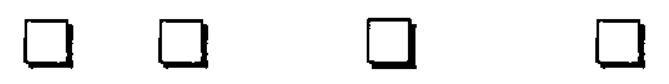
e manipulados?

Anotações:

\section{Gerenciamento de Configuração de Software}

A finalidade dessa área-chave é estabelecer e manter a integridade dos produtos do projeto de software ao longo do ciclo de vida do software. Isso envolve identificar os itens de configuração, controlar sistematicamente as alterações e manter a integridade da configuração ao longo do ciclo de vida do software. O gerenciamento da configuração utiliza linhas de referência (baselines) que servem como um marco no ciclo de vida do software. Os itens que passam por uma linha de referência podem ser alterados somente através de procedimentos 


\section{Meta1}

As atividades de gerenciamento de configuração de software serem planejadas.

Sim Não Não se aplica Não sei

1: Um plano de Gerenclamento de Conflguração de

Software é preparado para cada projeto de software?

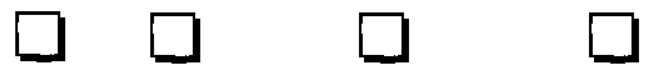

Anotações:

\section{Meta2}

Os produtos de trabalhos de software selecionados serem identificados, controlados e disponibilizados.

\section{Sim Não Não se aplica Não sei}

3: Uma biblioteca de gerenclamento de configuração é estabelecida como um repositório para as linhas de

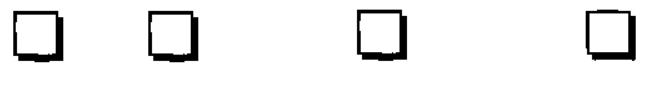
referência do software?

4: Os produtos de trabalho de software colocados sobre gerenciamento de configuração são identificados?

7: Os produtos da biblioteca da linha de referência de software são criados e suas versões são controladas?

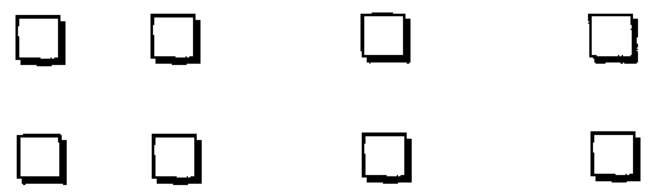

Anotações: 


\section{Meta3}

As mudanças em prodıtos de trabalhos de software identificados serem controladas.

Sim Não Não se aplica Não sei

5: Os pedidos de mudanças e relatório de problemas são inicializados, revistos, aprovados e acompanhados para
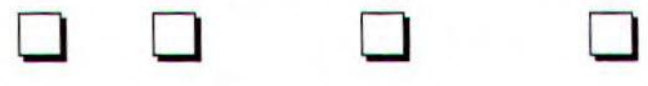
todos os itens/unidades de configuração?

6: As mudanças nas linhas de referências são controladas?

Anotações:

\section{Meta4}

Os grupos e indivíduos envolvidos serem informados sobre a situação e conteúdos das linhas de referências (baseline).

\section{Sim Não Não se aplica Não sei}

8: A situação dos itens/unidades de configuração é registrada?

9: Os relatórios padrões documentando as atividades de Gerenciamento de Configuração de Software e o conteúdo das linhas de referência de software é desenvolvido e disponibilizado aos grupos e indivíduos envolvidos?

10: As auditorias para linhas de referências de software são conduzidas?

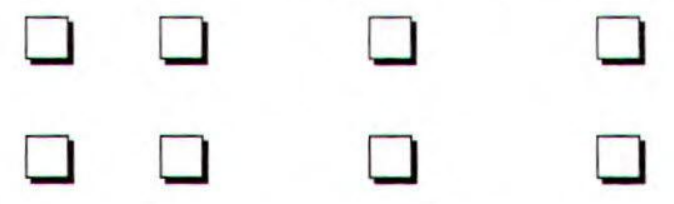

Anotações: 